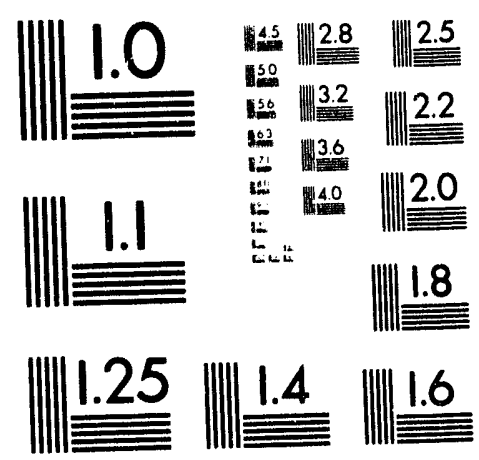



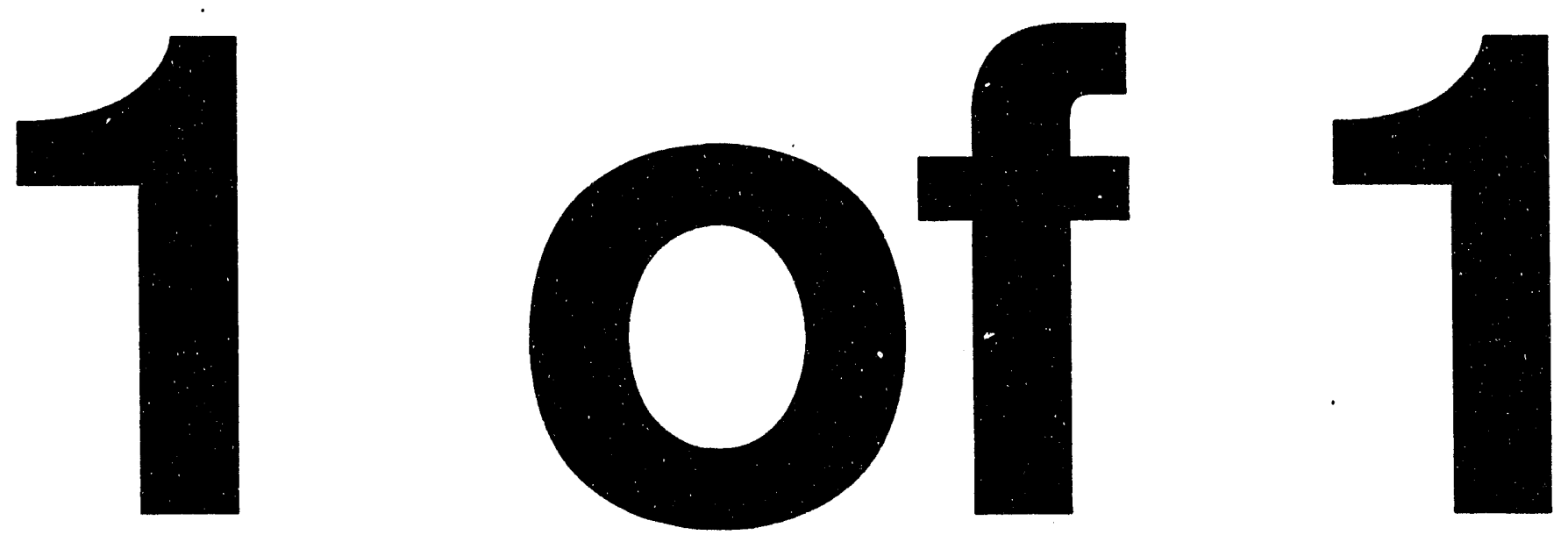
SAND93-1055

Unlimited Release

Printed August 1993
Distribution

Category UC-721

\title{
Waste Isolation Pilot Plant Materials Interface Interactions Test: \\ Papers Presented at the Commission of European Communities Workshop on In Situ Testing of Radioactive Waste Forms and Engineered Barriers*
}

\author{
Editors: \\ Martin A. Molecke and N. Robert Sorensen \\ Sandia National Laboratories \\ Albuquerque, NM 87185 \\ and \\ George G. Wicks \\ Westinghouse-Savannah River Technology Center \\ Aiken, SC 29808
}

* This work was performed by Sandia National Laboratories and Westinghouse-Savannah River Technology Center. Support provided by the US Department of Energy under Contracts DE-AC04-76DP00789 and DE-AC09-76SR00001. 


\section{WIPP MATERIALS INTERFACE INTERACTIONS TEST (MIIT) PAPERS}

An Overview of the Materials Interface Interactions Test (MIIT) After Five Years of
Testing - 1992 Update (original document number WSRC-MS-92-392 and SAND92-1953C)

George G. Wicks, Savannah River Technology Center, and

Martin A. Molecke, Sandia National Laboratories

Materials Interface Interactions Test (MIIT) Details and Observations on In Situ Sample Retrievals and Test Termination (original document number SAND92-1954C)

Martin A. Molecke, Sandia National Laboratories, and

George G. Wicks, Savannah River Technology Center

Summary of the WIPP Materials Interface Interactions Test - Metal Corrosion (original document number SAND92-1921C)

N. Robert Sorensen and Martin A. Molecke, Sandia National Laboratories

These papers were presented at the Commission of European Communities Workshop on In Situ Tests on Waste Packages and Engineered Barriers, in Corsendonk, Belgium, October 13-16, 1992. The Proceedings of this workshop will be published by the Commission of European Communities in 1993. The three papers included in this document, SAND93-1055, are being printed (or preprinted) in order to have an earlier and broader distribution, specifically for participants or reviewers of the Waste Isolation Pilot Plant project. 


\section{PREFACE}

The Materials Interface Interactions Test (MIIT) is an in situ glass waste form (nonradioactive defense high-level, other high-level, and transuranic waste formulations), brine leaching, and container metal interactions test. It was conducted in the bedded salt at the WIPP facility from January 1986 through July 1991, when it was retrieved successfully and completed on schedule after five years of heated test operations. Sandia National Laboratories and Westinghouse-Savannah River Technology Center cooperatively directed and conducted the MIIT program, with international participation and cooperation from seven foreign countries plus multiple U.S. laboratories. An international workshop meeting of all test participants, to discuss initial data after two years of testing and future plans for the MIIT, was sponsored by the Commission of the European Communities (CEC), the Commissariat à l'Energie Atomique (CEA, France), and the Savannah River Laboratory (on behalf of the U.S. Department of Energy) and held in Cadarache, France, in October 1988. The proceedings of this Workshop on Testing of High-Level Waste Glass Under Repository Conditions were published by the CEC, in Proceedings: Testing of High-Level Waste Forms Under Repository Conditions, Report EUR 12017 EN, 1989, Ed. T. McMenamin (McMenamin, 1989).

The three papers in this report were presented at the second international workshop to feature the WIPP Materials Interface Interactions Test. This Workshop on In Situ Tests on Radioactive Waste Forms and Engineered Barriers was held in Corsendonk, Belgium, on October 13-16, 1992, and was again sponsored by the CEC. The Studiecentrum voor Kernenergie/Centre D'Energie Nucleaire (SCK/CEN, Belgium), and the U.S. Department of Energy (via Savannah River) also cosponsored this workshop. Workshop participants from Belgium, France, Germany, Sweden, and the United States gathered to discuss the status, results, and overviews of the MIIT Program. Nine of the twenty-five total workshop papers were presented on the status and results from the WIPP MIIT program after the five-year in situ conclusion of the program. The total number of published MIIT papers is now up to almost forty. Posttest laboratory analyses are still in progress at multiple participating laboratories. The first MIIT paper in this document, by Wicks and Molecke, provides an overview of the entire test program and focuses on the waste form samples. The second paper, by Molecke and Wicks, concentrates on technical details and repository relevant observations on the in situ conduct, sampling, and termination operations of the MIIT. The third paper, by Sorensen and Molecke, presents and summarizes the available laboratory, posttest corrosion data and results for all of the candidate waste container or overpack metal specimens included in the MIIT program.

Attendance at this workshop allowed us to continue interactive discussions with multiple foreign scientists (of previous acquaintance) on the topics of both WIPP and several foreign in situ tests and results, and future plans on the topic of performance testing of nuclear waste packages. Workshop participants discussed problem areas for performing in situ tests, related laboratory analyses of samples, and limitations of the subsequent interpretations. Participants were close to unanimous in proclaiming the usefulness and validity of in situ testing, particularly 
for evaluating the relative in situ durability or performance of nuclear waste forms-when combined with complementary laboratory programs and analyses. There was an excellent interchange of analytical data and interpretations between the various workshop participants concerning multiple aspects of the MIIT program during this workshop. 


\section{CONTENTS}

1.0 Overview of the Materials Interface Interactions Test (MIIT): International In Situ Testing of Waste Forms and Package Components ................................................ 1-1

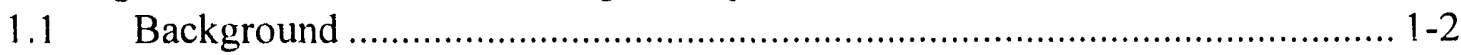

1.2 The Waste Isolation Pilot Plant (WIPP) .............................................. 1-2

1.3 Materials Interface Interactions Test (MIIT) …….................................... 1-4

1.3.1 Stripa Experience ..................................................................... 1-4

1.3.2 MIIT- MI and MIIT-SS Experiments.......................................... 1-4

1.3.3 Unique MIIT Features and Resulting Cost Avoidance/Savings ...... 1-6

1.4 MIIT Objectives ............................................................................. 1-6

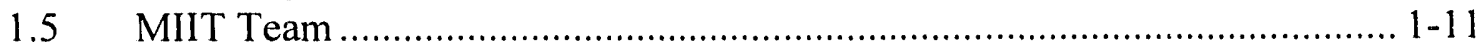

1.6 MIIT Experimental Matrix: Glass, Metal and Geologic Samples ............... 1-11

1.6.1 U.S. Waste Form Compositions..................................................... 1-14

1.6.2 International Waste Form Compositions ........................................... 1-14

1.7 MIIT Responsibilities, Analyses and Measurements.................................. 1-17

1.8 Conclusions ................................................................................. 1-22

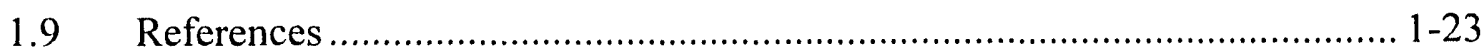

2.0 Materials Interface Interactions Test (MIIT) Details and Observations on In Situ Sample Retrievals and Test Termination ............................................................. 2-1

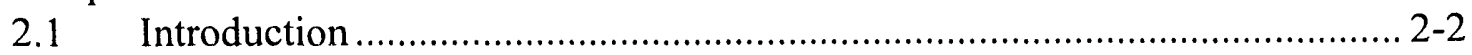

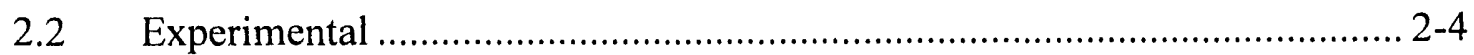

2.2.1 Overview and Test Assemblies ................................................... 2-4

2.2.2 MIIT Materials Specimens and Brine …………............................. 2-6

2.3 Experimental Operations and Observations …………............................... 2-8

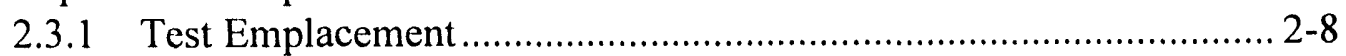

2.3.2 Test Assembly Retrievals........................................................... 2-8

2.3.3 Assembly Reemplacement Activities ............................................ 2-11

2.3.4 Brine Monitoring, Control, and Sampling ………........................... 2-13

2.3.5 Temperature Monitoring …………………................................... 2-14

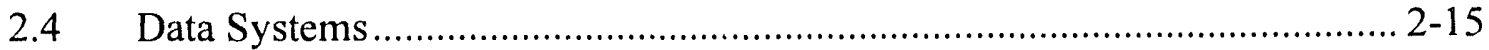

2.4.1 Data Acquisition System............................................................ 2-15

2.4.2 Data Management System............................................................ 2-15

2.5 Additional Termination Activities and Summary ..................................... 2-16

2.6 References ..................................................................................... 2-18

3.0 Summary of the WIPP Materials Interface Interactions Test - Metal Corrosion....... 3-1

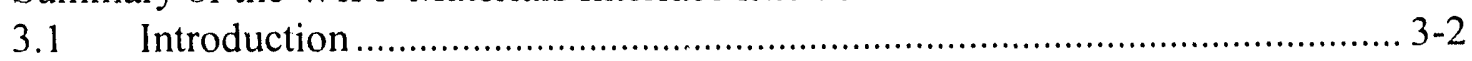

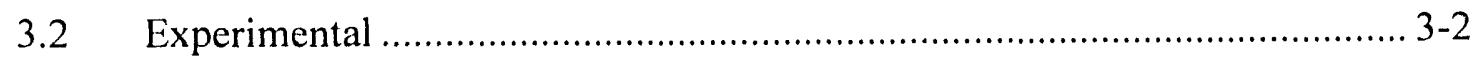

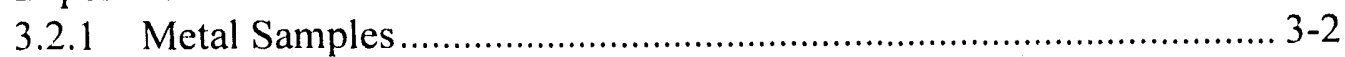

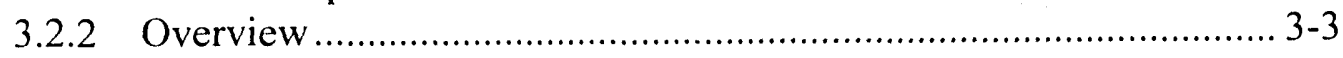

3.2.3 Metal Sample Analyses.............................................................. 3-4 


\section{CONTENTS (Continued)}

3.3 Results and Discussion........................................................................ 3-5

3.3.1 Metals Corrosion and Metallurgical Alteration Results.................... 3-5

3.3.1.1 Austenitic Stainless Steels............................................ 3-5

3.3.1.2 Titanium Alloys ...................................................... 3-7

3.3.1.3 Steel ...................................................................... 3-9

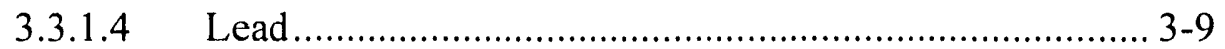

3.3.1.5 Copper ................................................................. 3-9

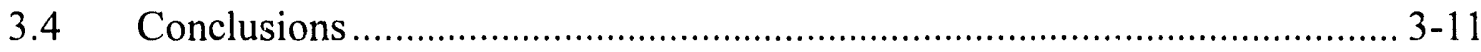

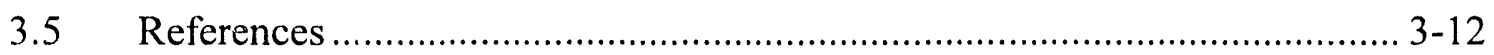

Figures

1-1. Simplified overview of SRL Waste Glass Program............................................... 1-3

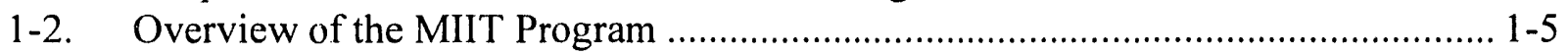

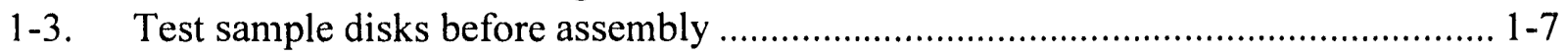

1-4. Stacking sample disks on rod heater assembly .................................................... 1-7

1-5. Fabricated MIIT assemblies (above ground) …….......................................... 1-7

1-6. Fifty MIIT assemblies in Room J, before emplacement ......................................... 1-7

1-7. Installing heater-power and instrument cables in Room J .................................... 1-8

1-8. MIIT assembly awating emplacement .............................................................. 1-8

1-9. MIIT assembly being installed...................................................................... 1-8

1-10. Completion of test installation ........................................................................ 1-8

1-11. Installed MIIT assemblies, west side of Room J, at test initiation.......................... 1-9

1-12. Overcoring retrieval of MIIT assembly; assembly sheathed in precipitated and

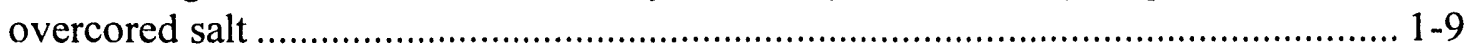

1-13. Washing and removal of salt encapsulating the test assembly ............................... 1-9

1-14. Washed test assembly at the 2-year retrieval period, prior to removing glass

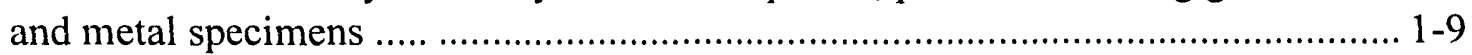

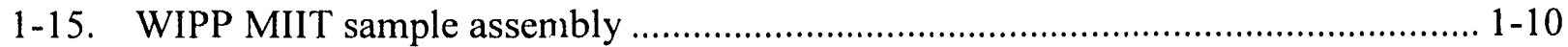

1-16. WIPP/SRL MIIT Progran ........................................................................... 1-12

1-17. Schematic layout of Room J; MIIT boreholes and 7-part MIIT Program ................ 1-13

1-18. Compositional correlations of MIIT waste forms .............................................. 1-18

1-19. Surface analyses of SRL Y leached glass surface layers ...................................... 1-21

2-1. Representative WIPP MIIT assembly with metal samples ...................................... 2-4

3-1. Weight change data for type 304L stainless steel .................................................. 3-6

3-2. Weight change data for type 309 and 316 stainless steel...................................... 3-6

3-3. Weight change data for grade-12 titanium ..................................................... 3-8

3-4. Weight change data for grade-2 titanium ......................................................... 3-8 


\section{Figures (Continued)}

3-5. Weight change data for carbon steel ........................................................... 3-10

3-6. Weight change data for lead ......................................................................... 3-10

3-7. Weight change data for copper.............................................................. 3-11

\section{Tables}

1-1. MIIT waste form compositions [United States] ............................................... 1-15

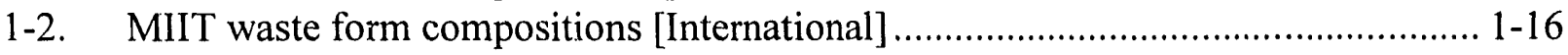

$1-3$. Five-year analytical studies tracking sheets ............................................... 1-20 


\title{
1.0 OVERVIEW OF THE \\ MATERIALS INTERFACE INTERACTIONS TEST (MIIT): INTERNATIONAL IN SITU TESTING OF WASTE FORMS AND PACKAGE COMPONENTS
}

\author{
George G. Wicks \\ Savannah River Technology Center \\ Westinghouse Savannah River Company \\ Aiken, SC 29808 \\ Martin A. Molecke \\ Sandia National Laboratories \\ Department 6345 \\ Albuquerque, NM 87185
}

\begin{abstract}
The first in situ leaching tests to be conducted in the United States involving burial of simulated high level waste glasses and proposed package components, began in July 1986. In July 1991, the experimental portion of this 5-year program was completed, on schedule. Almost 2000 samples of waste forms, package component metals and geologic specimens were buried in the bedded salt site at the Waste Isolation Pilot Plant (WIPP), near Carlsbad, New Mexico. The program, called the Materials Interface Interactions Test (MIIT), involved the underground emplacement and subsequent assessment of the performance of 15 different waste glass and waste form compositions supplied from 7 countries, along with assessment of the effects of a variety of proposed waste container or overpack components.

Samples and solutions were obtained from the WIPP at pre-determined time intervals over the 5-year testing program. Analyses of samples were conducted using an integrated study approach, involving the input of many laboratories and universities in France, Germany, Belgium, Canada, Japan, the United Kingdom, Sweden, and the United States. This program represents the largest and most cooperative venture of its type in the international waste management community. Because of the structure of this program and its cooperative nature, resources and expertise were able to be pooled and a quality program containing a high caliber of work was prorluced in a cost effective manner.

All samples have now been exhumed from WIPP and although analyses are still in progress, important results have already been obtained. These results will be of benefit to a wide cross-section of the waste management community and contribute to national and international waste management goals. An overview of the MIIT program will be presented and during this Workshop, we will be hearing described some the of many interesting and important findings that have been made, thus far. These results will be documented by our colleagues in this effort, the Commission of European Communities (CEC). These proceedings will be published in book form, as done for the earlier workshop on in situ testing, jointly organized by the CEC, US DOE, and CEA held in Cadarache France, in October of 1988 (McMenamin, 1989).
\end{abstract}




\subsection{BACKGROUND}

For more than a decade, a primary objective of the high level waste management program at the Savannah River Site (SRS) has been to safely and effectively immobilize approximately 34 million gallons of high-level radioactive waste (HLW) (currently stored mainly in a liquid form in large underground tanks on site), into borosilicate glass (Wicks and Bickford, 1989). The waste glass products will then be permanently disposed of by deep burial in a geologic repository. The vitrification building, the Defense Waste Processing Facility (DWPF), has recently been completed at SRS and later this year, cold chemical runs will be started. The almost 1 billion dollar DWPF is scheduled for actual production in 1994. Important to this program is the ability to understand and assess waste glass performance, especially under repository relevant conditions. As part of this goal, the Savannah River Site has been involved in a multi-phase experimental effort for many years which is summarized schematically in Figure 1-1 (Wicks, 1986; Wicks, 1985a).

An important part of this effort involves repository-relevant testing which includes (a) laboratory-scale waste glass leaching studies, (b) repository simulation tests (rock-cup experiments), and (c) in situ or field experiments. The in situ testing efforts involve (1) the burial of Savannah River (SR) waste glass samples in the granite site at Stripa in Sweden, (2) burial of SR glasses in clay at Mol, Belgium, (3) in situ testing of SR samples in limestone at Ballidon in the United Kingdom and (4) field testing of SR and international compositions in the salt at WIPP in the United States. By putting together all of these elements of the repository related program, with those of the remaining integrated program, one can obtain the most complete picture possible of the performance of SR waste glass during fabrication, transportation, interim and final storage (Wicks, 1992).

\subsection{THE WASTE ISOLATION PILOT PLANT (WIPP)}

The mission of the Waste Isolation Pilot "lant or WIPP was defined by Congress as "providing a research and development facility to demonstrate the safe disposal of radioactive waste resulting from the defense activities and programs of the United States." Construction of the WIPP began in 1981 in the salt beds in Carlsbad, New Mexico. The WIPP excavation consists of more than four miles of tunnels at a depth of approximately 655 meters in the Salado Formation. This facility will be used to (a) permanently isolate transuranic (TRU) waste generated from U.S. defense programs, and (b) to serve as an "underground laboratory" to evaluate and demonstrate safe and effective disposal of TRU wastes (simulated and actual), as well as defense high-level waste (simulated DHLW only) (Sandia National Laboratories, 1985; Matalucci et al., 1982; Sandia National Laboratories, 1983). 


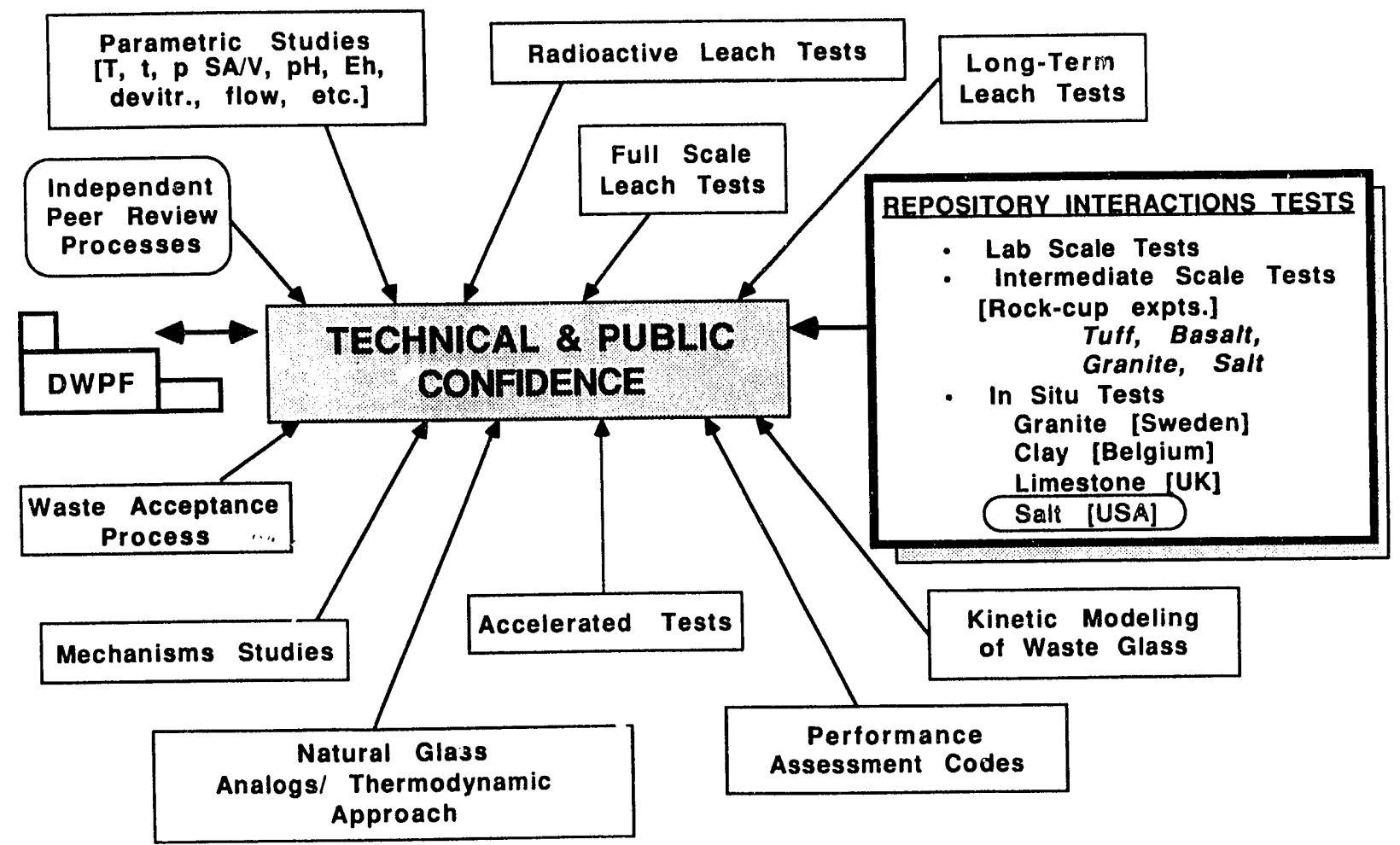

Figure 1-1. Simplified overview of the SRL Waste Glass Program. 


\subsection{MATERIALS INTERFACE INTERACTIONS TEST (MIIT)}

An overview of the entire MIIT program and its logistics is summarized in the flowsheet given in Figure 1-2. The representation outlines participating nations, waste form types, pre- and post-test analyses, responsibilities, engineering support and measurements, and documentation of results.

\subsubsection{Stripa Experience}

The MIIT effort which is described in detail elsewhere (McMenamin, 1989; Molecke and Wicks, 1985; Wicks, 1y85b; Wicks et al., 1987; Ramsey and Wicks, 1988; Wicks and Molecke, 1986; Wicks and Molecke, 1988), is a part of the WIPP underground testing program. These in situ experiments represent a "second generation" of the Swedish Stripa tests. In 1982, in a joint effort with KBS-Sweden, the University of Florida, and SRS, over 100 simulated SR waste glasses were buried in the granite site at Stripa in Sweden. Over the next two years, samples were extracted from burial, analyzed, and results documented (Clark et al., 1984; Zhu et al., 1985; Lodding et al., 1986). It was found from this study that the SR waste glass compositions performed very well in the field, in fact even better in the field than would be expected from many so-called "standard laboratory leaching tests." MIIT is derived from this Swedish experience and contains a number of similiuities as well as important and unique differences and improvements, which characterize this effort.

\subsubsection{MIIT-MI and MIIT-SS Experiments}

The MIIT program contains two basic types of experiments. First, are the MIITMI (Multiple Interactions) studies. These experiments involve stacking all of the different types of samples to produce the various glass/metal/salt interactions of interest. These tests are designed to conveniently evaluate the effects of the many different package components on glass durability, in a limited number of experiments. Analyses are based predominantly on surface studies and weight losses.

The second type of test is the MIIT-SS (Solution/Surface Interactions). This represents most of the MIIT effort and also a significant and unique improvement on existing in situ experimentation. Due to the design of these tests, both solution data and time dependent or kinetic information can be obtained for the first time, in a test of this type. To conduct these experiments, an entire borehole must be dedicated to one relatively simple set of interfaces. Therefore, the MIIT-MI and the MIIT-SS experiments complement each other. 


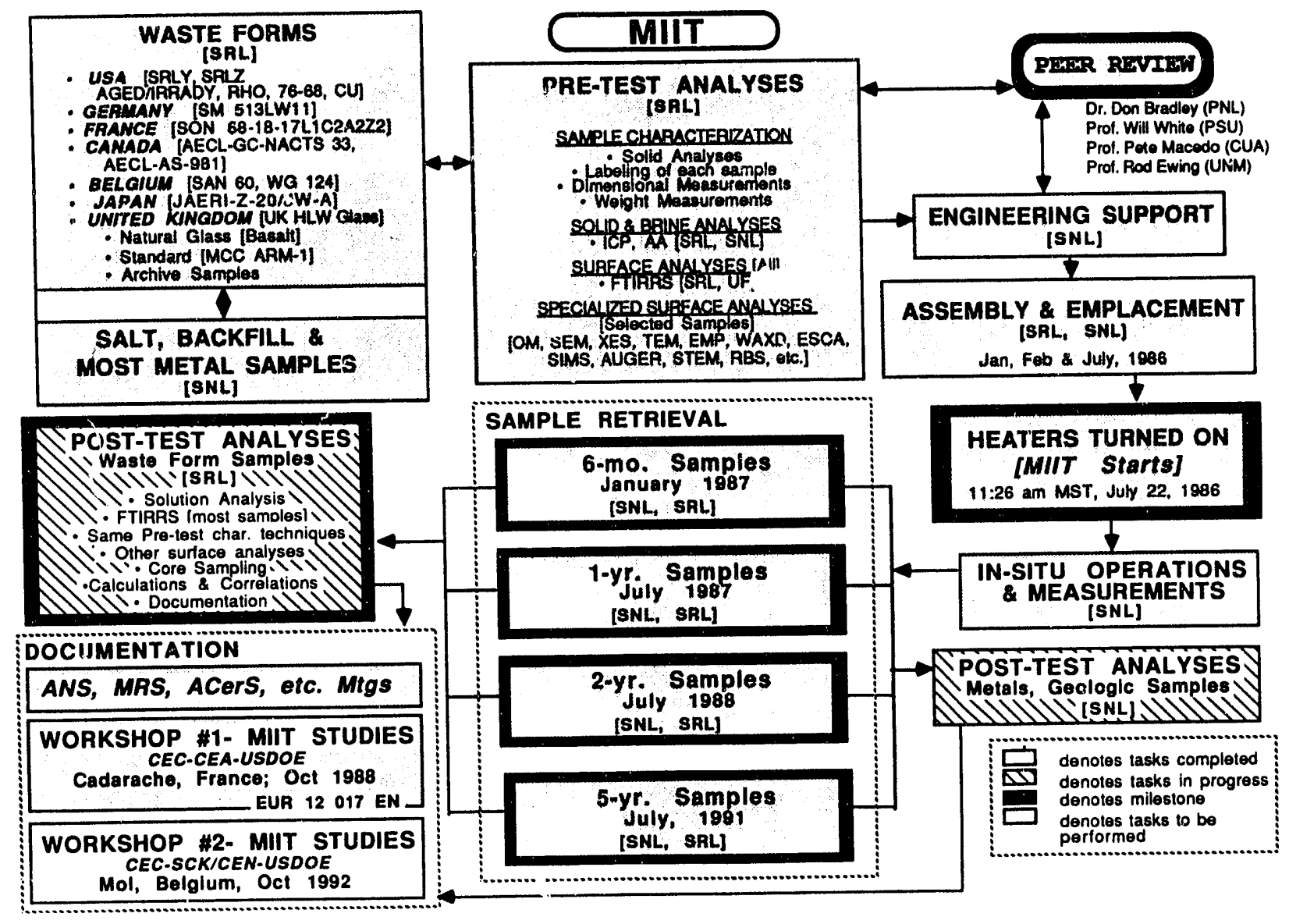

Figure 1-2. Overview of the MIIT program. 
After all samples were emplaced, the MIIT program was officially begun on July 22, 1986, which marked the turning on of the fifty MIIT heaters. In January and February of 1987, the first group of samples were removed from test after being buried for six months and in July of 1987 the 1-year samples were exhumed, in July of 1988, the 2-year samples removed, and in July of 1991, the final group of 5-year samples were removed, thus completing the testing phase of this program. Technical details and a description of test operations and observations on the sample retrievals are described in a separate paper in this workshop (Molecke and Wicks, 1993). A pictorial collage summarizing fabrication, installation, and retrieval of MIIT samples is given in Figures 1-3 through $1-14$.

\subsubsection{Unique MIIT Features and Resulting Cost Avoidance or Savings}

Because of the unique design of MIIT, two very important sets of data can be obtained that are not generally available in other types of field experiments; [1] solution data to correlate with surface studies; and [2] time dependent data from individual boreholes, due to the sub-assembly design. To provide these data, the MIIT-SS tests are modular in design as illustrated in Figure 1-15, for glass/metal/salt interactions. The assembly consists of four identical units that are removed is dividually after 6 mo., 1-yr., 2-yrs. and 5-yrs., respectively. This design allows a significant reduction in the number of boreholes needed to produce the same amount of data. This is not only important from a technical viewpoint, but also is cost effective. It has been estimated that the reduction in boreholes and associated mining, hardware and field support results in a cost savings of approximately $\$ 2.2$ million dollars.

In addition to savings resulting from experimental design, further costs are avoided due to the very cooperative nature of the study and the sharing of the large analytical load. As a result of each country sharing sample fabrication costs and the many bulk and surface pre- and post test analyses, an additional $\$ 2.0$ million dollars is avoided. These estimates are based on U.S. costs and for only those samples assessed thus far. It must be emphasized, that while cost savings are always desirable, the most important benefit of the cooperation in this program is the improved quality and credibility of the data produced.

\subsection{MIIT OBJECTIVES}

The overall objectives of the MIIT International In Situ Testing Program are as follows: (Wicks, 1985b):

- Assess the performance of Savannah River Defense Waste Processing Facility [DWPF] waste glass compositions under anticipated and accelerated testing conditions relevant to a salt environment. 


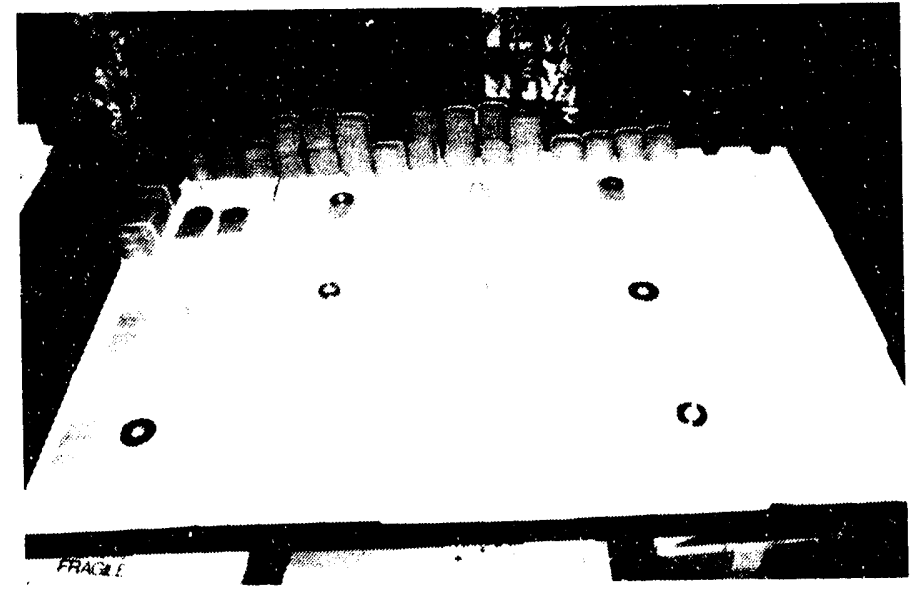

figrure 1-3. Test sample distis hefore assembly.

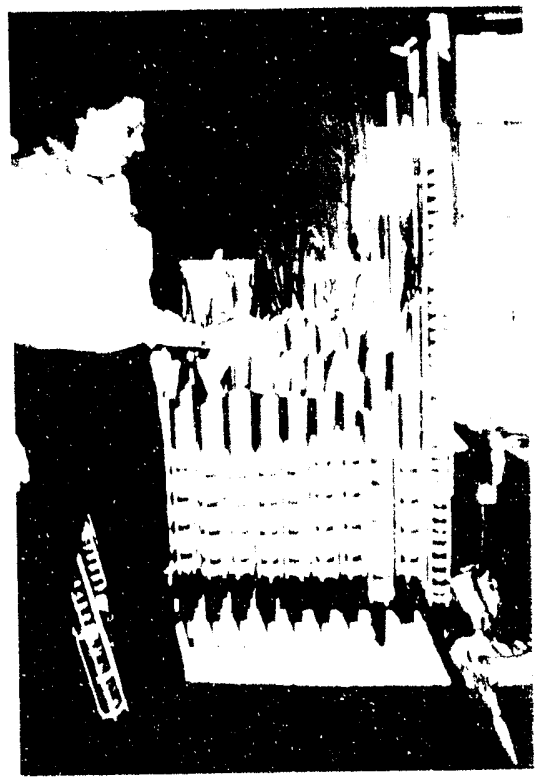

Figure 1-5. Fabricalled Mll' assomblies

(above ground).

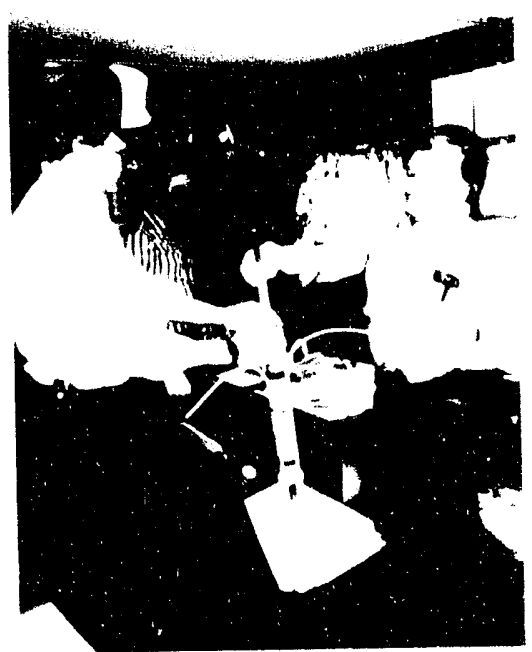

liggure 1-4. Stacking sample disks on rod-heater assembly.

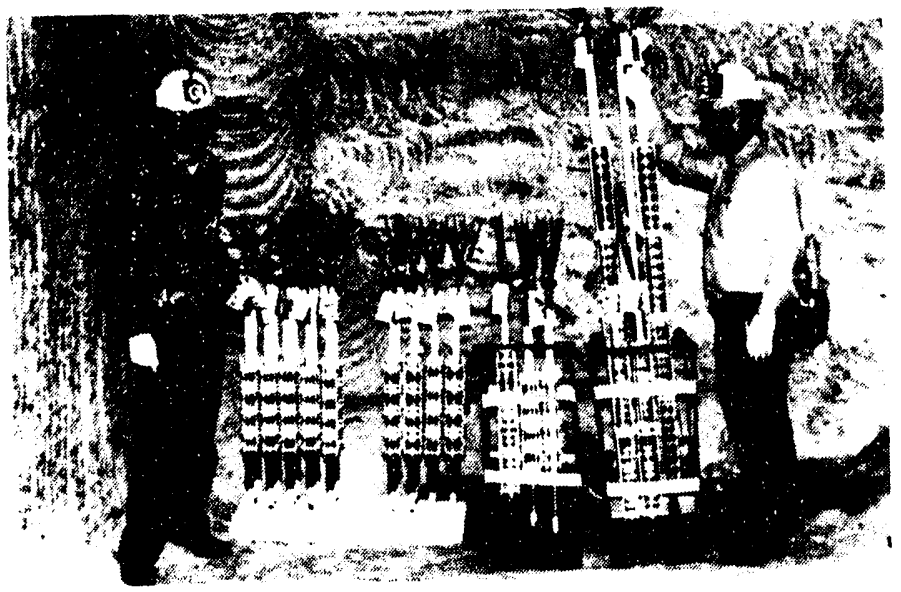

Figure 1 (1. filty Mll'l ascemblices in Remon J. hefore complacemcint. 


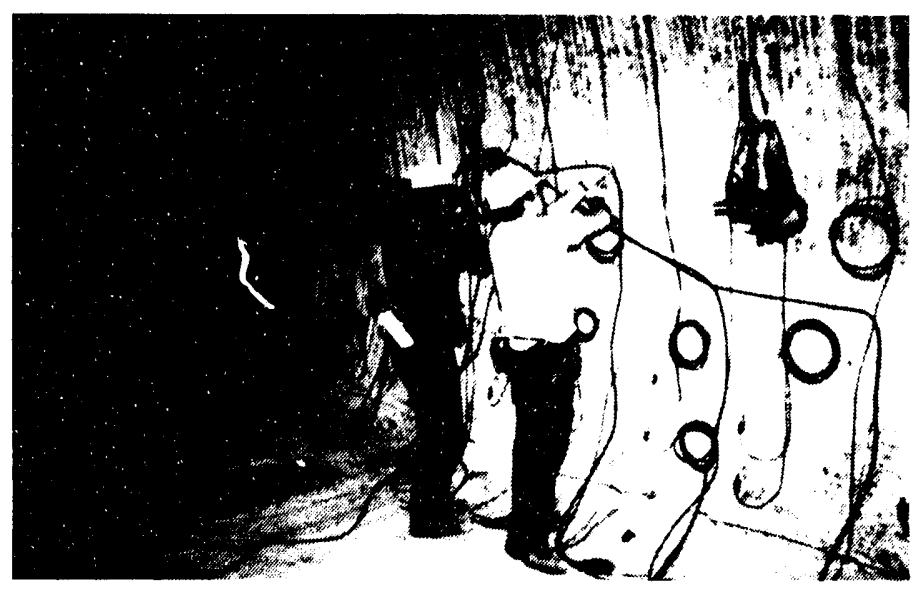

Figure 1-7. Installing heater-power and instrument cables in Room J.

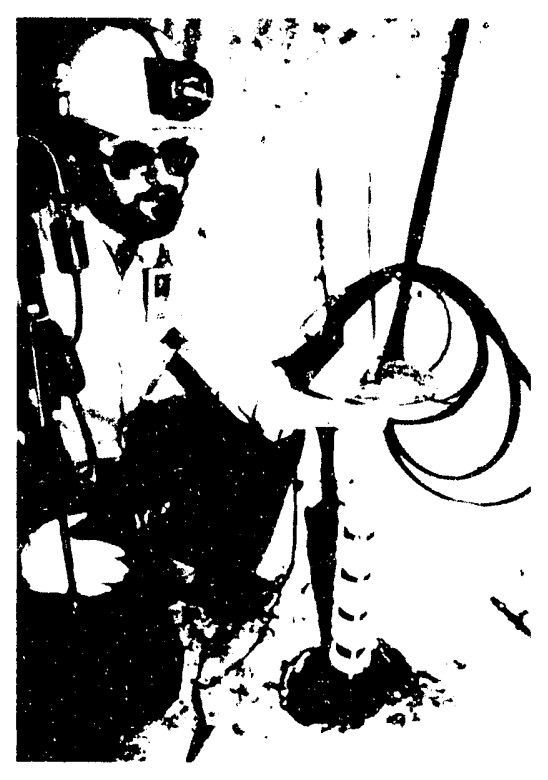

Figure 1-9. MIIT assembly being installed.

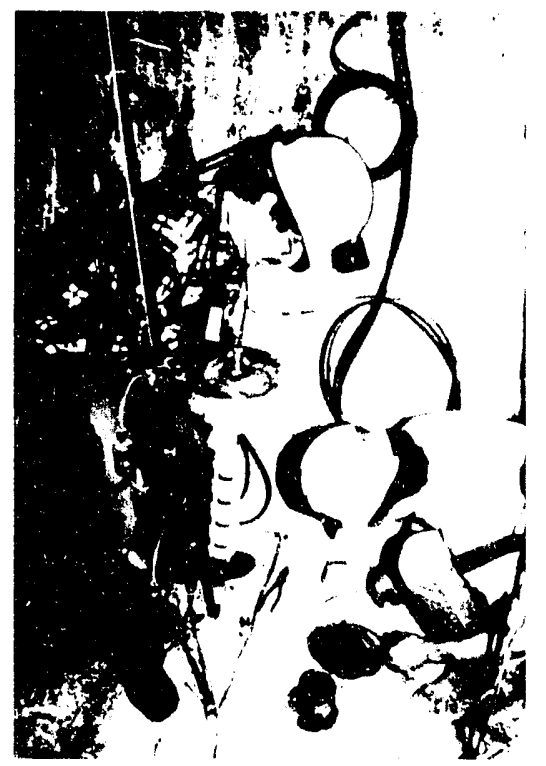

Figure 1-8. MIIT assembly awaiting emplacement.

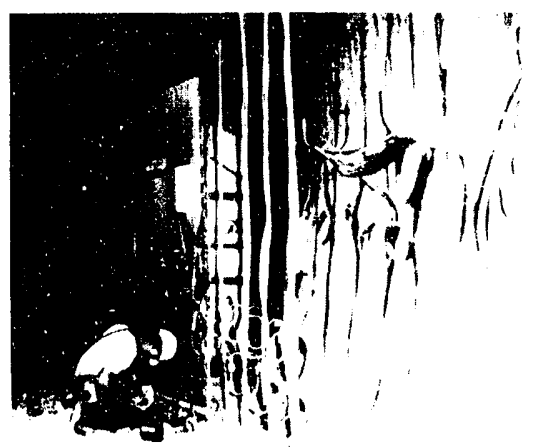

This 63451920

Figure 1-10. Completion of test installation. 


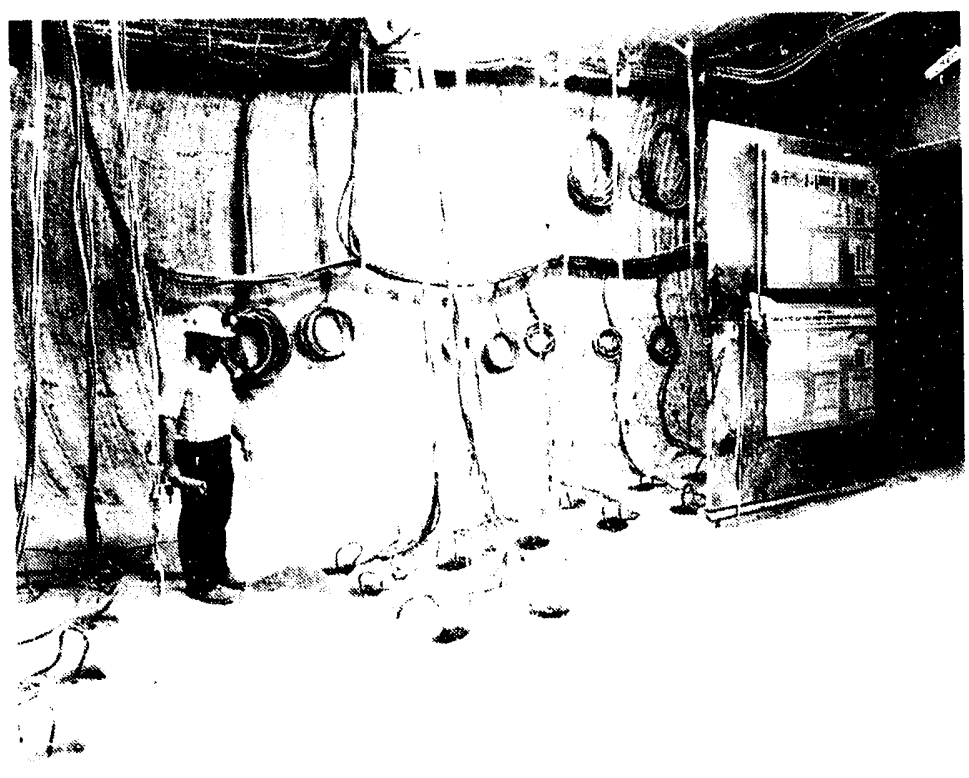

Figure 1-11. Installed MIIT

assemblies, west

side of Room J, at

test initiation.

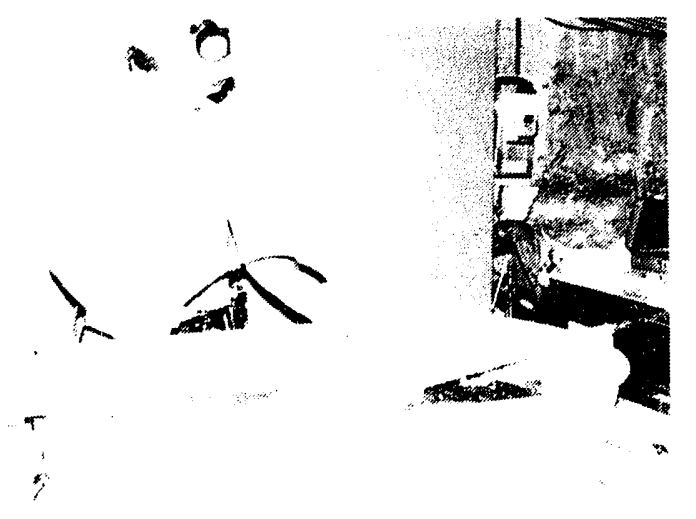

Figure 1-13. Washing and removal of silt encapsulating the test assembly.

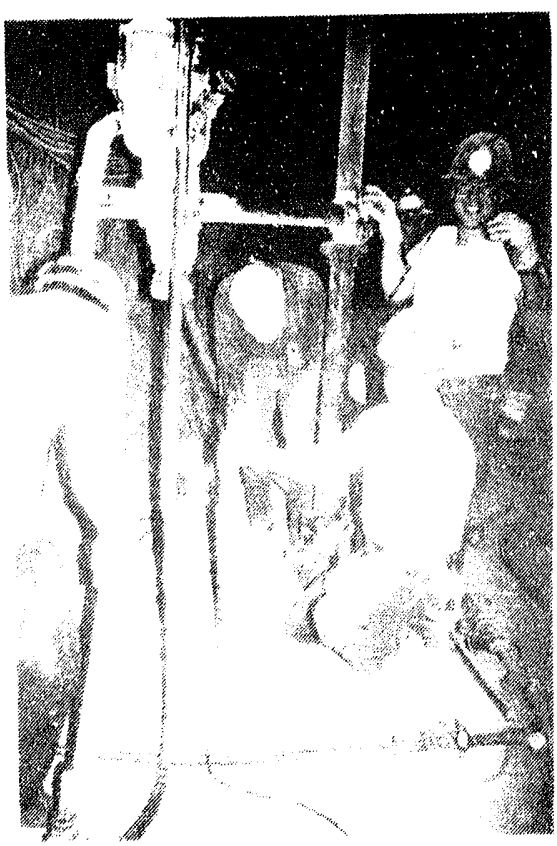

Figure 1-12. Overcoring retrieval of MIIT assembly: assembly sheathed in precipitated and overeored salt. rigure 1-14. Washed lest assembly at the 2-year retrieval period, prior lo removing glass and metal specimens. 


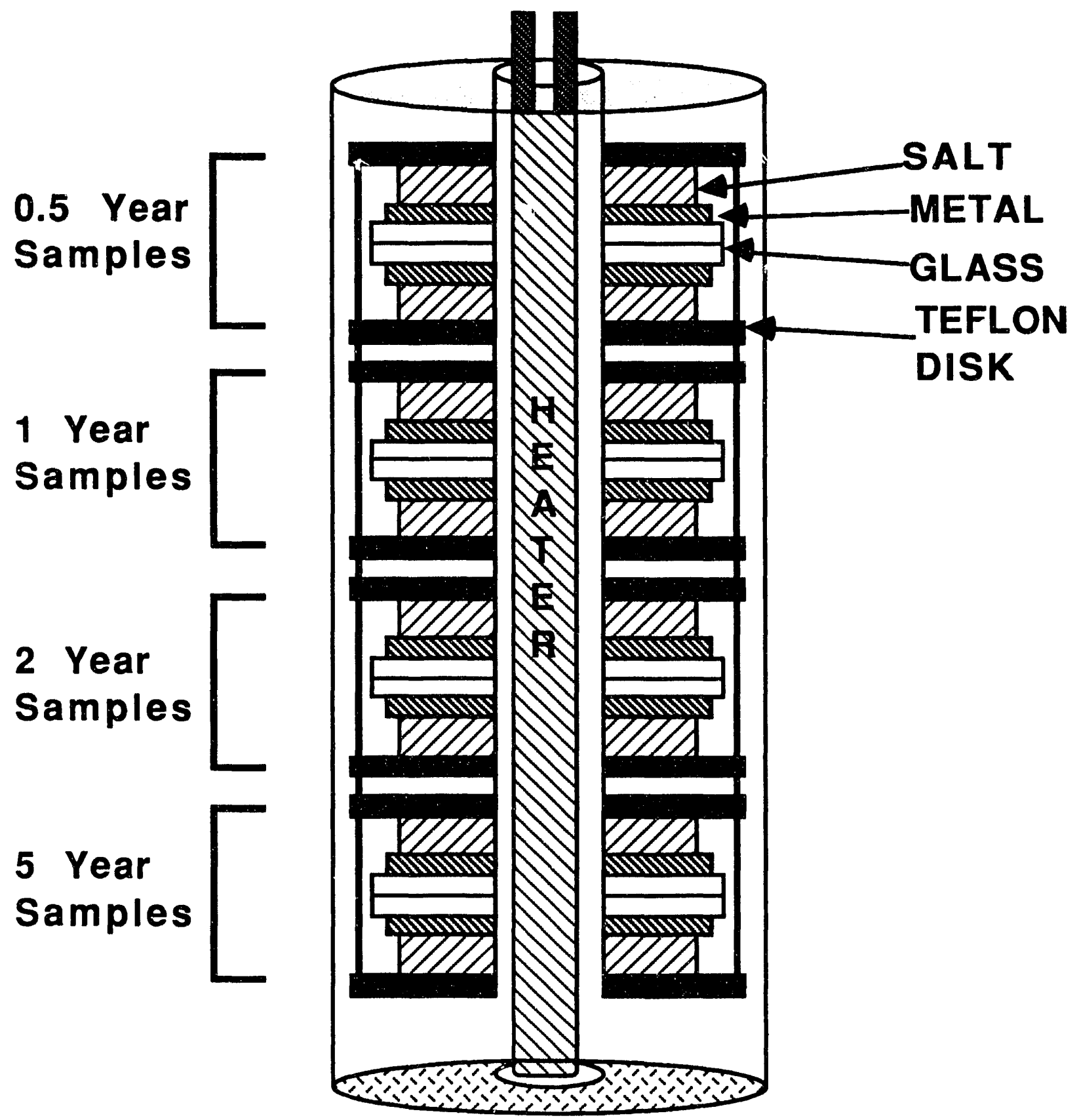

Figure 1-15. WIPP MIIT sample assembly. 
- $\quad$ Compare the relative performance and behavior of SR waste glass with the performance of other U.S. and foreign waste glasses, under similar, repository-relevant test conditions.

- Determine any effects of waste package component materials on waste glass durability and provide potential input to waste package designers.

- Provide a standardized, in situ data base on waste glass leaching including relevant interactions with metal canister or overpack components, salt and brine. This in situ data can then be correlated with other in situ data and the large body of existing laboratory data.

- Contribute to mechanistic studies aimed at understanding the behavior of waste glasses by coupling solution analyses with surface studies. This information can help in development of source terms that can be used to describe long-term waste form and package materials' behavior in salt.

- $\quad$ Provide data that will ultimately be useful in a technical data base to help demonstrate compliance with emerging specifications and regulations.

- Provide a large body of in situ test information, data, results and experience to be freely shared by all test participants and interested parties.

\subsection{MIIT TEAM}

In addition to the co-sponsors of the MIIT program, Sandia National Laboratories, Albuquerque, New Mexico, and the Savannah River Site, Aiken, South Carolina, there are many other participants involved. Some contributors supplied samples, some are participating in post-test analyses and some participated in a Peer Review process of the entire MIIT program. Additional U.S. participants include the Hanford Waste Vitrification Project, Battelle Pacific Northwest Laboratory, the University of Florida, Catholic University of America, University of New Mexico, the Pennsylvania State University, Clemson University, and the Materials Characterization Center. International representatives include Hahn-Meitner Institute and Kernforschungszentrum Karlsruhe (Germany), Centre D'Etudes Nucleaires (France), Atomic Energy of Canada, Ltd. (Canada), British Nuclear Fuels, Ltd. (United Kingdom), Studiecentrum Voor Kernenergie/Centre D'Etude de L'Energie Nucleaire (Belgium), Japan Atomic Energy Research Institute (Japan), and the Chalmers Institute of Technology (Sweden).

\subsection{MIIT EXPERIMENTAL MATRIX: GLASS, METAL AND GEOLOGIC SAMPLES}

The MIIT program, consisting of MIIT-MI and MIIT-SS experiments, involves testing of almost 2000 samples in 50 boreholes. This program can be broken into a 7-part effort (Molecke and Wicks, 1985), each part containing a different experimental configuration or stacking of samples and hence, a different series of associated objectives (Wicks et al., 1987). The entire 7-part program is summarized schematically in Figure 116 , and in Figure 1-17, the layout of each assembly in Room J in WIPP is shown. 


\section{7-Part Program \& Borehole/Assembly Conflgurations}

MIIT GSC. George WICke (803) 725-3180 FTS: 239-3100

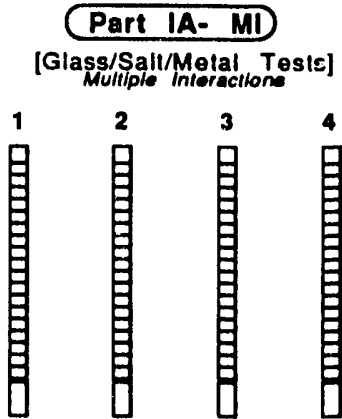

TIME: $2 \mathrm{yrs}$

$2 y r s$

$5 y r s$
Glesses:

SRL Y, SRL Z, Aged Y, RHO, 76-68, ARM, Basalt HMI, FR, CAN-AS, CAN-Sp, MOL-TRU, MOL-AVB, J, UK

\section{Metals:}

304L SS, TiCode 12, Lead

A216, Hastelloy C4.

Bel. C-Stoel, Copper.

Grade 2-TI, 316 SS, 309 S

\section{Part IB- MD \\ [Dry Salt Systems Tosis] \\ Multiote interections}

Glasses:

SRL Y, SRL Z, Agod Y, RHO, 76-68, ARM, Basall,

HMI, FR, CAN-AS, CAN-SP, MOL-TRU, MOL-AVB, J, UK

Metals:

304L SS, TiCode 12, Lead, A216. Hastelloy C4.

Bol. C-Steol, Copper, Grado 2-TI, 316 SS, 309 S

Beckflli:

$70 \%$ Bentonile $+30 \%$ Sand

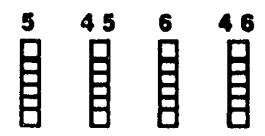

TIME: $5 y r s \quad 2 y r s \quad 1 y r 6 m o$

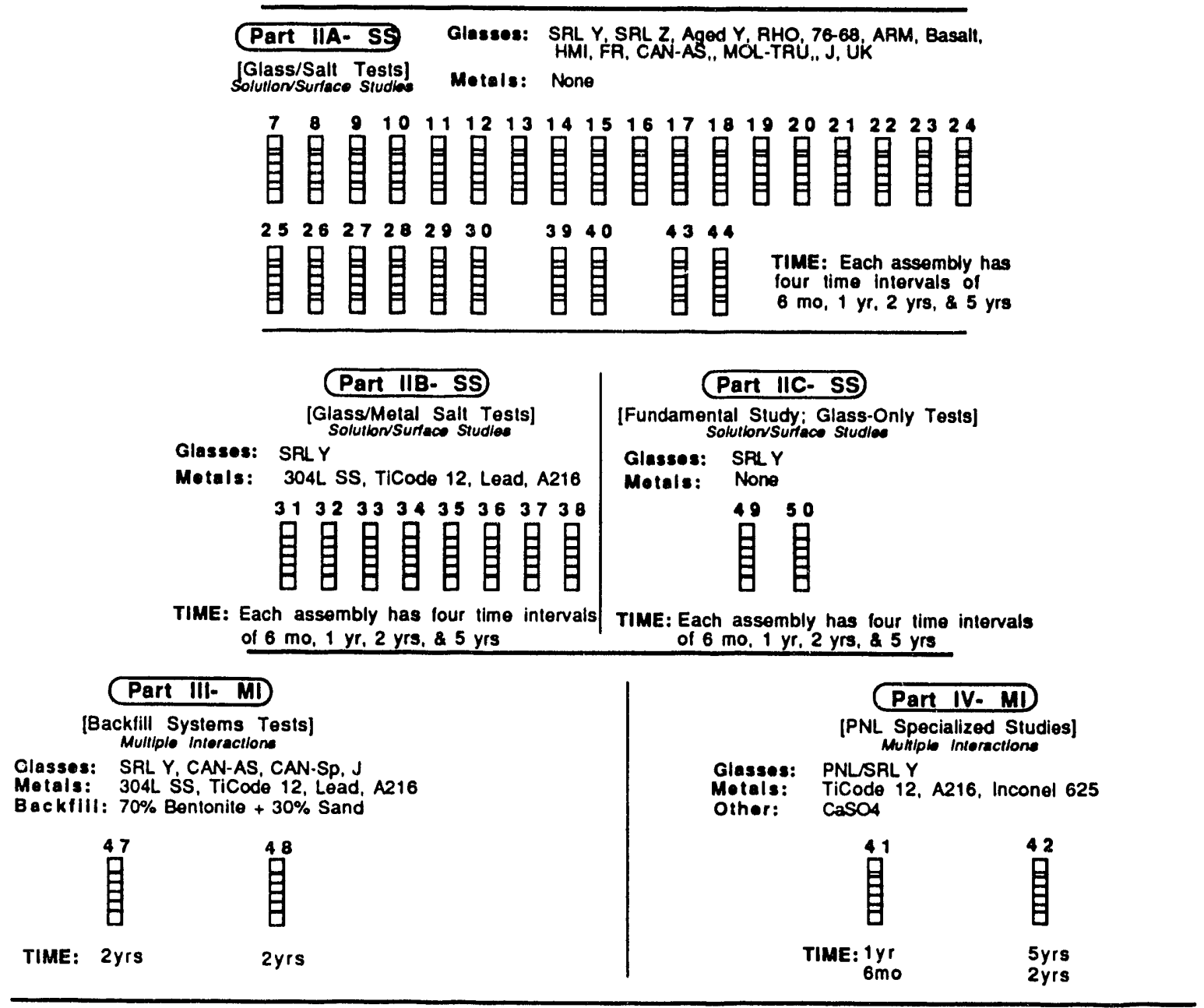

Figure 1-16. WIPP/SRL MIIT Program. 


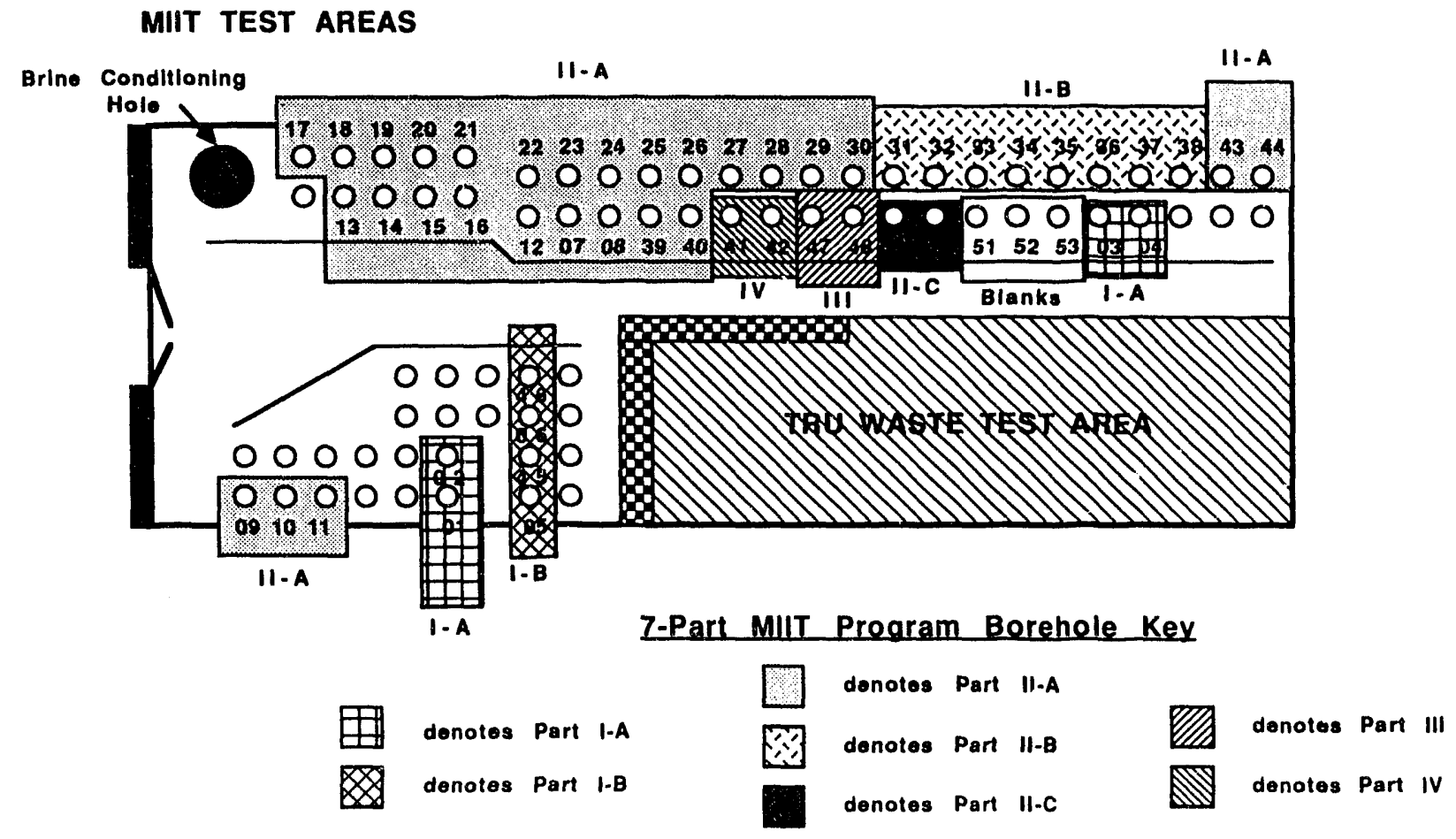

Figure 1-17. Schematic layout of Room J, MIIT boreholes, and 7-part MIIT Program. 
There are 15 distinct waste glass and waste form systems, along with variations of these systems, that have been supplied from seven different countries in the MIIT program. These compositions are listed below and given in more detail in Tables 1-1 and $1-2$.

\subsubsection{U.S. Waste Form Compositions}

- $\quad$ SR 165/TDS waste glass; prepared by Savannah River (SR)

- $\quad$ SR 165/TDS waste glass specially prepared at SR for Pacific Northwest Laboratory (PNL) studies

- SR 165/TDS waste glass chemically doped and Co-60 irradiated; prepared by SR

- $\quad$ SR 131/35\% TDS waste glass; prepared by SR

- $\quad$ 76-68 waste glass supplied by PNL; prepared by SR

- $\quad$ HWVP-HW39 waste glass; supplied and prepared by Rockwell Hanford Operations (RHO)

- $\quad \mathrm{CU}$ borosilicate waste glass; supplied and prepared by The Catholic University of America

- $\quad$ Basalt, a natural glass analogue; prepared by SR

- $\mathrm{ARM}-1$, a standard reference glass; developed and supplied by the Materials Characterization Center (MCC)

\subsubsection{International Waste Form Compositions}

- $\quad$ SON 68-18-17-L1-C2-A2-Z2; supplied and prepared by Centre D'Etudes Nucleaires de la Vallee du Rhone (CEN/VALRHO), France

- SM 513LV11; supplied and prepared by Hahn-Meitner Institut (HMI), Germany

- $\quad$ AECL-GC-NACTS 33; supplied and prepared by Atomic Energy of Canada Ltd. (AECL), Canada

- $\quad$ AECL-AS-981; supplied and prepared by AECL, Canada

- $\quad$ FLK TRUW, WG124; supplied and prepared by Studiecentrum Voor Kernenergie/Centre D'Energie Nucleaire (SCK/CEN), Belgium

- $\quad$ AVB/SAN 602519 L3C2; supplied and prepared by SCK/CEN, Belgium

- JAERI-Z-20/JW-A; supplied and prepared by Japan Atomic Energy Research Institute (JAERI), Japan

- $\quad$ BNFL WG; supplied and prepared by British Nuclear Fuels Ltd (BNFL), United Kingdom

As a result of the MIIT program, a compositional correlation was found which tied together the various waste glass compositions (Ramsey and Wicks, 1990), based on the use of bonding energies, structural roles of components and leaching characteristics. This analysis is based on the fact that in all glass systems, components can play only one 


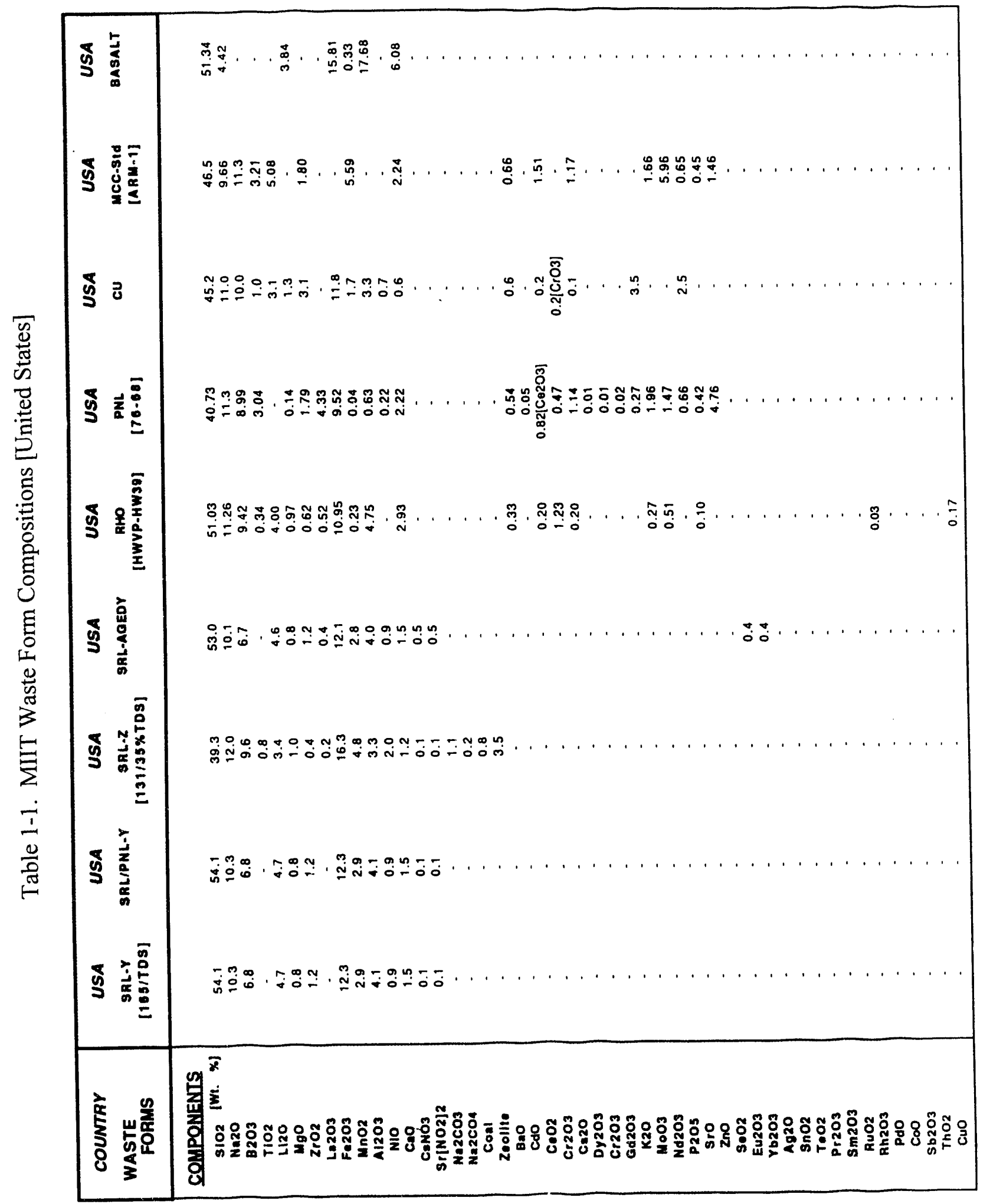




\begin{tabular}{|c|c|}
\hline 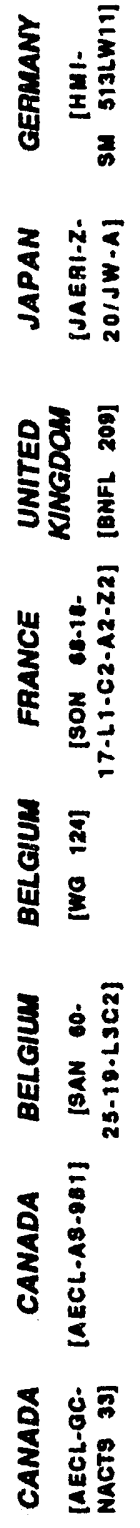 & 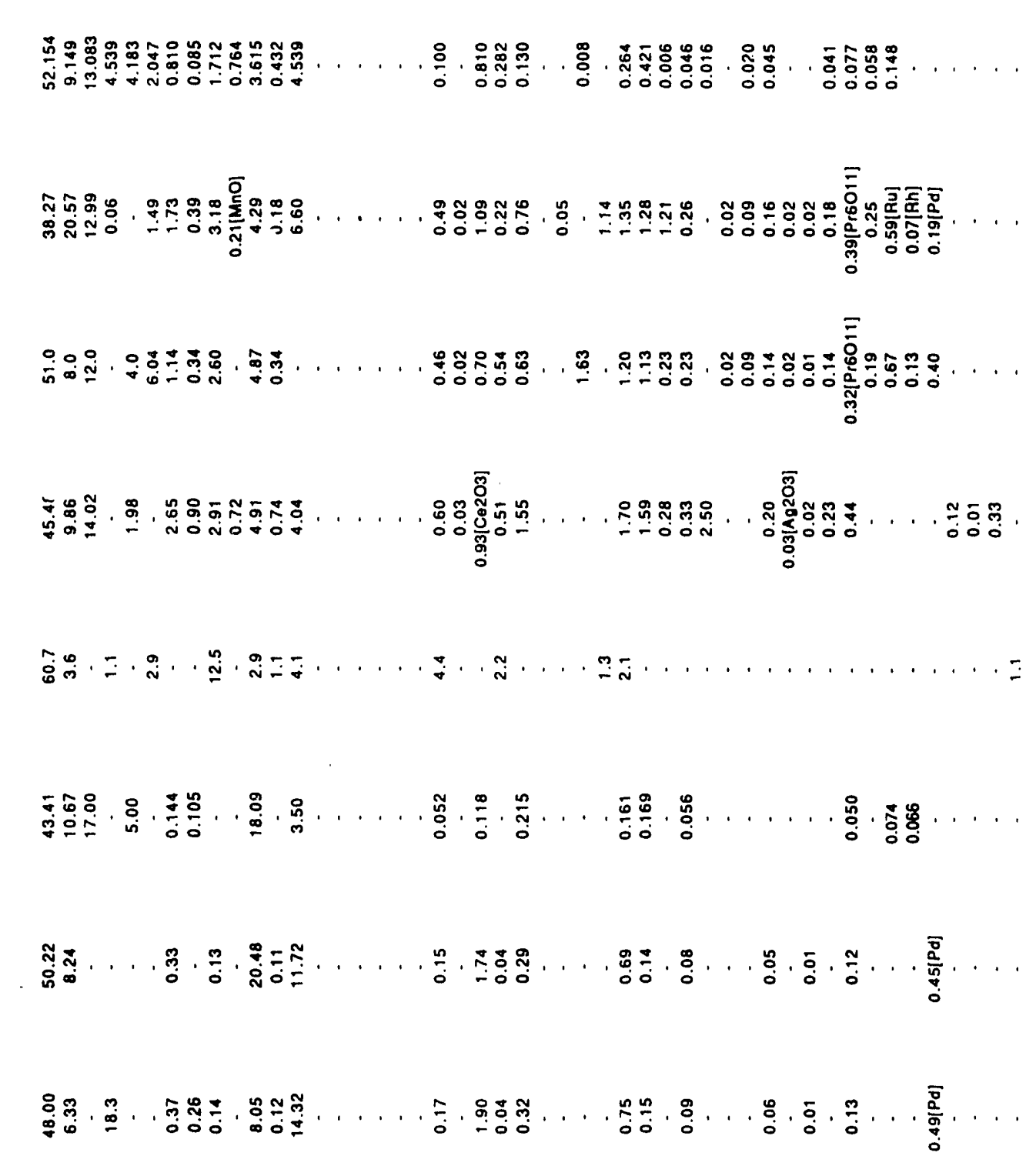 \\
\hline 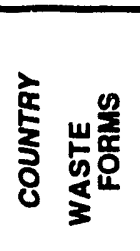 & 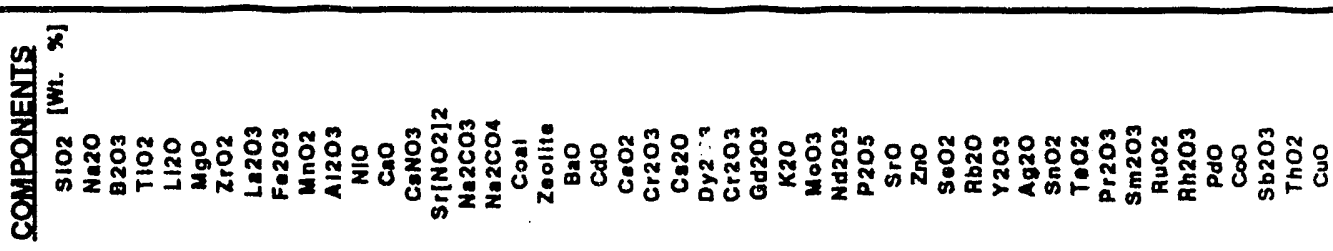 \\
\hline
\end{tabular}


of three basic roles; network formers, intermediates and modifiers. When the various waste glass compositions are plotted in these ierms, we find that they are very similar. These data suggest that the behavior of these systems may be similar as well as the dominate mechanisms of glass dissolution. In addition, the data further suggest, that within a given group of compositions (e.g., borosilicate glasses), the behavior of glasses such as the SR compositions and others, would be expected to be similar to other glasses in actual production world-wide. This compositional correlation or commonality is illustrated in Figure 1-18.

There are eleven different potential waste container or overpack metals in the WIPP MIIT program. These include: A216 carbon steel, copper, grade-2 titanium, Hastelloy C4, Inconel 625, lead, TiCode 12, 304L stainless steel, NS 24/309 stainless steel, 316 stainless steel, Belgium carbon steel. In addition to the metal samples, there are also three geologic sample types included in MIIT. These are rock salt and calcium sulfate from the WIPP mine, and a potential backfill mixture composed of $70 \%$ bentonite, $30 \%$ sand.

Of the 50 MIIT boreholes containing MIIT assemblies, 46 were emersed in saltequilibrated brine and heated to $90^{\circ} \mathrm{C}$ while the remaining four boreholes contained samples also heated to $90^{\circ} \mathrm{C}$ but in dry salt. Most boreholes were run in duplicate and samples were exhumed for post-test analyses and assessment in four time intervals of 6 mo., 1 yr., 2 yrs., and 5 yrs.

\subsection{MIIT RESPONSIBILITIES, ANALYSES AND MEASUREMENTS}

The MIIT tests are operated and managed jointly by Sandia National Laboratories (SNL) and the Savannah River Site (SRS), and sponsored by the U.S. Department of Energy. Sandia was responsible for procurement and installation of all MIIT hardware and for conducting the tests within the salt mine. Additional responsibilities also included preparation of brine leachants and fabrication of selected metal, backfill and salt samples for testing, and subsequent correlation of all analyses and interpretations pertaining to these materials.

The Savannah River Site had primary responsibility for all activities involving waste forms. This included identifying key participants and coordinating the many individual and cooperative analytical studies being performed. In addition to these tasks, SRS was also responsible for providing SR simulated waste glass samples, aged glass and basalt, and preparing the MCC ARM-1 standard glass for testing. SRS also performed some solution analyses in cooperation with WIPP and Catholic University of America and conducted selected surface and bulk studies of leached waste forms. Coordination of all samples and interactions of the MIIT program and subsequent coordination and correlation of the many analyses and interpretations that resulted from this program, were among the most important tasks of the MIIT Glass Studies Coordinator (GSC) at SRS. 


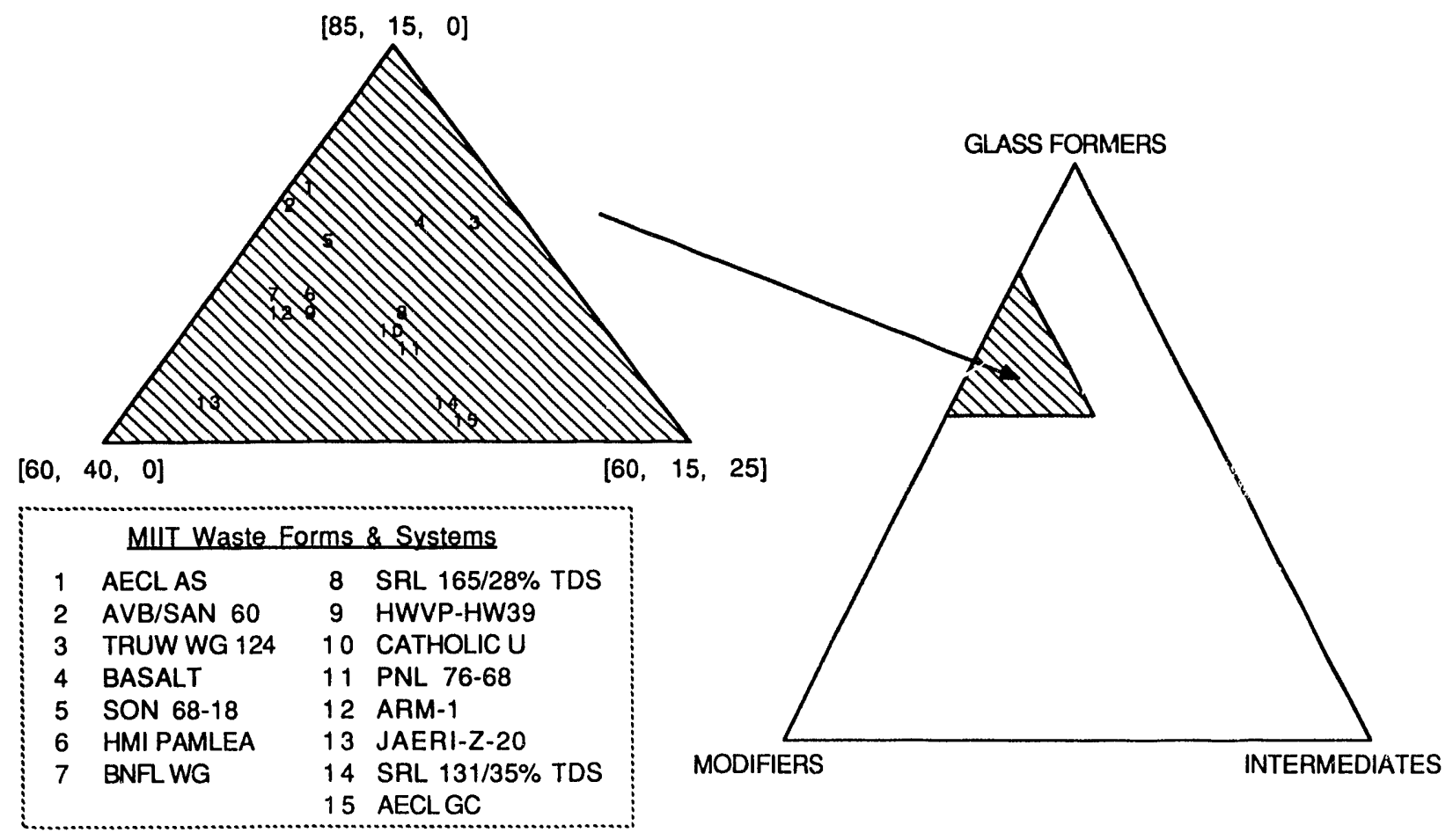

Figure 1-18. Compositional correlations of MIIT waste forms. 
WIPP also provided important field measurements relevant to the MIIT study and obtained both sclid and liquid samples as defined in the MIIT Test Plan (Molecke and Wicks, 1985). Examples of measurements conducted in the field included temperature readings, leachant and leachate $\mathrm{pH}$ values, and solution volumes lost and added. In addition, WIPP provided 'over-coring' of selected boreholes at the end of the 5-year test period.

As part of the MIIT effort, each of the active participants were responsible for fabricating their waste forms in accordance with procedures provided by the GSC. They were also responsible for some pre-test characterization of their product, including identifying samples, performing dimensional and weight measurements, optical microscopy as well as performing any other characterization that they believe important.

In addition, each participant was asked to contribute to overall postcharacterization of not only their waste forms, but other participants' forms as well. These analyses include, Scanning Electron Microscopy (SEM), Electron Microprobe Analysis (EMP), Secordary Ion-Mass Spectroscopy (SIMS), Auger Electron Spectroscopy (AES), Scanning/Transmission Electron Microscopy (STEM), Electron Spectroscopy for Chemical Analysis (ESCA), X-ray Energy Spectroscopy (XES) and Wide Angle X-ray Diffraction (WAXD). In addition, the University of Florida, in cooperation with SRS, provided pre-characterization of all waste form samples by Fourier Transform Infrared Reflection Spectroscopy (FTIRRS) for quaiity assurance purposes.

In order to keep track of the almost 2000 individual samples, interactions and subsequent analyses performed in MIIT, a master computer listing was formed which allowed the many samples to be listed in terms of assembly number, sample type, interaction, time of burial, glass orientation, individual glass ID number and MIIT code number, which describes the complete in situ history of the sample. This listing also included the type of analyses to be performed and who had the samples. This listing could be rearranged rapidly to pick out any of the parameters or combination of parameters listed above. These listings were made for each of the four time intervals. The first page of the 5-yr. samples tracking listing is shown in Table 1-3 for illustration.

In addition to the variety of sophisticated surface analyses performed, solid and solution analyses were also conducted using techniques such as Inductively Coupled Plasma Spectroscopy (ICP) and Atomic Absorption (AA). Brine solution analyses were provided by Sandia, SRS and especially Catholic University of America. These data were then correlated to bulk and surface studies. In Figure 1-19, the various MIIT analytical techniques, involving bulk, surface and solution analyses, are summarized schematically. 


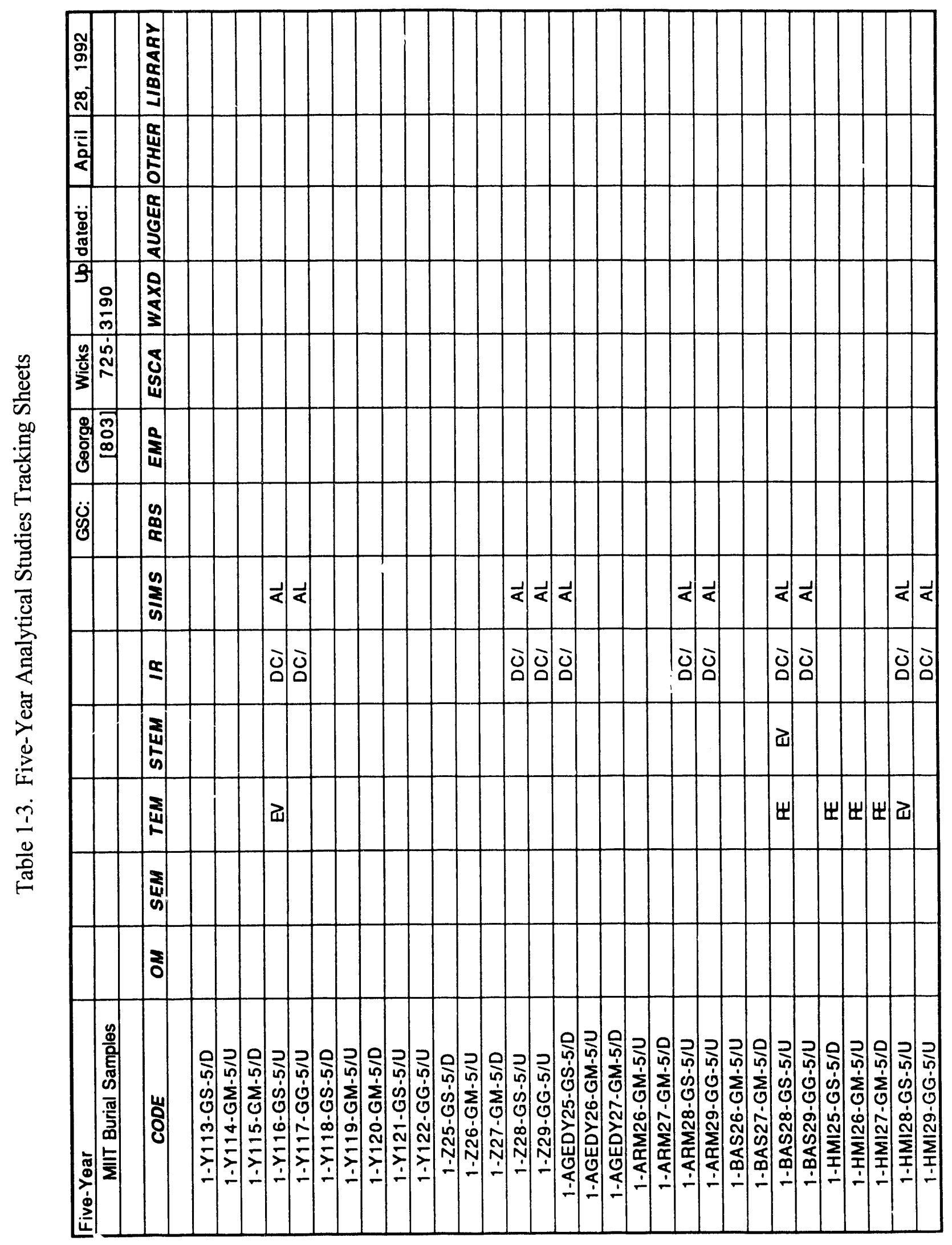




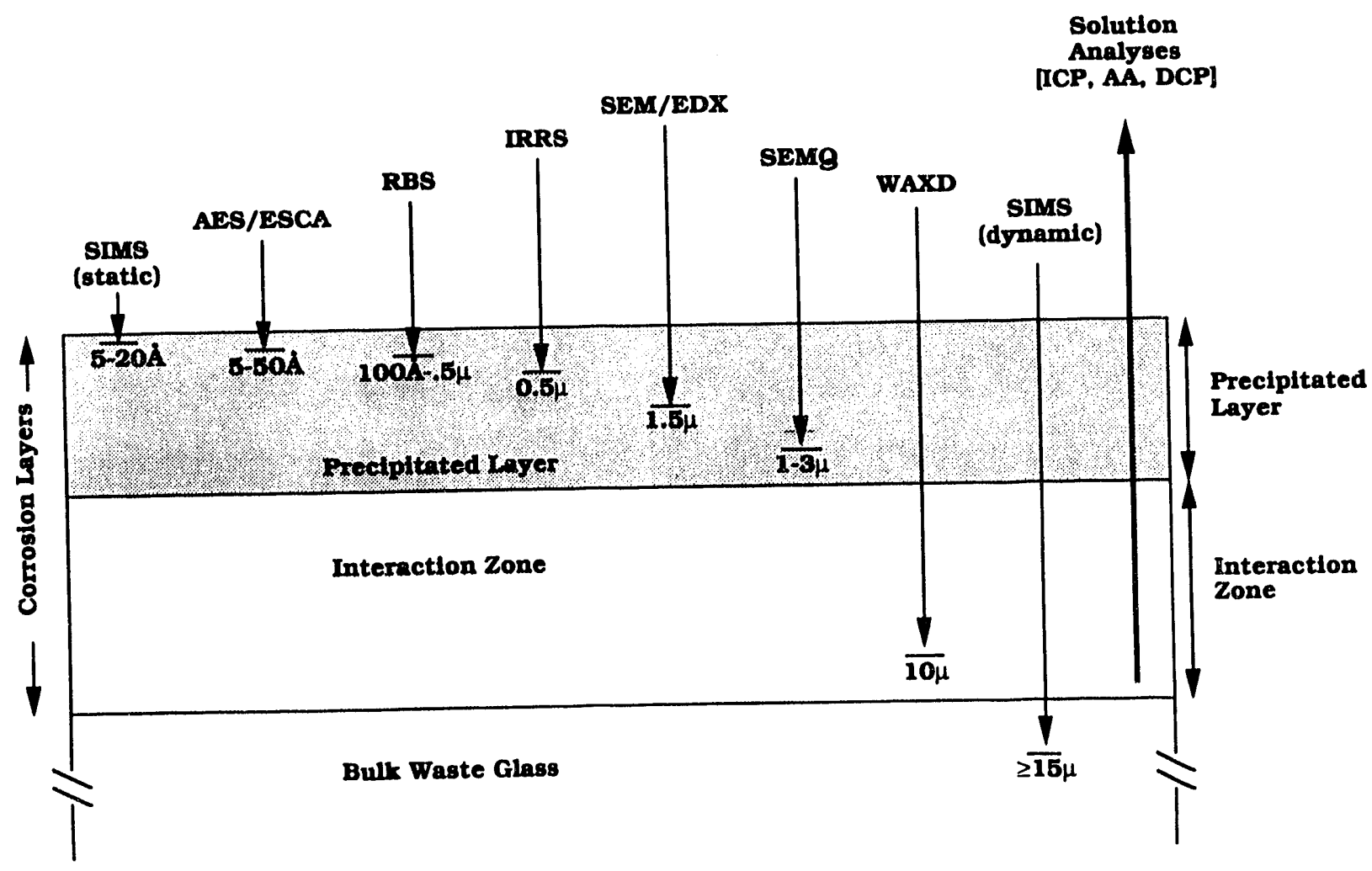

Figure 1-19. Surface analyses of SRL Y leached glass surface layers. 


\subsection{CONCLUSIONS}

In conclusion, the MIIT program is one of the largest cooperative efforts ever undertaken by the waste management community. Due to the unique design of these experiments and as a result of the cooperative nature of these tests, an extensive database is currently being produced, which has already been of benefit to national and international waste management goals and to a variety of disciplines. These in situ tests are an invaluable step in gaining an understanding of the performance of waste glass in a realistic repository environment and in helping to assure confidence in the safe and reliable performance of waste products during final disposal (over 40 individual references including McMenamin, 1989; Wicks et al., 1990; Wicks et al., 1992) . 


\subsection{REFERENCES}

Clark, D.E., B.F. Zhu, R.S. Robinson, and G.G. Wicks. 1984. "Preliminary Report on a Glass Burial Experiment in Granite," Nuclear Waste Management, 85th American Ceramic Society Annual Meeting, Chicago, IL, April 25, 1983. Advances in Ceramics Volume 8. Columbus, OH: American Ceramic Society, Inc. 324-336.

Lodding, A.R., E.U. Engstrom, D.E. Clark, L.O. Werme, and G.G. Wicks. 1986. "SIMS Analysis of Leached Layers Formed on SRL Glasses During Burial," Nuclear Waste Management II, 3rd International Symposium on Ceramics in Nuclear Waste Management, Chicago, IL, August 28, 1986. Eds. W.F. Passchier and B.F.M. Bosnjakovic. Advances in Ceramirs Volume 20. Westerville, OK: American Ceramic Society, Inc. 567-582.

Matalucci, R.V., C.L. Christensen, T.O. Hunter, M.A. Molecke, and D.E. Munson. 1982. Waste Isolation Pilot Plant (WIPP) Research and Development Program: In Situ Testing Plan, March 1982. SAND81-2628. Albuquerque, NM: Sandia National Laboratories.

McMenamin, T., ed. 1989. Testing of High-Level Waste Forms Under Repository Conditions, Proceedings of a Workshop Jointly Organized by CEC, US DOE and CEA, Cadarache, France, October 17-21, 1988. EUR 12017 EN. Luxembourg: Commission of the European Communities.

Molecke, M.A., and G.G. Wicks. 1985. "Test Plan: WIPP Materials Interface Interactions Test (MIIT)." Albuquerque, NM: Sandia National Laboratories.

Molecke, M.A., and G.G. Wicks. 1993. "Materials Interface Interactions Test (MIIT) Details and Observations on In Situ Sample Retrievals and Test Termination," Waste Isolation Pilot Plant Materials Interface Interactions Test: Papers Presentea at the Commission of European Communities Workshop on In Situ Testing of Radioactive Waste Forms and Engineered Barriers. SAND93-1055. Eds. M. A. Molecke, N.R. Sorensen, and G.G. Wicks. SAND93-1055. Albuquerque, NM: Sandia National Laboratories. 2-1 to 2-19.

Ramsey, W.G., and G.G. Wicks. 1988. WIPP/SRL In Situ Tests-Part III: Compositional Correlations of MIIT Waste Glasses. DP-1769. Aiken, SC: E.I. du Pont de Nemours \& Co., Savannah River Laboratory. 
Ramsey, W.G., and G.G. Wicks. 1990. "WIPP/SRL In-Situ Tests: Compositional Correlations of MIIT Waste Glasses," Ceramic Transactions, 4th International Symposium on Ceramics in Nuclear Waste Management, Indianapolis, IN, April 2426, 1990. Ed. G.B. Mellinger. Columbus, OH: American Ceramic Society, Inc. 257270.

Sandia National Laboratories. 1983. "Waste Isolation Pilot Plant (WIPP) Program Plan for Fiscal Year 1984." Albuquerque, NM: Sandia National Laboratories. (Copy on file at the Waste Management and Transportation Library, Sandia National Laboratories, Albuquerque, NM).

Sandia National Laboratories. 1985. Sandia Technology. SAND84-2326. Vol. 9, no. 1.

Wicks, G.G. 1985a. "Nuclear Waste Glasses," Treatise on Materials Science and Technology Volume 26, Glass IV. Eds. M. Tomozawa and R.H. Doremus. Orlando, FL: Academic Press, Inc. 57-118.

Wicks, G.G. 1985b. WIPP/SRL In-Situ and Laboratory Testing Program. Part I: MIIT Overview, Nonradioactive Waste Glass Studies. DP-1706. Aiken, SC: E.I. du Pont de Nemours \& Co., Savannah River Laboratory.

Wicks, G.G. 1986. "Nuclear Waste Vitrification-The Geology Connection," Journal of Non-Crystalline Solids. Vol. 84, no. 1-3, 241-250.

Wicks, G.G. 1992. "Nuclear Waste Glasses; Corrosion Behavior and Field Tests," Corrosion of Glass, Ceramics, and Ceramic Superconductors. Eds. D.E. Clark and B.K. Zoitos. Park Ridge, NJ: Noyes Publication. 218-268.

Wicks, G.[G.], and D. Bickford. 1989. "Doing Something About High-Level Nuclear Waste," Technology Review. Vol. 92, no. 8, [51] - 58.

Wicks, G.G., and M.A. Molecke. 1986. "WIPP/SRL In Situ Testing Program," Nuclear Waste Management II, 3rd International Symposium on Ceramics in Nuclear Waste Management, Chicago, IL, August 28, 1986. Eds. W.F. Passchier and B.F.M. Bosnjakovic. Advances in Ceramics Volume 20. SAND86-1038C. Westerville, OK: American Ceramic Society, Inc. 657-670.

Wicks, G.G., and M.A. Molecke. 1988. "WIPP/SRL In Situ Testing Program: MIIT Update 1988," Waste Management '88, Waste Processing, Transportation, Storage and Disposal, Technical Programs and Public Education, Tucson, AZ, February 28March 3, 1988. Ed. R.G. Post. SAND87-2654C. Tucson, AZ: University of Arizona. Vol. 2, 383-392. 
Wicks, G.G., M.E. Weinle, and M.A. Molecke. 1987. WIPP/SRL In Situ Tests-Part II: Pictorial History of MIIT and Final MIIT Matrices, Assemblies, and Sample Listings. DP-1733. Aiken, SC: E.I. du Pont de Nemours \& Co., Savannah River Laboratory.

Wicks, G.G., A.R. Lodding, P.B. Macedo, D.E. Clark, and M.A. Molecke. 1990. "MIIT: International In-Situ Testing of Simulated HLW Forms-Preliminary Analyses of SRL 165/TDS Waste Glass and Metal Systems," High Level Radioactive Waste Management, Proceedings of the International Topical Meeting, Las Vegas, NV, April 8-12, 1990. La Grange Park, IL: American Nuclear Society, Inc.; New York, NY: American Society of Civil Engineers. Vol. 1, 443-450.

Wicks, G.G., A.R. Lodding, P.B. Macedo, and D.E. Clark. 1991. "MIIT: International In-Situ Testing of Simulated HLW Forms-Performance of SRS Simulated Waste Glass After 6 Mos., 1 Yr., 2 Yrs. and 5 Yrs. of Burial at WIPP," Scientific Basis for Nuclear Waste Management XV, Strasbourg, France, November 5-8, 1991. WSRCMS-91-263. Aiken, SC: Westinghouse Savannah River Co.

Wicks, G.G., A.R. Lodding, P.B. Macedo, and D.E. Clark. [1992.] "MIIT: Summary of the Performance of SRS Waste Glass Buried in Salt at WIPP-1992 Update," Workshop on In Situ Tests on Radioactive Woste Forms and Engineered Barriers, Corsendonk, Belgium, October 13-16, 1992. WSRC-MS-92-462. Aiken, SC: Westinghouse Savannah River Site.

Zhu, B.F., D.E. Clark, L.L. Hench, G.G. Wicks, and L. Werme. 1985. "One-Year Leaching of Three SRL Glasses in Granite," Scientific Basis for Nuclear Waste Management VIII, Materials Research Society Symposia Proceedings, Boston, MA, November 26-29, 1984. Eds. C.M. Jantzen, J.A. Stone, and R.C. Ewing. Pittsburgh, PA: Materials Research Society. Vol. 44, 187-194. 


\title{
2.0 MATERIALS INTERFACE INTERACTIONS TEST (MIIT) DETAILS AND OBSERVATIONS ON IN SITU SAMPLE RETRIEVALS AND TEST TERMINATION
}

\author{
Martin A. Molecke \\ Sandia National Laboratories \\ Albuquerque, NM 87185 USA \\ and \\ George G. Wicks \\ Westinghouse-Savannah River Technology Center \\ Aiken, SC 29808 USA
}

\begin{abstract}
The Materials Interface Interaction Tests (MIIT) program involves the comparative performance-evaluation testing of multiple U.S. and foreign nuclear waste glasses (nonradioactive), potential canister and overpack metals, brine, and geologic materials in the rock salt repository environment at the Waste Isolation Pilot Plant (WIPP) facility. We emplaced about 2000 materials specimens onto fifty separate test assemblies and exposed them to a heated, salt-brine environment at the WIPP for multi-year periods. We successfully terminated the in situ conduct of the MIIT in July 1991, after five years of testing, and retrieved all samples for posttest laboratory analyses. These 5-year glass and metal samples, along with samples previously retrieved after $0.5,1$, and 2 years, are being analyzed in multiple international laboratories, in a cooperative testing effort. Individual test participants will present available laboratory results, and interpretations, on MIIT specimens in this workshop. Our focus in this paper is to summarize technical details and repository-relevant observations on the in situ conduct, sampling, and termination operations of the MIIT experimental program. Such information should be useful for the interpretation of the laboratory-based analyses. This information also will be relevant and instructive for other organizations contemplating, planning, or conducting additional materials-related, in situ tests.
\end{abstract}




\section{$2.1 \quad$ INTRODUCTION}

The Waste Isolation Pilot Plant facility is planned to be the first deep geologic, nuclear waste isolation repository in the United States, and is located near Carlsbad, New Mexico. The underground portion of the WIPP is approximately 655 meters telow the surface, mined into the thick bedded salt deposits of the Salado Formation. The WIPP, a U.S. Department of Energy facility, will be used (a) to serve initially as an "underground laboratory," to evaluate and demonstrate safe and effective disposal of both transuranic (TRU; simulated and actual) and defense-related high-level wastes (DHLW; simulated only), and (b) to permanently isolate transuranic wastes generated from U.S. defense programs (Tyler et al., 1988). Construction of the WIPP facility began in 1981 and is now essentially complete. This facility is scheduled to begin accepting actual TRU wastes in 1993, for testing.

The Materials Interface Interactions Tests (MIIT) program is an important, multinational cooperative segment of the WIPP Waste Package Performance (WPP) program (Tyler et al., 1988; Molecke and Wicks, 1986; Wicks and Molecke, 1988; Wicks and Molecke, 1989). This WPP program includes the direction and performance of all materials-related, and associated technical operations-related, in situ testing on simulated (nonradioactive) remote-handled and contact-handled TRU and DHLW waste containers and emplacements and, for the MIIT, high-level waste forms contributed by non-U.S. participants (Molecke, 1993; Molecke, 1984; Wicks, 1985; Wicks et al., 1987). The predominant goals of the WIPP WPP testing program are to provide: comprehensive in situ and supporting laboratory data bases for waste package engineered-barrier material selections, testing, and detailed evaluations; fabrication and test experience for waste package designs and design options; and, repository relevant data for the WIPP performance assessment modeling studies (Tyler et al., 1988). The WPP in situ testing program was also designed:

- to provide relevant scientific and technical guidance plus information for supporting both performance assessment and regulatory compliance evaluations, and;

- to support eventual radioactive waste repository operations at the WIPP facility, and elsewhere.

The MIIT is one of the major, predominantly non-TRU-related experimental programs conducted at the WIPP facility (Tyler et al., 1988). The MIIT involves the comparative performance-evaluation testing of multiple simulated (i.e., nonradioactive) ruclear waste glasses, potential waste canister or overpack metals, brine, and geologic materials in the WIPP rock salt repository environment (Molecke and Wicks, 1986; Wicks and Molecke, 1988; Wicks and Molecke, 1989; Wicks, 1985; Wicks et al., 1987; Molecke et al., 1989). The major intent of the MIIT program is to evaluate, then model, glass waste form in situ leaching behavior(s) and comparative performance, metal 
sample(s) corrosion (Molecke et al., 1989), and overall interactions in a heated, brine-salt geologic repository environment. The MIIT Principal Investigator, from Sandia National Laboratories, and the MIIT Glass Studies Coordinator, from Westinghouse-Savannah River Technology Center, technically directed and conducted the MIIT program at the WIPP (Molecke and Wicks, 1986). The MIIT program also includes a major degree of international participation by multiple researchers in the United States, Canada, Belgium, France, Germany, the United Kingdom, Sweden, and Japan. All of the MIIT participants are associated with transuranic or high-level waste form development and testing, ard have provided test samples (glass waste forms and metals) and/or are participating in posttest sample analyses (Molecke and Wicks, 1986; Wicks and Molecke, 1988; Wicks and Molecke, 1989; Wicks, 1985; Wicks et al., 1987; Molecke et al., 1989; Molecke, 1989). Overall details on the MIIT program and its participants have been described previously and will be reviewed in this workshop (Wicks and Molecke, 1993).

We developed the concept for the MIIT program in late 1984 then revised, documented, and received formal DOE approval in 1985 and 1986 (Molecke and Wicks, 1986; Wicks, 1985). We installed the MIIT materials specimens onto 50 separate test assemblies (Wicks et al., 1987), then emplaced them into cored holes in the salt of WIPP Room J in February 1986. MIIT heated test operations were initiated in July 1986. We continued testing for five years, through July 1991, when the in situ portion of this program was successfully retrieved, then terminated. We retrieved specific test assemblies and samples for multiple posttest laboratory analyses after $0.5,1$, and 2 years of test exposure (Wicks and Molecke, 1989; Molecke et al., 1989; Molecke, 1989), as well as at the 5-year termination point. Brine leachate samples were retrieved at these and multiple, additional time intervals.

Our focus in this paper is to summarize technical details and repository-relevant observations on the in situ conduct, sampling, and termination operations for the MIIT experimental program. We shall briefly summarize details of the various test samples and associated equipment necessary for in situ test performance; more comprehensive test descriptions, details, and reviews have already been documented (Molecke and Wicks, 1986; Wicks and Molecke, 1988; Wicks and Molecke, 1989; Wicks, 1985; Wicks et al., 1987; Molecke et al., 1989; Molecke, 1989). In this paper, we intend to emphasize descriptions of the test and operational difficulties encountered for the two- through fiveyear period of conduct. Such information should be useful for assisting in interpretations of the laboratory-based analyses. We also believe that this information should be relevant to, and instructive for, other organizations contemplating or conducting other materials-related in situ tests. In this workshop, individual test participants will present available posttest results and interpretations on, primarily, the retrieved glass waste form MIIT specimens (Wicks and Molecke, 1993). We will also summarize the corrosion results of the various metal samples in a separate paper (Sorensen and Molecke, 1993). 


\subsection{EXPERIMENTAL}

\subsubsection{Overview and Test Assemblies}

The total MIIT experimental array involves the multi-year, in situ testing and posttest (laboratory) analyses of almost 2000 different specimens of various waste form glasses, candidate waste container or overpack metals, WIPP rock salt, etc., emplaced onto 50 separate test assemblies. Individual test assemblies consist of multiple samples, combinations of samples, and different experimental configurations or stacking sequences of samples, producing various interface-interactions of interest. All "pineapple-slice" shaped samples are stacked around a central, electric rod heater (Molecke and Wicks, 1986; Molecke, 1989). The specific glass and metal specimens on each test assembly, and their arrangements, are summarized elsewhere (Wicks et al., 1987); Figure 2-1 shows a representative MIIT assembly with metal samples. The types of specimens will

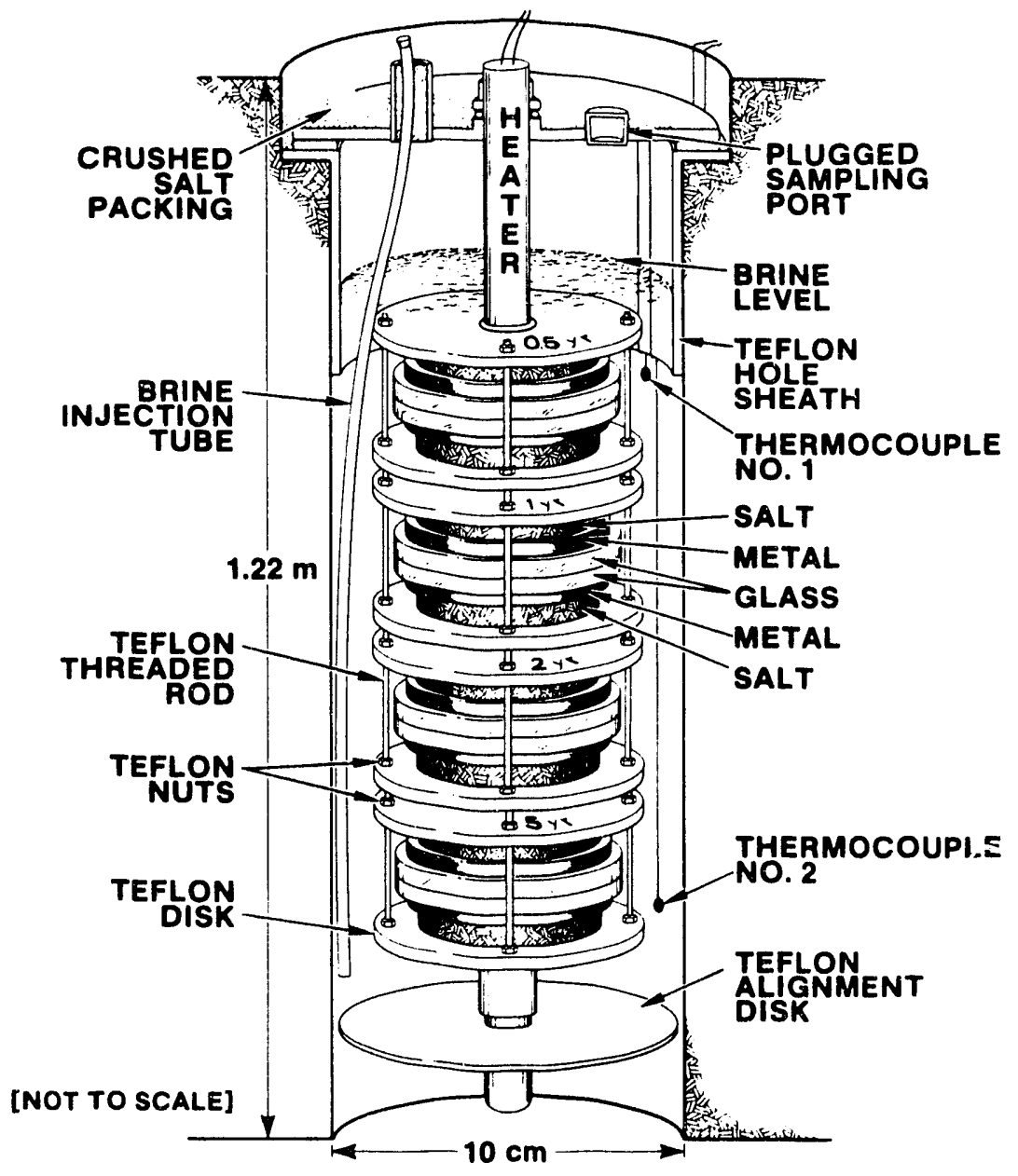

Figure 2-1. Representative WIPP MIIT assembly with metal samples. 
be described in Section 2.2. All sample assemblies were tested in duplicate, in case specific specimens or groups of specimens were damaged or lost during the retrieval process, to be described. We also included three additional, identical "blank" test assemblies, into the overall experiment matrix, but with only test hardware and no materials samples on them. These three assemblies were immersed in test holes filled with brine, in order to provide brine control blanks for the leachate solution analyses.

All test assemblies were hooked-up to underground power supplies and instrument monitoring, control, and data-handling systems (Molecke and Wicks, 1986; Molecke, 1989). The data acquisition and control systems, including the aboveground computers, are described in Section 2-4. We have documented details of the test rod heaters, other hardware, and associated instrumentation elsewhere (Molecke and Wicks, 1986). Further test hardware details were reviewed in the last workshop and will be expanded upon herein only as relevant (Molecke, 1989).

The overall MIIT program consists of two basic experiment subsets (Wicks, 1985; Wicks et al., 1987), the MIIT-SS (Solution/Surface Interactions) and the MIIT-MI (Multiple Interactions) studies. The MIIT-SS subset represents the bulk of the total MIIT effort and includes 38 of the 50 sample-containing test assemblies. All of the MIIT-SS assemblies were immersed in brine at the initiation of testing: 28 have only glass (one type per assembly) and WIPP rock salt sample disks; 2 have only glass samples; and 8 have (one) glass, (one) metal, and rock salt samples. Individual MIIT-SS test assemblies were dedicated to the evaluation of one relatively simple set of materials test interfaces (i.e., one glass type with or without one metal type) interacting in a heated brine-salt repository relevant environment. We designed the MIIT-SS sample assemblies to obtain two specific, very important sets of data: (1) time-dependent data from separate glass and metal specimens from individual test holes, available from a four-part test subassembly type of design (this setup allowed specimens to be individually removed after $0.5,1,2$, or 5 years of test exposure) and (2) brine solution-leachate composition data (concentrations of leached and original ions, $\mathrm{pH}$ ), to correlate with glass surface studies (Wicks and Molecke, 1989; Wicks, 1985; Molecke et al., 1989; Wicks and Molecke, 1993).

We designed the MIIT-MI experiments to help evaluate the effects of many different package component interactions on glass waste form(s) and metals durability, in a limited number of tests. Multiple glasses, metals, etc. were tested simultaneously. Interpretations of the "simple"-system MIIT-SS test data will aid in and directly complement the interpretation of the more "complex"-system MIIT-MI tests. There were a total of twelve MIIT-MI test assemblies. Eight were immersed into initially brine-filled test boreholes. The other four were surrounded by initially dry, finely crushed WIPP salt rather than brine, for baseline comparisons; these are considered quite "repository relevant." 


\subsubsection{MIIT Materials Specimens and Brine}

Glass Samples: The MIIT test specimens include a total of about 980 waste form samples. The glasses, predominantly borosilicates, are all simulated or nonradioactive and are representative of various defense HLW, other HLW, TRU, natural analogue, and reference compositions. These consist of fifteen different waste form glasses, seven formulations contributed by multiple U.S. laboratories (with the bulk quantity originating at the Savannah River facility), and eight types contributed by our foreign participants. Exact compositions, preparation details, and suppliers of the glasses are summarized elsewhere (Molecke and Wicks, 1986; Wicks, 1985; Wicks et al., 1987; Molecke, 1989). All of the glass specimens are flat, annular-ring ("pineapple-slice") disks with an outer diameter of $53.3 \mathrm{~mm}$ (2.1 inch), an inner diameter of $20.3 \mathrm{~mm}(0.8 \mathrm{inch})$, and a thickness of 3.8 to $5.1 \mathrm{~mm}(0.15$ to $0.20 \mathrm{inch})$. The "pineappie-slice" sample configuration was derived from earlier in situ waste form-leaching tests in the Stripa facility in Sweden (Wicks, 1985). Each sample has one polished face and an edge notch for locating purposes. The polished face of the samples were located either face up or face down on the test assembly. This placement allowed any effects caused by precipitates settling out of solution to be differentiated.

Metal Samples: There are a total of 278 individual metal samples of eleven different metal alloys used in the WIPP MIIT (Molecke and Wicks, 1986; Wicks, 1985; Molecke et al., 1989; Sorensen and Molecke, 1993). The tested alloys, all proposed for waste canister or overpack use, include: titanium alloys (grade-2 and grade-12), austenitic stainless steels (304L, 316, and NS 24/AISI 309), carbon steels (ASTM A216/WCA and Belgian C), Hastelloy C4, Inconel 625, copper, and lead. There were a minimum of three different types of metal alloy in each of the MIIT-MI assemblies and only one specific alloy on the eight MIIT-SS assemblies with metals. No two metals on an assembly were allowed to physically touch during the test period. All of the metal samples are flat, annular disks with an outer diameter of $38 \mathrm{~mm}$ (1.5 inch), an inner diameter of $20.3 \mathrm{~mm}(0.8 \mathrm{inch})$, and a thickness of about $6.4 \mathrm{~mm}(0.25 \mathrm{inch})$. Some have circumferential welds to allow posttest evaluations of weld and weld heat-affected zones, in addition to posttest analyses of uniform and localized corrosion attack. Most of the disks also have four $3.2-\mathrm{mm}(0.125 \mathrm{inch})$ holes through the disks. These holes are representative of potential pits; more importantly, they allow easier penetration of brine to the metal-other material interfacial surfaces. We provide further details on these MIIT metal alloy samples, plus a summary of their corrosion behavior results, in a separate paper in this workshop (Sorensen and Molecke, 1993).

WIPP Salt and Backfill Specimens: Annular disks of rock salt were machined from large cores $(41-\mathrm{cm}$ diameter) of halite obtained at about the $650-\mathrm{m}$ horizon of the WIPP. Disk specimens are of large-crystal halite plus impurities and are basically identical in mineralogic content to the rock salt (test boreholes) that surround each emplaced test assembly. The rock salt at the WIPP test horizon is predominantly a 
heterogeneous mixture of halite $(\mathrm{NaCl})$, with a maximum of $5 \mathrm{wt}$. \% total of the following minerals: anhydrite $\left(\mathrm{CaSO}_{4}\right)$, polyhalite $\left[\mathrm{K}_{2} \mathrm{MgCa}_{2}\left(\mathrm{SO}_{4}\right) \cdot 2 \mathrm{H}_{2} \mathrm{O}\right]$, assorted clays, quartz $\left(\mathrm{SiO}_{2}\right)$, gypsum $\left(\mathrm{CaSO}_{4} \cdot 2 \mathrm{H}_{2} \mathrm{O}\right)$, and magnesite $\left(\mathrm{MgCO}_{3}\right)$. There are heterogeneous, mineralogical salt/impurity variations on a centimeter-to-meter scale. Individual salt disks have an outer diameter of $43.2 \mathrm{~mm}$ (1.7 inch), an inner diameter of $20.3 \mathrm{~mm}$ (0.8 inch), and a nominal thickness of $19.1 \mathrm{~mm}(0.75 \mathrm{inch})$.

We also fabricated several sample "backfill" disks made of $70 \mathrm{wt}$. \% bentonite clay and $30 \mathrm{wt}$. \% silica sand, for use in a few of the test assemblies. This backfill material has been evaluated and previously tested for remote-handled TRU (Molecke, 1993) and DHLW (Tyler et al., 1988; Molecke, 1984) applications in the WIPP. This bentonite/sand mixture was uniaxially compressed at $20 \mathrm{MPa}$ (Molecke and Wicks, 1986) into annular disks with a final density of $1.8 \mathrm{~g} / \mathrm{cm}^{3}$. Backfill disks had an overall size identical to the rock salt disks. Individual geologic material disks were placed adjacent to either glass or metal samples, to provide an interface for interactions. We specifically made the diameters of the glass, metal, and geologic test specimens different, in order to produce sample/liquid interfaces, plus glass/glass, glass/metal, glass/salt, and metal/salt interfaces.

Brine Leachant: We used WIPP Brine $A$ as the initial leachant liquid in all the (brine-filled) MIIT emplacement holes (Molecke and Wicks, 1986). Brine A is a concentrated $\mathrm{Na}-\mathrm{Mg}-\mathrm{K}-\mathrm{Cl}-\mathrm{SO}_{4}$ brine that is representative of rock salt fluid inclusions and intergranular liquids. The initial concentrations of the major components in Brine A, in units of molarity and/or $\mathrm{mg} / \mathrm{l}(\mathrm{ppm})$ are:

$$
\begin{array}{lllr}
\mathrm{Na}^{+}=1.83 \mathrm{M}, & \mathrm{Mg}^{++}=1.44 \mathrm{M}, & \mathrm{K}^{+}=0.77 \mathrm{M}, \quad \mathrm{Ca}^{++}=0.02 \mathrm{M}, \mathrm{Li}^{+}=20 \mathrm{mg} / \mathrm{l}, \\
\mathrm{Rb}^{+}=20 \mathrm{mg} / \mathrm{l} ; & \mathrm{Cl}^{-}=5.35 \mathrm{M}, & \mathrm{SO}_{4}^{-}=0.04 \mathrm{M}, & \mathrm{B}\left(\text { as } \mathrm{BO}_{3}^{-}\right)=0.02 \mathrm{M} \text { or } 1200 \mathrm{mg} / \mathrm{l}, \\
\mathrm{HCO}_{3}^{-}=0.01 \mathrm{M} & \mathrm{Br}^{-}=0.01 \mathrm{M}, & \mathrm{I}^{-}=10 \mathrm{mg} / \mathrm{l} ; & \text { and, } \mathrm{pH}=\sim 6.5
\end{array}
$$

This brine leachant was kept in equilibrium with the host rock salt and the sample assemblies at about $90 \pm 10^{\circ} \mathrm{C}$. As such, its composition changed as a function of time, as rock salt and impurity dissolution and precipitation, plus waste form leaching, occurred. We previously documented the periodic analyses results on the brine compositions (Molecke et al., 1989). Over most of the two- to five-year test period of the MIIT, the test assemblies were immersed not in brine, but were encased instead in nearsolid, slightly damp (precipitated) salts. The precipitated salts were predominantly $\mathrm{NaCl}$, with much smaller amounts of gypsum, carnallite $\left[\mathrm{KMg}(\mathrm{Cl})_{3} \bullet 6 \mathrm{H}_{2} \mathrm{O}\right]$, possibly bichofite $\left[\mathrm{MgCl}_{2} \bullet 6 \mathrm{H}_{2} \mathrm{O}\right]$, and other minor phase (Molecke et al., 1989). While this condition makes interpretations of waste form leaching tests more difficult, it is considered quite realistic and (salt) repository relevant; interactions take place in the presence of wastes, waste package materials, (initially dry) host rock, and any intruding liquid leachant. 


\subsection{EXPERIMENTAL OPERATIONS AND OBSERVATIONS}

\subsubsection{Test Experiment}

We installed all of the MIIT samples onto individual test assemblies in January 1986, then emplaced these assemblies into WIPP test boreholes in February 1986. Assemblies were allowed to remain at ambient temperature, about $30^{\circ} \mathrm{C}$, in leachant brine, until the test rod-heaters were energized. This heater turn-on (the formal test initiation) (ccurred on July 22, 1986, after we received the required Department of Energy/WIPY Project Office approval. Following turn-on, the power (wattage) of the rod-heaters were increased, then periodically adjusted so that the resultant brine temperatures were maintained at about $90 \pm 10^{\circ} \mathrm{C}$, as monitored with two thermocouples in each test borehole.

Each test borehole was located in a relatively thick layer of rock salt (halite) in the northern half, and eastern side of test Room $\mathbf{J}$ in the WIPP. Room J, as mined, was $3.7 \times 7.0 \times 29.9 \mathrm{~m}(12 \times 23 \times 98 \mathrm{ft}$. $), \mathrm{H} \times \mathrm{W} \times \mathrm{L}$. Because of another WIPP waste package performance experiment occupying the same test room, the ambient air temperature in Room J was about $40^{\circ} \mathrm{C}$ (Tyler et al., 1988; Molecke and Wicks, 1986). More than 50 test emplacement holes were cored into the floor of this room, with each

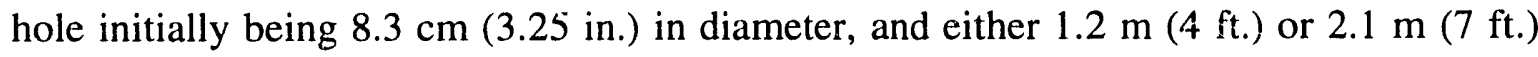
deep. The longer holes extended very near, or into, a bedded layer of anhydrite. Multiple spare holes were also drilled for future use, such as for test replacements (after sampling/retrieval periods) and as blank/control holes.

We examined several of the emplaced test assemblies and boreholes approximately five weeks after they had been filled 'vith brine. We found that essentially all of the bentonite/sand backfill disks, and a large fraction of the rock salt disks, had dissolved in the brine. They were no longer present nor available for posttest analyses. Fiecipitated salt on the surfaces of most test specimens served to replace the rock salt disks in providing salt-waste form interfaces.

\subsubsection{Test Assembly Retrievals}

During the course of this program, we retrieved and sampled each test assembly four times, after $0.5,1,2$, and 5 years of heated operations. After sampling and maintenance operations, to be described, the assemblies were reemplaced for further testing, except after the final, 5-year termination period. With about 50 test assemblies to be retrieved each sampling period, the total retrieval and reemplacement process was very labor intensive and time consuming. This process required a total of about five weeks each period, with the participation of about eight people, including the principal investigator, the glass studies coordinator, highly qualified and dedicated technicians, drillers, and instrumentation installers. The final, 5-year sample retrieval and in situ test 
termination cycle required only two weeks of work; there were no subsequent maintenance and reemplacement activities.

We removed 45 test assemblies for sampling at the 0.5 -year retrieval period; another 5 assemblies were also retrieved for maintenance purposes only. Most of these retrievals occurred during January to March 1987. Five of the assembly retrievals occurred in May 1987; these were delayed due to the late arrival of a longer coring barrel, required to accommodate the $1.8 \mathrm{~m}$-long MIIT-MI test assemblies. One test assembly was retired from testing at this point, as originally scheduled; the rest were reemplaced for further testing. The 1-year sampling period extended from August to October 1987 and also included the retrievals of 50 test assemblies. Three MIIT assemblies were retired at this point, two as scheduled, and one due to sample coringdamage. All damaged samples were removed for posttest analyses. At the 2-year retrieval period, from August to September 1988, 48 assemblies were removed for sampling and maintenance, two were retired as scheduled, and another 15 assemblies were prematurely retired due to significant coring damage. This left 32 sample assemblies (including 3 hlank assemblies) that could be reemplaced for the full 5-year testing period. Fortunately, replicate specimens from duplicate test assemblies compensated for many of the coring-damaged or destroyed glass specimens; therefore, many of the desired time intervals and samples of interest were retained. The electrical heaters for all of these remaining assemblies were turned off on June 26, 1991. These assemblies were successfully retrieved during July 1991, after a total of 4.82 to 4.96 years of heated testing at the WIPP. We officially completed the in situ conduct of the MIIT at this time, on schedule. Posttest laboratory analyses of numerous retrieved specimens are still in progress at many cooperating laboratories.

Due to extensive precipitation buildup of salts in each test hole, assembly retrieval operations required the overcoring of each test assembly from the emplacement hole and the surrounding, encapsulating rock salt. The WIPP drilling crew normally used a $10-\mathrm{cm}$ diameter by $1.2-\mathrm{m}$ long core barrel, connected to a mining drill rig. A $12.7-\mathrm{cm}$ by $2.1-\mathrm{m}$ long core barrel was used for the longer MIIT-MI test assemblies. We had originally anticipated in the MIIT Test Plan (Molecke and Wicks, 1986) that overcoring was probably not necessary, but changed our plans to always overcore after encountering some difficulties when physically pulling several assemblies five weeks after emplacement. We have documented the overcoring retrieval and subsequent reemplacement operations in a separate, safety and quality assurance-approved WIPP (internal) procedure.

We immersed the overcored, retrieved test assembly into a large water bath to wash and scrape off the precipitated salt shell. During the 0.5 - and 1-year retrievals, precipitated salts nominally encapsulated from $2.5 \%$ up to $100 \%$ of the overall assembly length. The 2-year and 5-year test assemblies were totally salt-encased. All assemblies were removed and washed-off, whether samples were to be taken or not. We carefully 
removed the appropriate glass and metal samples from the top end of the assembly using scalpels, dental picks and water jet-irrigators, other tools, and much manual labor. The precipitated salt behaved like a strong cement, bonding everything together into one large mass. We advisedly added hammers and chisels to the required tool set at the 5-year sampling period, to more rapidly help remove large chunks of salt not immediately adjacent to glass samples. Originally, we planned to remove test specimens from the bottom end of each assembly (Molecke and Wicks, 1986; Wicks, 1985; Wicks et al., 1987), but switched to top sampling because of severe salt cementing of test hardware at the assembly bottom. If at all possible, we did not disturb or remove glass and metal specimens on the rod assembly that were not scheduled for retrieval.

Some of the glass specimens were found to be cracked or chipped during the overcoring-retrieval and sampling process; most samples were still quite adequate for analyses. Unfortunately, a small number of glass samples were fractured so much, i.e., shattered, that identification was not possible. The quantities of damaged glass specimens increased after multiple retrievals, particularly at the 2-year sampling period, and especially for the $1.8-\mathrm{m}$ long MIIT-MI assemblies. This damage was unavoidable, particularly considering the "brute force" overcoring technique required to free assemblies from the encapsulating rock salt. We must commend the skill of the dedicated drilling crew personnel for keeping sample coring damage to a minimum.

We photographed many samples for further documentation after the removed glass and metal samples had been rinsed off and carefully identified. We then wrapped the glasses in brine-moistened towelettes (to prevent drying of glass surface layers), and wrapped the glass or metal specimens in individual plastic bags for transfer to the appropriate analysts.

\section{Other Observations:}

1. When the MIIT-MI test assemblies that were surrounded by initially dry, crushed salt (rather than brine) were removed for sampling after two and five years, we found that they were in contact with slightly damp salt, not dry. The source of this moisture was found to be interconnections to adjacent, brine-filled boreholes; refer to Section 2.3.3.

2. During the 0.5-, 1-, and 2-year sample retrieval periods, we found a dark blue, to brown, to black-colored dispersed precipitate or colloid mixed with precipitated salts near the top of the test emplacements which contained mild steel A216/WCA metal specimens. A significant amount of this material was also found in solution and precipitated on glass samples. This corrosion-product material was primarily magnetite and hydrous ferric-iron hydroxy carbonate (pyroaurite) (Molecke et al., 1989). 
3. During the 2- and 5-year sample retrievals, we also found considerable bonding between adjacent A216/WCA metal and glass waste form samples and lead-glass samples. This metal-glass bonding or "sticking" made specimen retrievals very difficult, particularly in the assemblies containing lead.

\subsubsection{Assembly Reemplacement Activities}

We repaired the remaining segments of each test assembly, as necessary, prior to reemplacement for the next test-exposure period. Damaged electric rod-heaters were replaced as necessary; all rod-heaters were wrapped in new Teflon tape. Any cracked glass samples to be tested further were held in place on the rod-heater with additional Teflon tape. Missing samples were replaced with thin Teflon sheet spacers to prevent any unwanted interfaces from occurring. We stored each restored test assembly in a large plastic bag until it could be reinstalled. We also added some brine to each bag to maintain a humid environment, to prevent sample surface drying.

Due to some brine-dissolution occurring in many holes and the effects of retrieval overcorings, we had all the test holes refurbished prior to assembly reemplacements. The top surface of the holes were leveled to help ensure tighter fits for the metal seal-plate hardware (Molecke and Wicks, 1986; Molecke, 1989). Many boreholes had to be abandoned after use primarily due to excessive brine leakage (observed during periodic brine refilling activities) and interconnecting cracks to other test holes (observed during coring-retrieval activities). These interconnections allowed some mixing of brine leachates between holes and may complicate interpretations of the analyzed leachant compositions (Molecke et al., 1989). Interconnections were due to either minor, isolated (mining, excavation-induced) cracks in the host rock salt formation, or from crackingporosity in, or through, an anhydrite $\left(\mathrm{CaSO}_{4}\right)$ impurity layer just below the bottoms of the test holes. We also abandoned a few boreholes because a larger than 10-cm (4-inch) diameter core barrel was used to retrieve a "stuck" or tilted, off-center assembly in a hole.

Some test assemblies were reemplaced into either new, spare boreholes or into boreholes that had been occupied by removed and retired test assemblies, but were still good. At the 0.5-year retrieval period, we switched two assemblies into a previously used borehole and one assembly into a new, spare hole. At the 1-year retrieval period, we switched one assembly into previously used boreholes and five into new, spare holes. At the 2-year retrieval period, we switched seven assemblies into previously used boreholes.

We found it necessary to destroy, then replace all thermocouples during each test assembly retrieval and reemplacement cycle. Initially, instrumentation technicians would snip-off the top end of each installed thermocouple prior to beginning the overcoring. The old thermocouples would normally be encased in precipitated salt, then removed 
along with the test assembly. However, the thermocouple removal procedure was soon modified when we observed that the core barrel could occasionally grab onto a thermocouple, whip it around inside the test hole, and, unfortunately, damage some glass specimens. As soon as this problem was observed, during the 0.5 -year retrieval cycle, we modified the thermocouple removal procedure. The test drillers now would mechanically pull each thermocouple (and the separate liquid fill tube) from the test hole prior to overcoring (Molecke, 1989). No glass or other samples would then be damaged by spinning thermocouples. Instrumentation technicians would then install two new Type E, Chromel-Constantan thermocouples $(3.2-\mathrm{mm}$ in diameter, sheathed in corrosion resistant Inconel 625) per hole, as part of the borehole refurbishment procedure.

While we had anticipated the periodic reinstallation of new thermocouples in each test hole following coring activities, we had not anticipated the extent of failure of the electric rod-heaters. These rods were Chromalox type CIR cartridge heaters, with Incoloy 800-cladding, initially; they were replaced later by more corrosion-resistant Inconel 625-clad heaters. Heater failures were due predominantly to mechanical coring damage, usually at the bottom of the rod, or from twisted-off power leads at the heater top occurring during the coring process. Five failures were due to electrical shorting of power leads at the top end of the heater; several of these failed heaters were repaired by installing shrink-wrap insulation on the power leads. Two other failures were due to corrosion of the heater Incoloy 800-cladding. Brine was able to penetrate and moisten the internal refractory insulation, causing swelling, and resulting in a bubble aneurysm-type failure. A total of twenty five rod heaters were replaced during the periodic retrieval cycles. We replaced six heaters during the 0.5 -year retrievals. Five were replaced at the 1 -year point. Thirteen were replaced at the 2 -year point, including the two heaters that failed by corrosion. Also, one heater failed after about 4.5 years, due to a nonrepairable electrical short, but was left in place until test termination. After the 2-year sample retrieval period, all the assemblies were $0.9 \mathrm{~m}$ in length. We reemplaced the (fewer) remaining glass and metal specimens from the original $1.8 \mathrm{~m}$-long MIIIT-MI assemblies onto $0.9 \mathrm{~m}$-long rod heaters.

Finally, we reemplaced each test assembly into their original (or substitute, as necessary) borehole, added a measured amount of new Brine A to fill, connected and checked the instrument and power cables, and then turned the individual assembly on again. This reinitiation of heated testing usually occurred within one to two weeks after the assembly had been overcored and sampled. 


\subsubsection{Brine Monitoring, Control, and Sampling}

We monitored the volume of brine leachant in each MIIT emplacement hole frequently, to ensure that the brine always covered the test samples. The liquid level was maintained at about $5 \mathrm{~cm}$ below the top seal plate, well above the top of the sample stack. No glass specimens were ever exposed to air due to a low brine level. For the first four months of the MIIT, observed rates of brine loss ranged from about zero up to 500 $\mathrm{ml} /$ day, averaging about $130 \mathrm{ml} /$ day. Therefore, we maintained brine monitoring and refilling activities at once/each weekday; this was a very labor-intensive activity. Most of the liquid loss was due to volatilization of water vapor past the top seal plates on the assembly (Molecke and Wicks, 1986; Molecke, 1989). Some loss was due to fractures in the rock salt, with some observed interconnections and brine inflow or outflow to adjacent boreholes. We were able to significantly minimize volatilization losses by packing finely powdered salt around and over the top hole-seal plate. This salt packing, assisted by brine-salt consolidation, helped form a better vapor barrier. The average rate of liquid loss was cut to about $60 \mathrm{ml} /$ day by this technique, allowing us to change the brine monitoring frequency to three times/week. Daily records were kept on the quantity of refill liquid used in each MIIT test borehole. However, there is no way to estimate what fraction of water was vaporized, was lost to fracture flow, or was incorporated into hydrated, precipitated salts. As such, the validity of performing liquid (mass) balance calculations appears questionable.

Replacement leachant, when needed, was injected through a 6-mm diameter, Inconel 600 liquid-fill tube, that extended down towards the bottom of the emplacement hole. The added liquids (not saturated at temperature) percolated upward through the denser, existing (saturated) leachant. Due to thermal convection currents, we assume that this system was almost self-stirring. For the first six months of the MIIT, we used WIPP Brine $\mathrm{A}$ as the replacement liquid, as requested by the test peer reviewers (Molecke, 1989). However, since most fluid was lost due to water volatilization, continued addition of concentrated brine resulted in a very significant amount of salt precipitation buildup in the test holes, almost filling them up with solid salt. We first noticed this salt precipitation buildup after about two months of heated testing. After four months, 29 of the 53 emplacements had significant salt buildup or were essentially solidified. After five months, 43 of the test emplacements were so affected. Precipitation within the test holes also tended to heavily coat the surfaces of the test specimens with salt.

Starting after the end of the first 0.5-year retrieval period, we added either Brine A or deionized water as the replacement liquid, on alternate weeks, as necessary. This procedure was used through the 2-year sampling period and helped minimize salt precipitate buildup somewhat while still maintaining (some of) the leachant as saturated brine. The addition of liquids after the initiation of the 2-through 5-year test period was different and is discussed in Section 2.5. 
We previously documented the operations and schedules for obtaining MIIT brine leachate samples for composition analyses (Molecke et al., 1989). Solute analytical results for many of the brines were also summarized, through the 1-year sampling period (Molecke et al., 1989).

\subsubsection{Temperature Monitoring}

We monitored the brine leachant temperature(s) in each test borehole with two thermocouples attached to the borehole salt wall. One of these thermocouples was near the top of the test assembly, the second was nearer the bottom (Molecke and Wicks, 1986; Molecke, 1989). For the first two years of MIIT conduct, most recorded temperatures were in the range of $90 \pm 10^{\circ} \mathrm{C}$, with the top thermocouple (usually) registering the higher temperature. Immediately after periodic assembly retrieval and reemplacement, and turn-on of the electric rod-heater, the brine temperatures would take several days to increase from about $40^{\circ} \mathrm{C}$ back up to $90 \pm 10^{\circ} \mathrm{C}$. For the 2 - through 5year period of test conduct, measured temperatures were generally in the range of $85 \pm$ $10^{\circ} \mathrm{C}$. There were many brief periods of power outages at the WIPP site during this time period; sharp drops in temperature of $10^{\circ}$ to $15^{\circ} \mathrm{C}$ would occur and would last about a day.

On a weekly schedule, we also obtained secondary, manual readings of brine leachant temperature near the top of the brine in each emplacement hole. We considered this manual "dip-temperature" procedure to be necessary after salt precipitate buildup in test holes became significant, and self-mixing of the leachant was hindered. Our concern was that salt precipitates in the hole, between the wall-mounted thermocouples and the centrally located, heat-generating rod heater, would result in incorrect (low) thermocouple readings, causing us to incorrectly readjust the power to the rod heater. About one month after test turn-on, we conducted a manual, dip-temperature mapping of several test holes, as a function of depth, as a check. We observed a dip-temperature range of $84.9^{\circ}$ to $92.7^{\circ} \mathrm{C}$, from 5 to $81 \mathrm{~cm}$-deep in a MIIT-SS borehole. We also observed up to a $3.5^{\circ} \mathrm{C}$ temperature range horizontally, between the hole wall and the hotter surface of the rod heater. The corresponding thermocouple readings were $87.7^{\circ} \mathrm{C}$ at $-30 \mathrm{~cm}$ in the brine and $75.5^{\circ} \mathrm{C}$ at $-60 \mathrm{~cm}$. In a longer MIIT-MI borehole, the observed dip-temperature range was $83.2^{\circ}$ to $88.5^{\circ} \mathrm{C}$, from 7.5 to $150 \mathrm{~cm}$-deep, at the borehole wall. This range compared to thermocouple readings of $83.9^{\circ} \mathrm{C}$ at $-60 \mathrm{~cm}$ and $72.0^{\circ} \mathrm{C}$ at $-91 \mathrm{~cm}$. We also determined that after appreciable salt precipitation had occurred in the borehole, the dip-temperature at about $-5 \mathrm{~cm}$ into the brine could be influenced by stratification of a magnesium-rich component at the top of the brine (Molecke et al., 1989). This magnesium-rich brine layer could have a very high boiling point. In several instances, we measured dip temperatures up to about $130^{\circ} \mathrm{C}$, while the remote-reading thermocouples (both above and below the test specimens) indicated temperatures in the range of $80^{\circ}$ to $95^{\circ} \mathrm{C}$ (Molecke et al., 1989). The measured dip temperature could, therefore, be excessively high in relation to the brine temperatures adjacent to the glass 
specimens located further down. Therefore, we adjusted the power to the rod heater based predominantly on the recorded temperature of the top-most thermocouple, with the dip temperature acting as an additional influencing factor.

\subsection{DATA SYSTEMS}

\subsubsection{Data Acquisition System}

The MIIT electric rod-heaters and thermocouples were connected to a computerized, data acquisition system, DAS. Individual heater voltages, wattages, and borehole in situ temperatures at multiple locations were monitored and recorded every 4 hours. This DAS provides both easy access to test data for evaluation and permanent records for later detailed analyses.

Essentially, the underground segment of the DAS consists of a controlledenvironment recording shed (station) that contains power supplies, signal conditioners, data scanners, digital multimeters, and calibrators. Analog voltage data from individual gages are periodically interrogated by the digital voltmeters. The resultar.i digital signals are communicated from the underground to the surface by means of a IEEE-488 interface data bus. The aboveground portion of the DAS consists of a multitasking and multi-user ModComp minicomputer system (ModComp Classic 7840) that converts the raw data to engineering units, stores the data in both raw and converted forms, provides plots and data listings, and manages remote (user) access via modem (Mcllmoyle et al., 1987). This DAS has a capacity of more than 5,000 data channels, adequate to operate the MIIT as well as all other Sandia-conducted underground WIPP experiments (Tyler et al., 1988). The DAS was designed, procured, installed, and is being operated by Sandia National Laboratories. Full details on this WIPP DAS can be found elsewhere (Tyler et al., 1988; Mcllmoyle et al., 1987).

Manually acquired data (dip temperatures, $\mathrm{pH}$ measurements, brine composition analyses, glass leaching, and metal corrosion data) are handled separately (Molecke and Wicks, 1986; Wicks and Molecke, 1988; Wicks and Molecke, 1989; Wicks, 1985; Wicks et al., 1987; Molecke et al., 1989; Molecke, 1989). These data are inputted into a computer spreadsheet (LOTUS 123) for organizational purposes, comparisons, data listings, plotting of graphs, and transfer to other participants, as required.

\subsubsection{Data Management System}

The database management and reduction system provides data plots and displays that have been appropriately corrected for errors or adjustments and that represent quality assurance-checked, in situ measurements (Tyler et al., 1988; Mcllmoyle et al., 1987; Munson et al., 1990; Ball and Shepherd, 1987). Essentially, this effort consists of: 1. an integrated database management system titled WISDAAM, an acronym for the WIPP In 
Situ Data Acquisition, Analysis, and Management system (Munson et al., 1990); and, 2. a data reduction software program called UNDERDOG (Ball and Shepherd, 1987), to assist in performing the necessary functions for data corrections, adjustments, display, output, etc. UNDERDOG is an acronym for the Underground Nuclear Depository Evaluation, Reduction, and Detailed Qutput Generator, and is documented elsewhere (Ball and Shepherd, 1987).

The WISDAAM system for the WIPP was developed especially for multi-user access to the database. This database is stored in a MicroVAX II computer at Sandia National Laboratories. The WISDAAM system and the UNDERDOG software were used to process the remotely-read instrumentation data for the MIIT. All such data are "certified" as approved by the test Principal Investigator and quality assurance (QA) stamped. Such certified data is available for use in analyses by interested parties associated with the MIIT or other WIPP-related programs.

\subsection{ADDITIONAL TERMINATION ACTIVITIES AND SUMMARY}

After almost three years of heated testing, i.e., about one year after the initiation of the 2- through 5-year test period, further leachant liquid-refill additions were discontinued. By then, all the test boreholes were essentially filled with precipitated salt (refer to Section 2.2 for analyzed content), not brine. From this point through test termination, we added deionized water to the top of each borehole biweekly, simply to maintain a degree of moistness in the salt. Because of this precipitation, we had already ended the collection of brine samples for future solute analyses several months after the start of the 2- through 5-year test-exposure period. At this point, if not before, the Materials Interface Interactions Test assemblies can be considered, more correctly, as part of a waste form-damp salt interactions test, not as an idealized waste form leaching test. This title of the test program reflects this fact.

For most of the final three years of in situ conduct of the MIIT program, except for the 5-year retrievals and test termination, we conducted the test in a "maintenance" only mode. We were basically compelled to start the MIIT test maintenance mode by a combination of two occurrences:

1. the cessation of liquid addition and leachant sampling activities, due to extensive salt precipitation;

2. a shift in the overall WIPP program focus and resources, away from highlevel waste test-associated activities towards, almost exclusively, transuranic waste testing, modeling, and performance assessment-related activities. 
Many of the MIIT waste form glass and essentially all of the metal samples recovered during all four of the retrieval periods have now been returned to the multiple participating laboratories for final posttest analyses. Many laboratory analyses are still in progress and will continue for some time. Interpretations of available results will be discussed in this workshop. Many more results and interpretations are expected over the next several years and will be documented separately by multiple test participants.

In this paper, we have provided a detailed summary of technical and operational aspects for the in situ conduct of the MIIT experimental program in the WIPP facility. We have included descriptions of relevant occurrences and problems encountered over the five-year period of test exposures, multiple assembly retrievals, materials sampling, and assembly reemplacements. This information should complement and aid in interpretations of the laboratory results obtained by our test coparticipants. It is also such occurrences and observations that unavoidably make an in situ test significantly more difficult to conduct and control than a laboratory test. However, we feel that these occurrences, and the interactions and complexities that may have resulted from them, also make the in situ tests more realistic and repository relevant. We anticipate that this information can be relevant and instructive for other organizations contemplating, planning, or conducting additional materials-related, in situ tests. 


\subsection{REFERENCES}

Ball, J.R., and L.K. Shepard. 1987. User's Manual for the UNDERDOG Data Reduction Software. SAND87-7149. Albuquerque, NM: Sandia National Laboratories.

Mcllmoyle, J.T., R.V. Matalucci, and H.C. Ogden. 1987. The Data Acquisition System for the Waste Isolation Pilot Plant In Situ Tests. SAND86-1031. Albuquerque, NM: Sandia National Laboratories.

Molecke, M.A. 1984. "TEST PLAN: Waste Package Performance Technology Experiments for Simulated DHLW." Albuquerque, NM: Sandia National Laboratories.

Molecke, M.A. 1989. "Technical Operations and Data Collection Details of the In Situ WIPP Materials Interface Interactions Test," Testing of High-Level Waste Forms Under Repository Conditions, Proceedings of a Workshop Jointly Organized by CEC, US DOE and CEA, Cadarache, France, October 17-21, 1988. Ed. T. McMenamin. EUR 12017 EN; SAND88-2022C. Luxembourg: Commission of the European Communities. 67-77.

Molecke, M.A. 1993. "Results from Simulated Remote-Handled Transuranic Waste Experiments at the Waste Isolation Pilot Plant (WIPP)," Scientific Basis for Nuclear Waste Management XVI, Boston, MA, November 30-December 4, 1992. Eds. C.G. Interrante and R.T. Pabalan. SAND92-1003C. Pittsburgh, PA: Materials Research Society. Vol. 294, 481-486.

Molecke, M.A., and G.G. Wicks. 1986. "TEST PLAN: WIPP Materials Interface Interactions Test (MIIT)." Albuquerque, NM: Sandia National Laboratories.

Molecke, M.A., N.R. Sorensen, and J.L. Krumhansl. 1989. "Summary of WIPP Materials Interface Interactions Test Data on Metals Interactions and Leachate Brine Analyses," Testing of High-Level Waste Forms Under Repository Conditions, Proceedings of a Workshop Jointly Organized by CEC, US DOE and CEA, Cadarache, France, October 17-21, 1988. Ed. T. McMenamin. EUR 12017 EN; SAND88-2023C. Luxembourg: Commission of the European Communities. 192203.

Munson, D.E., J.R. Ball, and R.L. Jones. 1990. "Data Quality Assurance Controls Through the WIPP In Situ Data Acquisition, Analysis, and Management System," High Level Radioactive Waste Management, Proceedings of the International Topical Meeting, Las Vegas, NV, April 8-12, 1990. SAND88-2845. La Grange Park, IL: American Nuclear Society; New York, NY: American Society of Civil Engineers. Vol. 2, 1337-1350. 
Sorensen, N.R., and M.A. Molecke. 1993. "Summary of the WIPP Materials Interface Interactions Test-Metal Corrosion," Waste Isolation Pilot Plant Materials Interface Interactions Test: Papers Presented at the Commission of European Communities Workshop on In Situ Testing of Radioactive Waste Forms and Engineered Barriers. Eds. M.A. Molecke, N.R. Sorensen, and G.G. Wicks. SAND93-1055. Albuquerque, NM: Sandia National Laboratories. 3-1 to 3-13.

Tyler, L.D., R.V. Matalucci, M.A. Molecke, D.E. Munson, E.J. Nowak, and J.C. Stormont. 1988. Summary Report for the WIPP Technology Development Program for Isolation of Radioactive Waste. SAND88-0844. Albuquerque, NM: Sandia National Laboratories.

Wicks, G.G. 1985. WIPP/SRL In-Situ and Laboratory Testing Programs. Part I: MIIT Overview, Nonradioactive Waste Glass Studies. DP-1706. Aiken, SC: E.I. du Pont de Nemours \& Co., Savannah River Laboratory.

Wicks, G.G., and M.A. Molecke. 1988. "WIPP/SRL In Situ Testing Program: MIIT Update 1988," Waste Management '88, Waste Processing, Transportation, Storage and Disposal, Technical Programs and Public Education, Tucson, AZ, February 28March 3, 1988. Ed. R.G. Post. SAND87-2654C. Tucson, AZ: University of Arizona. Vol. 2, 383-392.

Wicks, G.G., and M.A. Molecke. 1989. "WIPP/SRL International In Situ Testing Program-MIIT," Testing of High-Level Waste Forms Under Repository Conditions, Proceedings of a Workshop Jointly Organized by CEC, US DOE and CEA, Cadarache, France, October 17-21, 1988. Ed. T. McMenamin. EUR 12017 EN; SAND88-2838C. Luxembourg: Commission of the European Communities. 49-66.

Wicks, G.G., and M.A. Molecke. 1993. "Overview of the Materials Interface Interactions Tests (MIIT): International In Situ Testing of Waste Forms and Package Components," Waste Isolation Pilot Plant Materials Interface Interactions Test: Papers Presented at the Commission of European Communities Workshop on In Situ Testing of Radioactive Waste Forms and Engineered Barriers. Eds. M.A. Molecke, N.R. Sorensen, and G.G. Wicks. SAND93-1055. Albuquerque, NM: Sandia National Laboratories. 1-1 to 1-25.

Wicks, G.G., M.E. Weinle, and M.A. Molecke. 1987. WIPP/SRL In-Situ Tests, Part II: Pictorial History of MIIT and Final MIIT Matrices, Assemblies, and Sample Listings. DP-1733. Aiken, SC: E.I. du Pont de Nemours \& Co., Savannah River Laboratory. 


\title{
3.0 SUMMARY OF THE WIPP MATERIALS INTERFACE INTERACTIONS TEST - METAL CORROSION
}

\author{
N. Robert Sorensen and Martin A. Molecke \\ Sandia National Laboratories \\ Albuquerque, NM 87185 USA
}

\begin{abstract}
Several series of in situ, high-level and transuranic waste form-leaching and waste formengineered barrier materials-interactions tests were conducted at the Waste Isolation Pilot Plant (WIPP) facility, near Carlsbad, New Mexico, in the USA. This multi-national effort, the WIPP Materials Interface Interactions Tests (MIIT), involves the underground testing of about 1900 (nonradioactive) waste form, metal, and geologic samples in the bedded salt at the WIPP. This test program started on July 22, 1986 and has achieved its projected five-year lifetime. All in situ samples have been retrieved and sent to multiple laboratories for posttest analyses. Most of the analyses on metal samples have been completed and the results are summarized in this paper. The tested metal alloys proposed for waste canister or overpack use included titanium alloys (grade-2 and grade-12), Hastelloy C4, Inconel 625, austenitic stainless steels (304L, 316, and NS 24/AISI 309), carbon steels (Belgian C and ASTM A216/WCA), copper, and lead. After five-years of test exposure immersed in WIPP brine $\mathrm{A}$ and/or salt at about $90^{\circ} \mathrm{C}$, the corrosion-resistant materials ( $\mathrm{Ti}$, Inconel, Hastelloy) exhibited very little corrosion. The austenitic stainless steels suffered pitting, crevice corrosion, and some evidence of stress corrosion cracking. The carbon steels, copper, and lead exhibited both extensive general and localized attack. Details of the test, analyses, and results obtained will be discussed.
\end{abstract}




\subsection{INTRODUCTION}

The Waste Isolation Pilot Plant (WIPP), a U.S. Department of Energy facility, is the first deep geologic, nuclear waste isolation repository in the United States. The WIPP is located near Carlsbad, New Mexico. Its underground portion is about 655 meters below the surface, in the thick bedded salt (halite) deposits of the Salado Formation. The WIPP will be used first (a) to serve as an "underground laboratory," to evaluate and demonstrate the safe and effective disposal of transuranic (TRU) wastes, (Tyler et al., 1988) and then (b) to permanently isolate TRU wastes generated from U.S. defense programs. The WIPP facility is now essentially complete and is anticipated to begin accepting TRU wastes, for test purposes, in 1993.

The Materials Interface Interactions Test (MIIT) is one of the major experimental programs conducted at the WIPP facility (Tyler et al., 1988). It involves the in situ leaching and interactions testing of about 2000 (nonradioactive) high-level and transuranic waste form, metal, and geologic samples in the bedded rock salt. The WIPP MIIT international, cooperative program was conducted and managed by principal investigators from Sandia National Laboratories and Westinghouse-Savannah River Technology Center. MIIT glass waste form and metal samples were supplied from, and are being analyzed by eight countries (Molecke and Wicks, 1986; Wicks, 1985). The in situ conduct of the MIIT program extended from heated-test initiation, in July 1986, through the completion of the five-year test assembly and sample retrievals, in July 1991. Samples were obtained and analyzed after testing periods of $0.5,1,2$, and 5 years. Technical objectives of the MIIT, preliminary details on all test samples, and descriptions of in situ test operations and posttest sample analyses through the first two-year period of conduct have been presented previously (Tyler et al., 1988; Molecke and Wicks, 1986; Wicks, 1985; Wicks et al., 1987; Molecke, 1988; Wicks and Molecke, 1989; Molecke, 1983) and will not be repeated in this paper. Updates on these topics, through the fiveyear retrievals plus termination of the MIIT, will be presented in other papers in this workshop (Molecke and Wicks, 1993; Wicks and Molecke, 1993).

The major purpose of this paper is to summarize the laboratory, posttest corrosion results, metallurgical evaluations, and interpretations for all metal samples retrieved from the WIPP MIIT program. This information can help in the development of source terms and performance assessments that can be used to describe long-term waste package behavior in salt.

\subsection{EXPERIMENTAL}

\subsubsection{Metal Samples}

Eleven separate metai alloys were incorporated into the MIIT test assemblies. Each alloy was considered primarily as a potential high-level waste package canister or overpack material. Lead was included principally to evaluate potential impacts on waste form glass leaching — due to lead in brine solution or coated/precipitated onto the glass 
surfaces. A brief listing of the metals used in the WIPP MIIT, relevant test details, and the organizations supplying the metals and providing posttest analyses, are as follows (Molecke and Wicks, 1986):

Sandia National Laboratories (United States):

1. ASTM Grade-12 titanium (TiCode-12), both with and without welds

2. stainless steel $304 \mathrm{~L}$, both with and without welds

3. lead

Battelle Pacific Northwest Laboratory (United States):

4. cast mild steel ASTM A216/Grade WCA, with and without welds

5. Inconel 625 , both with and without velds

Atomic Energy of Canada, Ltd., Whiteshell Laboratory (Canada):

6. copper

7. ASTM grade-2 titanium (chemically pure)

Studiecentrum Voor Kernenergie/Centre D'Energie Nucleaire (Belgium):

8. Hastelloy C4

9. Belgian carbon steel (Bel-C)

Centre D'Etudes Nucleaires de la Vallee du Rhone (France):

10. NS24/AISl 309 stainless steel

Kernforschungszentrum Karlsruhe and Hahn-Meitner Institut (Germany)

11. stainless steel 316

Inconel 600, Inconel 625, and Incoloy 800 were also included in the test since they are the materials of construction of much of the test hardware. Most of the metal annular disks have four $3.2-\mathrm{mm}\left(0.125 \mathrm{in}\right.$.) holes drilled through the samples at $90^{\circ}$; these holes are representative of potential pits. Overall dimensions and fabrication details of these MIIT metal samples are described elsewhere (Molecke and Wicks, 1986; Molecke, 1988).

\subsubsection{Overview}

The above metal samples were included on twenty of the total of fifty (non-blank) MIIT assemblies. Eight of the metal sample-containing assemblies were part of the MIIT-SS (Solution/Surface Interactions) subset of tests, immersed in brine (Molecke and Wicks, 1986). These MII'T-SS (part II-B [Wicks et al., 1987]) assemblies consisted of a single glass waste form (SRL Glass 165/TDS, "Y" [Wicks et al., 1987]) in contact with a single metal alloy, either stainless steel $304 \mathrm{~L}$, titanium grade- 12 , cast mild steel A216/WCA, or lead.

The remaining twelve metal sample-containing assemblies were part of the MIITMI (Multiple Interactions) subset of studies, eight immersed in brine and four surrounded by initially dry, WIPP crushed salt. There were a minimum of three different types of metal alloy in each of the MIIT-MI assemblies. No two metal samples were allowed to physically touch during the test period. Individual metal samples were either in contact ivith a glass, salt, or bentonite/sand backfill material disk. When metal and non-metal 
samples were removed from a test assembly during the periodic sampling periods, a Teflon disk would be inserted between adjacent metal samples, to prevent direct contact. Teflon tape was wrapped around the central rod heater (sheathed in either Inconel 625 or Incoloy 800) to prevent contact with the metal sample disks.

All but four of the MIIT assemblies were initially immersed in a high Mg-Na-K chloride concentrated brine, WIPP brine A (Molecke and Wicks, 1986), controlled at about $90^{\circ} \pm 10^{\circ} \mathrm{C}$. As a function of test time, however, sodium chloride and other minerals would precipitate out (Molecke, 1988; Molecke and Wicks, 1993), yielding an increasingly magnesium-rich, concentrated brine. Within a matter of several months, most test assemblies would be immersed in near-solid hot salt, not brine.

Preliminary corrosion results for short time samples were reported previously (Molecke et al., 1989). Those data are included in this report to provide a complete history of metal corrosion in the MIIT program.

\subsubsection{Metal Sample Analyses}

The initial corrosion analyses for all of the MIIT metal specimens retrieved after 0.5 and 1, 2, and 5 years of test operation have been completed. The MIIT metal specimens were initially cleaned of clinging salt precipitates in an ultrasonic water bath; a soft bristled brush was used to remove the clinging salt. The samples were rinsed in deionized water, blown dry, anc photographed. Any significant corrosion products were sampled and analyzed separately. In some instances, significant quantities of salt and/or corrosion products adhered to the surface of the samples. These were often removed with a metal scraper. In such instances, care was taken to prevent metal removal during the procedure. All retrieved samples were then chemically cleaned using ASTM specified procedures (G1-81); to remove corrosion products. Samples were then weighed to the nearest $0.1 \mathrm{mg}$, visually evaluated for both uniform and localized attack, and evaluated in more detail as justified. Control samples exposed only to laboratory air at room temperature were also analyzed for comparison. Specimens were then returned to their originating organization for any further, destructive analyses. Results from these destructive analyses will be reported in the future by cooperating test partricipants.

Grade-12 titanium and stainless steel 304L samples, both unwelded base alloy and those with circumferential welds, were sectioned and metallurgically evaluated (by Sandia National Laboratories) for any alterations. The purposes of the metallurgical analyses are to evaluate any changes in microstructure caused by the thermal and chemical exposures to hot, saturated brines at about $90^{\circ} \mathrm{C}$, and to observe any material degradation such as general corrosion, pitting, or cracking. The metallurgical evaluations consisted of (l) a visual examination of the water-rinsed parts with a low-power optical microscope to look for gross corrosion or cracking on the outer surfaces; (2) high magnification optical microscope examination of polished and etched metallurgical crosssections of segments of the disks mounted to show surfaces exposed to brine; and, (3) Knoop microhardness measurements were made on metallographically polished cross- 
sections of each stainless steel 304L and Grade -12 titanium sample using a $200-\mathrm{g}$ load and a loading time of 15 seconds. These microhardness measurements can be a sensitive indicator of microstructural changes affecting the alloys' strength that are difficult to resolve by optical metallography. The welded samples were included to investigate brine-exposure effects on weld microstructures (fusion zone and heat-affected zone), as well as to assess effects of welding-induced residual stresses.

\subsection{RESULTS AND DISCUSSION}

\subsubsection{Metals Corrosion and Metallurgical Alteration Results}

Data plots in Sections 3.3.1.1 through 3.3.1.5 show the corrosion weight changes of the various metals over the 5 year exposure period. Corrosion rates are determined from weight change data. In almost all instances, the nature of the corrosion attack was not confined to general attack. Even in absence of pitting, the corrosion was localized to certain portions of each sample. This made calculating the corrosion rate in units of microns per year (or some other thickness change) essentially meaningless. Thus, the corrosion data are presented simply as changes in weight.

\subsubsection{Austenitic Stainless Steels}

Three austenitic stainless steel alloys (304L, 309, and 316) were tested in the MIIT program. Samples of type 304L SS were tested in both the welded and unwelded condition. Figure 3-1 shows the corrosion data for type $304 \mathrm{~L}$. There is a general and steady increase in the amount of material removed from the samples. There is significant scatter in the data, indicating both a variability in corrosion rate and the presence of localized attack. Figure 3-2 shows the corrosion rate for type 309 and 316 stainless steels. They exhibit behavior and corrosion rates similar to the $304 \mathrm{~L}$. The 316 corroded at a slightly higher rate than the 309 . The 316 stainless steel samples all exhibited localized attack in the form of pitting and possible crevice corrosion. No general attack was evident, nor was there any indication of stress corrosion cracking. The weight change data show that the corrosion reaction continued throughout the 5 year test, with no indication that the reaction is being limited by a passive film or the presence of a corrosion product film.

Both the welded and unwelded stainless steel 304L specimens exhibited good uniform corrosion resistance, with no evidence of pitting or crevice corrosion. In general, the welded samples appeared to corrode faster than the unwelded samples. For the welded disks, there was no apparent relation between time and severity of attack. The unwelded samples showed very little weight change, and no evidence of pitting, cracking, or crevice corrosion; the degree of attack on these samples does appear to be a function of exposure time. 


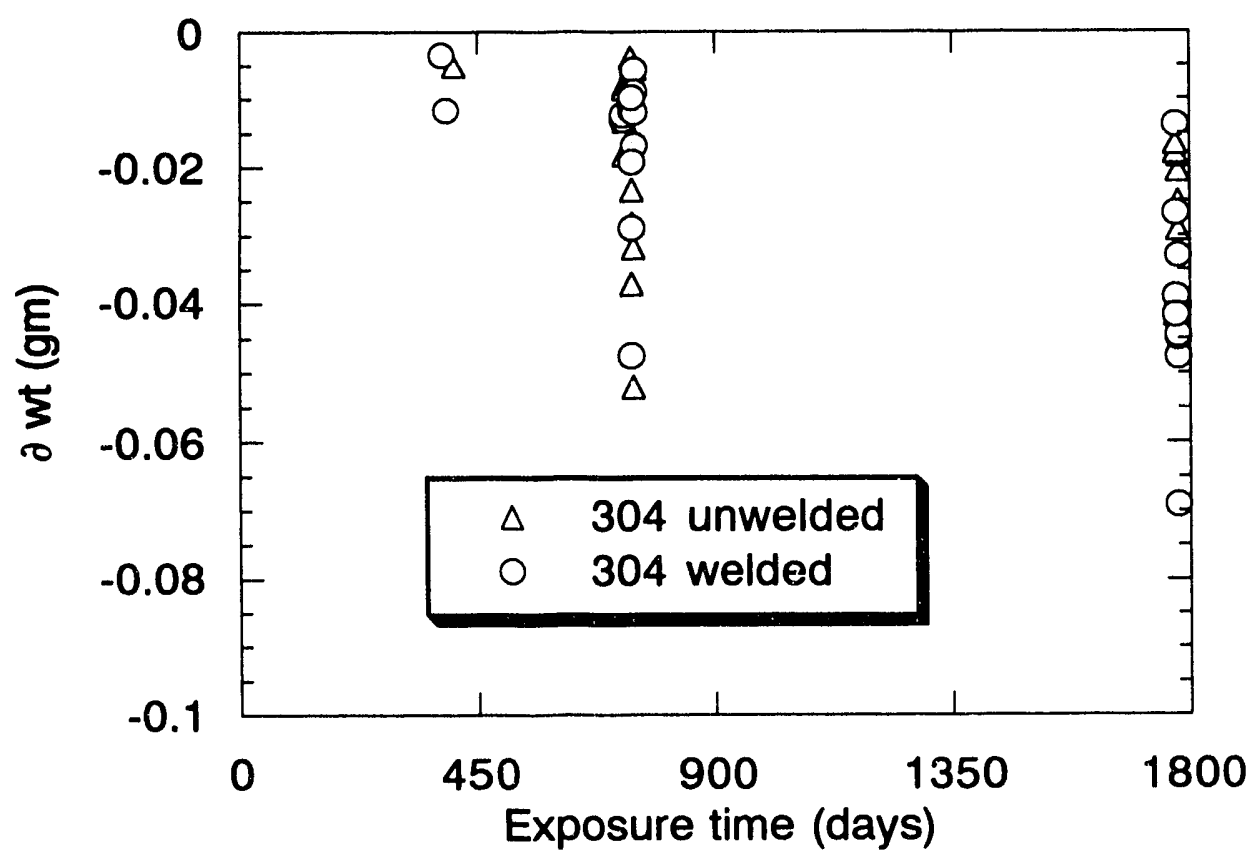

Figure 3-1. Weight change data for type 304L stainless steel.

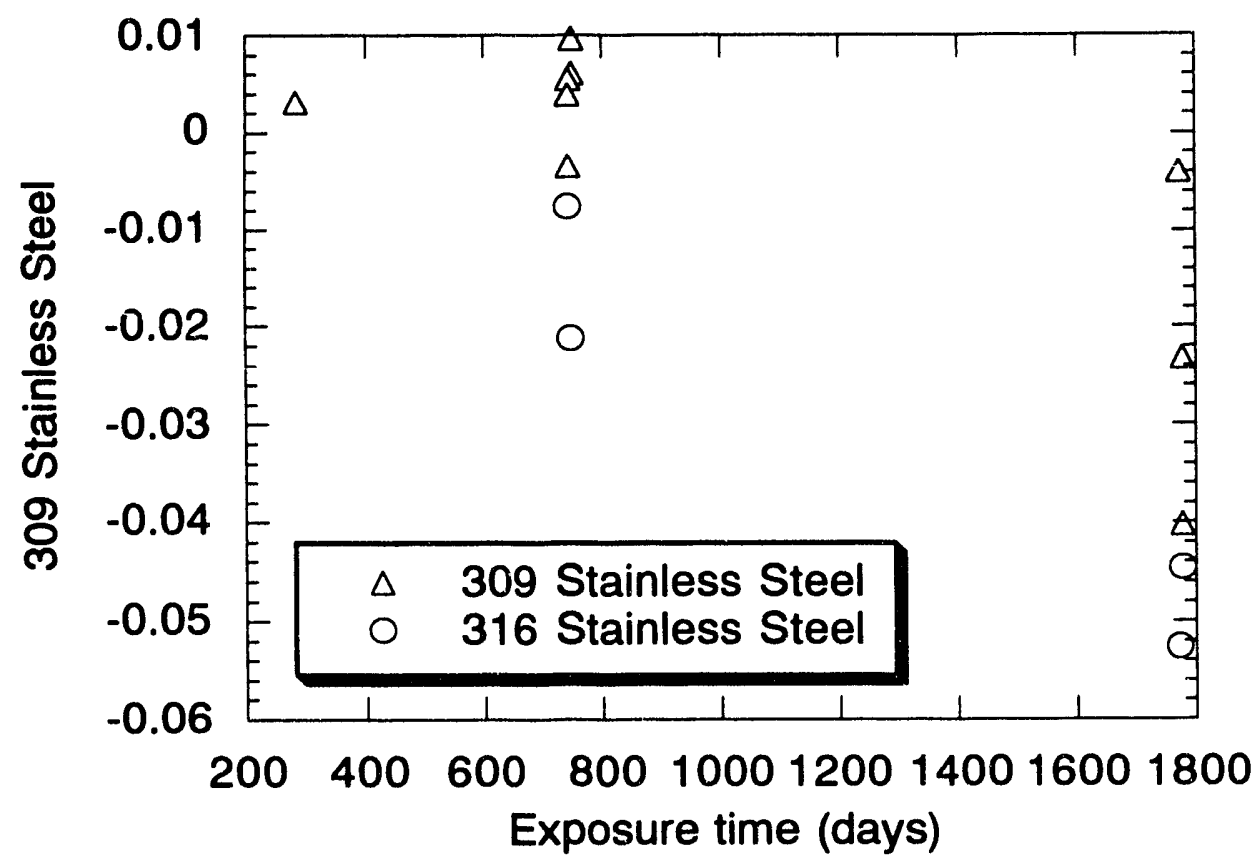

Figure 3-2. Weight change data for type 309 and 316 stainless steel. 
The stainless steel 304L samples did, however, show susceptibility to chlorideinduced, transgranular stress corrosion cracking in both the welded and base metal disks. In Sample D4 (no weld, 1-year exposure), cracks extended from the disk inner diameter to the 3.2-mm-diameter drilled hole, and from the same hole to the outer diameter of the disk. It was not possible to determine the initiation locations of these large cracks. Some small transgranular cracks obviously initiated at the drill hole. Shallow pits $100-150$ micrometers deep were also visible around the hole. No pitting or cracking was observed on the inner- or outer-diameter surfaces of the disk. There was a qualitative increase in the extent of cracking with exposure time: Sample C9 (welded, 0.5-year exposure) had short transgranular cracks approximately 100-micrometers long starting from the drilled hole; Sample Cll (welded, 1-year exposure) contained four large transgranular cracks which connected the inner- and outer-diameter of a drilled hole. Many more similar, but more extensive cracks were observed for the 2-year exposure samples; these have not yet been quantified. Cold work from the hole-drilling process may have accelerated cracking at the small holes; a sheared zone roughly 100 -micrometers thick was seen around the drill holes in the stainless steel samples. Cold working could provide enough residual stress to promote stress corrosion cracking. In any case, 304L SS, as expected, was highly susceptible to stress corrosion cracking in the chloride-containing brine test environment.

\subsubsection{Titanium Alloys}

None of the Grade-12 titanium (TiCode-12) test samples showed any evidence of general corrosion, stress corrosion cracking, crevice corrosion, pitting, or changes in microstructure. Neither general nor localized attack was significant in these samples. The 6 month and 1 year samples were pickled in an agressive manner during post test evaluation, resulting in some metal removal. This accounts for the higher apparent corrosion rates for these samples. The cleaning procedure was changed for the remainder of the samples to prevent or limit the amount of metal removed during cleaning. The rest of the samples show very little corrosion. There is, however, a slight correlation between exposure time and weight loss, indicating that the samples were corroding at a very low rate. Both the grade 12 and grade $2 \mathrm{Ti}$ exhibited similar weight change characteristics as shown in figures 3-3 and 3-4. Their corrosion rates were significantly lower than those of the austenitic stainless steels.

On the welded samples, the grain structure was evident in the weld affected zones, but there was no evidence of gross material removal. Exterior surfaces and microstructures of the tested samples were unchanged from the control samples. 


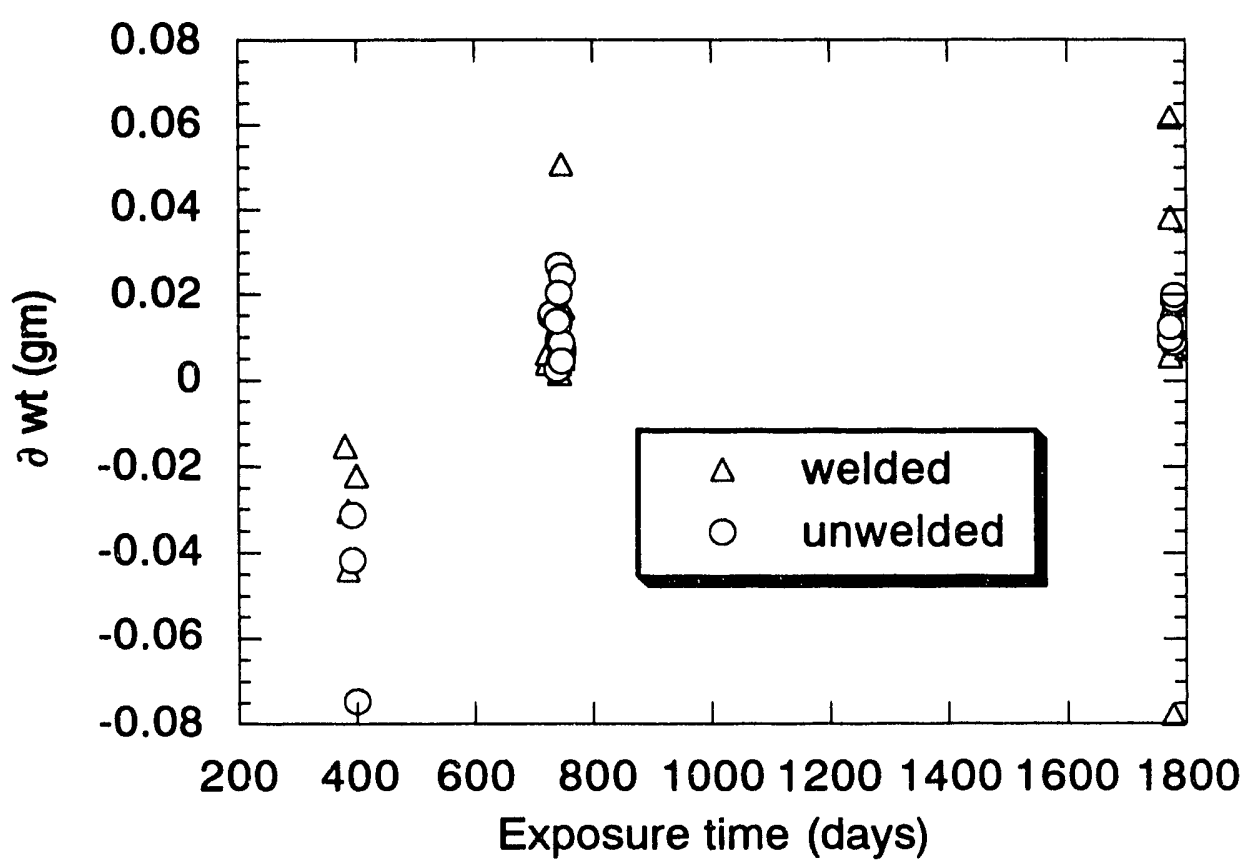

Figure 3-3. Weight change data for grade-12 titanium.

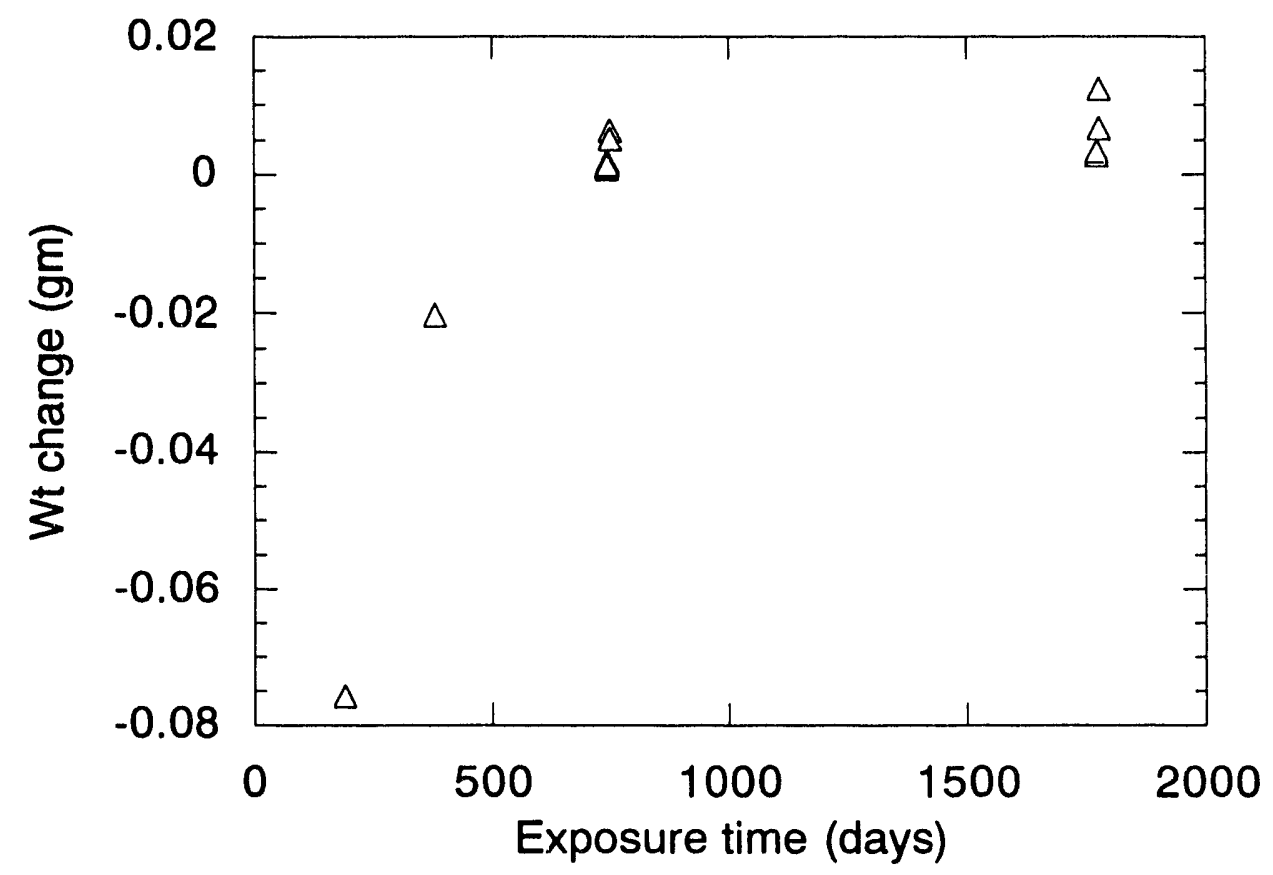

Figure 3-4. Weight change data for grade-2 titanium. 


\subsubsection{Lead}

Lead samples were used in these tests more to determine the effects of disso' red lead on glass leaching than for metal corrosion rates. The lead exhibited a large range of corrosion rates. In some instances, more that $1 / 10$ of the lead disk had been removed; in most cases, a correlation was observed between time and amount of material removed. The lead underwent both general and localized attack. Localized attack was observed on the top and bottom surfaces of the disks, but was most severe on the (most exposed) outer edge of the disk. At the 2-year sampling period, there was also appreciable bonding between adjacent lead and glass disks. This bonding made sample separations very difficult, much more so than in the case of A216/WCA metal-glass bonding (Molecke, 1988; Molecke and Wicks, 1993).

The lead samples removed from the MIIT test were all covered with a white lead corrosion product. Once the corrosion products were removed, all of the samples exhibited substantial corrosion, although the severity of attack ranged from nominal to severe. One sample (E28) had corroded to the extent that a section comprising almost $1 / 4$ of the sample was missing. Samples E19 and E17 also exhibited substantial corrosion. There was no evidence of pitting or cracking in any of the lead samples. The weight change data is presented in Figure 3-5.

\subsubsection{Steel}

All of the mild steel type A216/WCA samples suffered significant uniform corrosion with voluminous corrosion products present. General attack in the form of severe etching was observed. Some of the samples also suffered severe localized attack in the form of crevice corrosion. The localized attack seemed to occur with triangular symmetry around the sample, and seems to associated with the welds placed in the disks. Weight losses appear to be random with respect to time, and probably reflect the onset of localized corrosion rather than time of exposure (Figure 3-6). The frequency of localized attack for welded samples was considerably higher than for the unwelded samples.

\subsubsection{Copper}

All of the copper samples suffered general attack only. Discoloration of the surfaces was observed, but, in general, there was no evidence of localized attack or stress corrosion cracking. Measured weight changes were initially quite small (up through 1 year of exposure) but increased with increasing exposure time. At least 1 sample (C6) also exhibited some localized attack at the edge of the sample. The weight changes were significant, although the samples were not destroyed due to corrosion. The weight change data in shown in Figure 3-7. There is a correlation between exposure time and weight loss, which indicates that the samples continued to corrode throughout the entire MIIT test. The short time samples $(<6$ mo.) exhibited almost no weight loss. There may be an induction period before the copper begins to corrode. Once the process is initiated, attack continues at a substantial rate. 


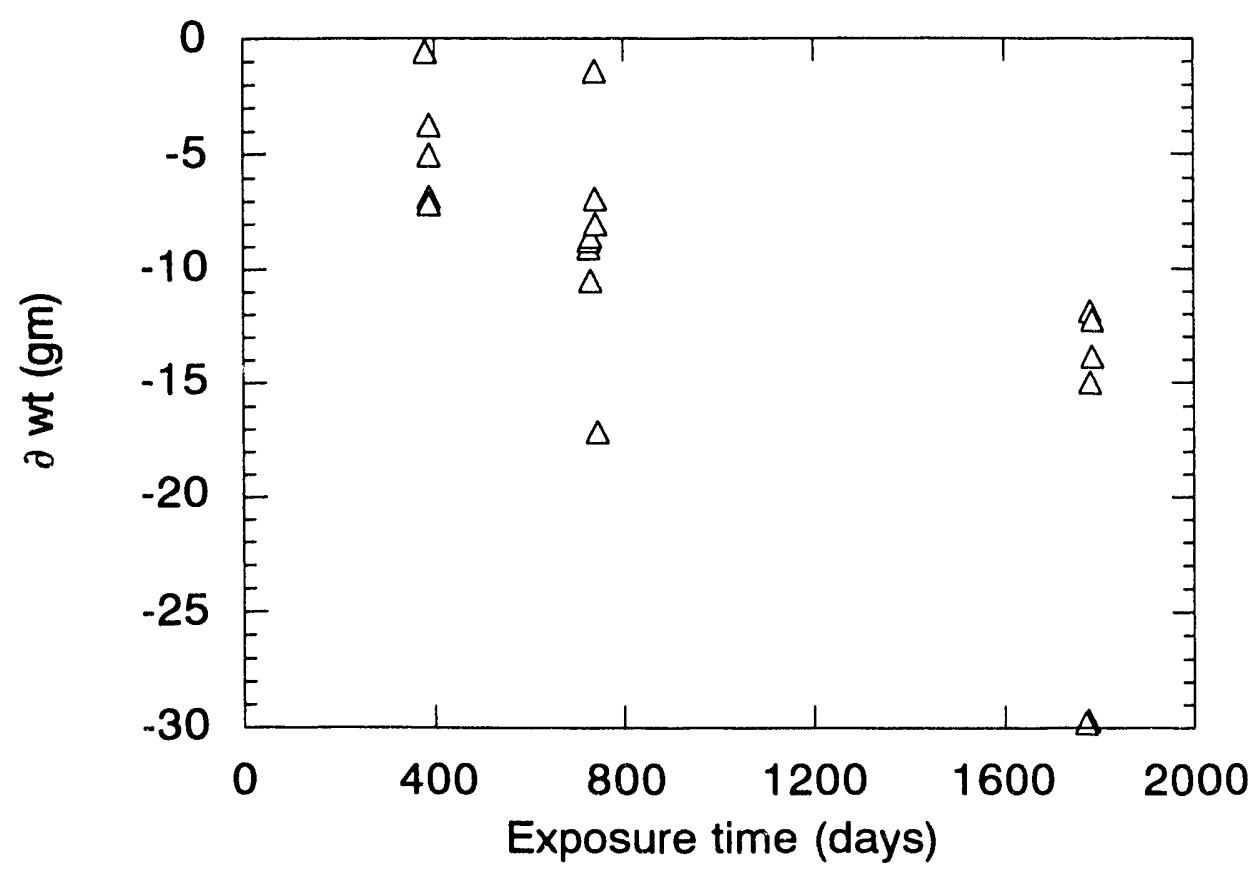

Figure 3-5. Weight change data for lead.

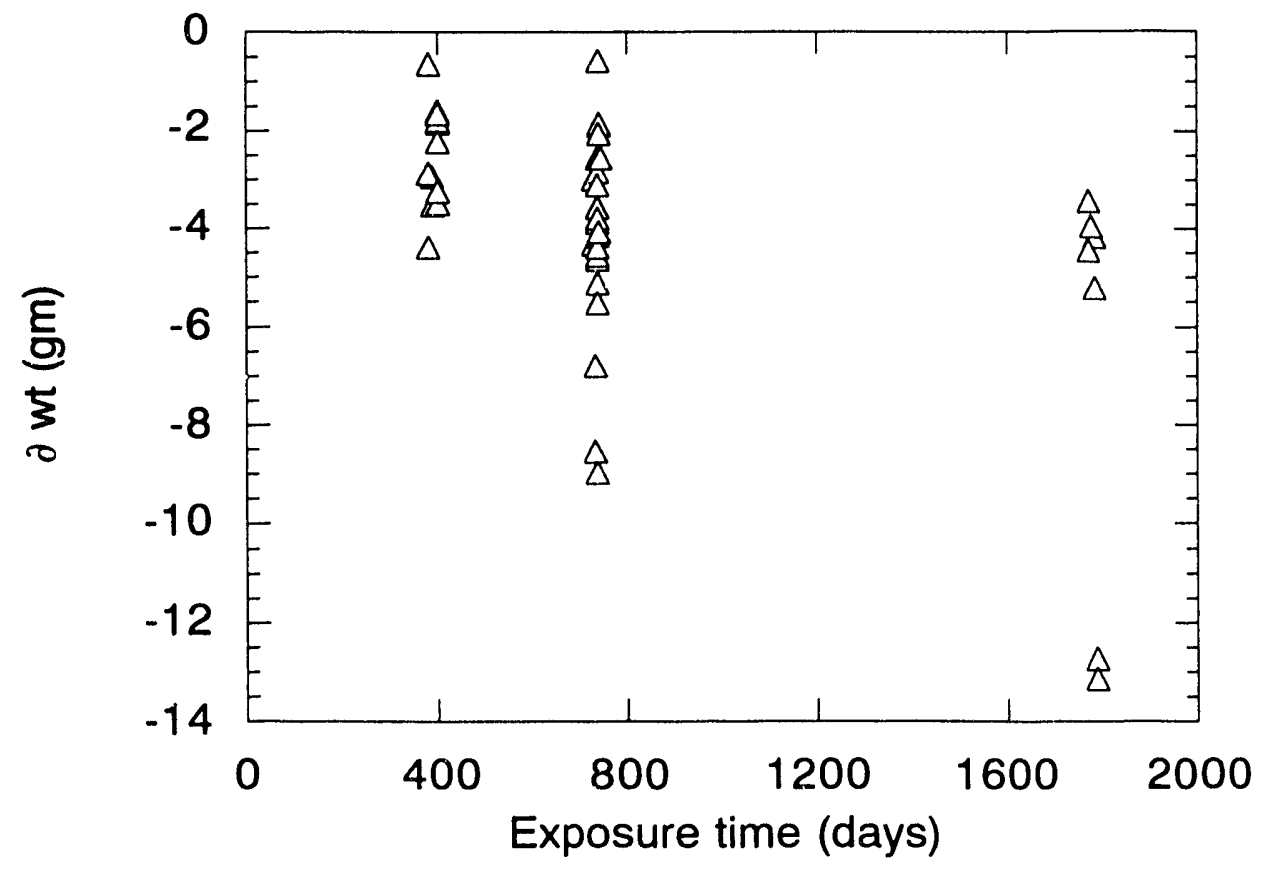

Figure 3-6. Weight change data for carbon steel. 


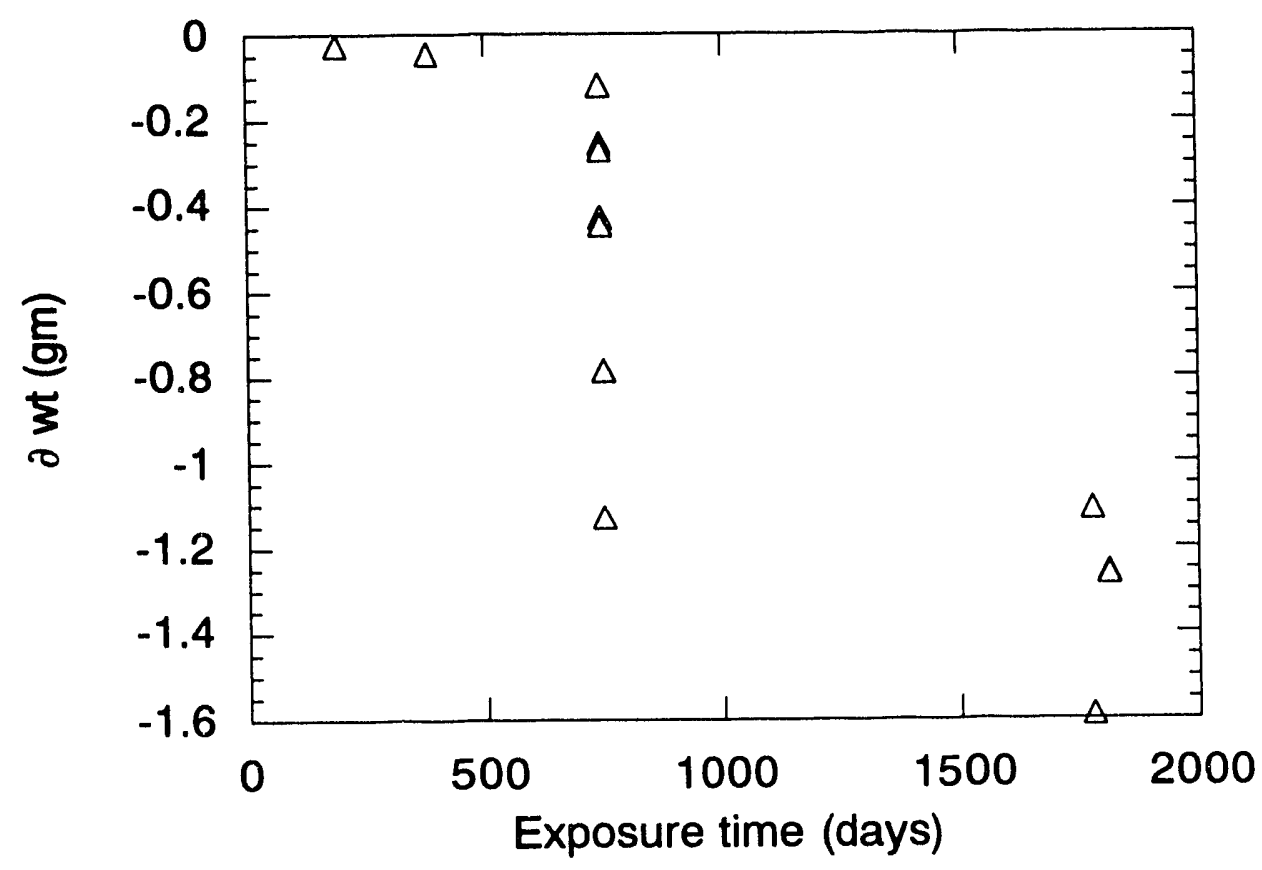

Figure 3-7. Weight change data for copper.

\subsection{CONCLUSIONS}

Interpretations of the extent of MIT metal sample corrosion in a brine and salt environment at $90^{\circ} \pm 10^{\circ} \mathrm{C}$ have been described and are fairly straightforward. Grade- 12 $\mathrm{Ti}$, grade- $2 \mathrm{Ti}$ and inconel 625 exhibited excellent corrosion resistance. The austenitic stainless steels were practically immune to general corrosion. They were quite susceptible, however, to localized attack and exhibited pitting, crevice corrosion and stress corrosion cracking. The mild steels all underwent extensive corrosion. They exhibited a combination of general and localized attack. The leaa samples suffered mainly general corrosion, with the severity of the attack varying among samples. The copper coupons suffered more corrosion than anticipated, with a mixture of both general and localized attack being observed. Further, more detailed corrosion results will be documented in the future, by individual MIIT program partricipants. 


\subsection{REFERENCES}

Molecke, M.A. 1983. A Comparison of Brines Relevant to Nuclear Waste Experimentation. SAND83-0516. Albuquerque, NM: Sandia National Laboratories.

Molecke, M.A. 1988. "Technical Operations and Data Collection Details of the In Situ WIPP Materials Interface Interactions Test," Testing of High-Level Waste Forms Under Repository Conditions, Proceedings of a Workshop Jointly Organized by CEC, US DOE and CEA, Cadarache, France, October 17-21, 1988. Ed. T. McMenamin. EUR 12017 EN; SAND88-2022C. Luxembourg: Commission of the European Communities. 67-77.

Molecke M.A., and G.G. Wicks. 1986. "TEST PLAN: WIPP Materials Interface Interactions Test (MIIT)." Albuquerque, NM: Sandia National Laboratories..

Molecke, M.A., and G.G. Wicks. 1993. "Materials Interface Interactions Test (MIIT) Details and Observations on In Situ Sample Retrievals and Test Termination," Waste Isolation Pilot Plant Materials Interface Interactions Test: Papers Presented at the Commission of European Communities Workshop on In Situ Testing of Radioactive Waste Forms and Engineered Barriers. Eds. M.A. Molecke, N.R. Sorensen, and G.G. Wicks. SAND93-1055. Albuquerque, NM: Sandia National Laboratories. 2-1 to $2-19$.

Molecke, M.A., N.R. Sorensen, and J.L. Krumhansl. 1989. "Summary of WIPP Materials Interface Interactions Test Data on Metals Interactions and Leachate Brine Analyses," Testing of High-Level Waste Forms Under Repository Conditions, Proceedings of a Workshop Jointly Organized by CEC, US DOE and CEA, Cadarache, France, October 17-21, 1988. Ed. T. McMenamin. EUR 12017 EN; SAND88-2023C. Luxembourg: Commission of the European Communities. $192-$ 203.

Tyler, L.D., R.V. Matalucci, M.A. Molecke, D.E. Munson, E.J. Nowak, and J.C. Stormont. 1988. Summary Report for the WIPP Technology Development Program for Isolation of Radioactive Waste. SAND88-0844. Albuquerque, NM: Sandia National Laboratories.

Wicks, G.G. 1985. WIPP/SRL In-Situ and Laboratory Testing Program-Part I: MIIT Overview, Nonradioactive Waste Glass Studies. DP-1706. Aiken, SC: E.I. du Pont de Nemours \& Co., Savannah River Laboratory. 
Wicks, G.G., and M.A. Molecke. 1989. "WIPP/SRL International In Situ Testing Program-MIIT," Testing of High-Level Waste Forms Under Repository Conditions, Proceedings of a Workshop Jointly Organized by CEC, US DOE and CEA, Cadarache, France, October 17-21, 1988. Ed. T. McMenamin. EUR 12017 EN; SAND88-2838C. Luxembourg: Commission of the European Communities. 49-66.

Wicks, G.G., and M.A. Molecke. 1993. "Overview of the Materials Interface Interactions Test (MITT): International In Situ Testing of Waste Forms and Package Components," Waste Isolation Pilot Plant Materials Interface Interactions Test: Papers Presented at the Commission of European Communities Workshop on In Situ Testing of Radioactive Waste Forms and Engineered Barriers. Eds. M.A. Molecke, N.R. Sorensen, and G.G. Wicks. SAND93-1055. Albuquerque, NM: Sandia National Laboratories. 1-1 to 1-25.

Wicks, G.G., M.E. Weinle, and M.A. Molecke. 1987. WIPP/SRL In Situ Tests-Part II: Pictorial History of MIIT and Final MIIT Matrices, Assemblies, and Sample Listings. DP-1733; SAND86-2720. Aiken, SC: E.I. du Pont de Nemours \& Co., Savannah River Laboratory. 


\section{DISTRIBUTION}

\section{Federal Agencies}

US Department of Energy (6)

Office of Civilian Radioactive Waste Management

Attn: Deputy Director, RW-2

Associate Director, RW-10/50 Office of Program and Resources Management Office of Contract Business Management

Director, Analysis and

Verification Division, RW-22

Associate Director, RW-30

Office of Systems and

Compliance

Associate Director, RW-40

Office of Storage and

Transportation

Director, $\mathrm{RW}-4 / 5$

Office of Strategic Planning and International Programs

Office of External Relations

Forrestal Building

Washington, DC 20585

US Department of Energy

Albuquerque Operations office

Attn: National Atomic Museum Library PO Box 5400

Albuquerque, NM 87185-5400

US Department of Energy (4)

WIPP Project Integration Office

Attn: W.J. Arthur III

L.W. Gage

P.J. Higgins

D.A. Olona

PO Box 5400

Albuquerque, NM 87115-5400

US Department of Energy (2)

WIPP Project Integration Satellite

Office

Attn: R. Batra

R. Becker

PO Box 3090

Carlsbad, NM 88221-3090

US Department of Energy (3)

WIPP Project Site office (Carlsbad)

Attn: V. Daub

$\mathrm{J}$. Lippis

J.A. Mewhinney

PO Box 3090

Carlsbad, NM 88221-3090
US Department of Energy

Research \& Waste Management Division Attn: Director

PO Box $\mathbf{E}$

Oak Ridge, TN 37831

US Department of Energy

Attn: E. Young

Room E-178

GAO/RCED/GTN

Washington, DC 20545

US Department of Energy

Office of Environmental Restoration

and Waste Management

Attn: J. Lytle, EM-30

(Trevion II)

Washington, DC 20585-0002

US Department of Energy (3)

Office of Environmental Restoration and Waste Management

Attn: M. Frei, EM-34

(Trevion II)

Washington, DC 20585-0002

US Department of Energy

Office of Environmental Restoration and Waste Management

Attn: S. Schneider, EM-342 (Trevion II)

Washington, DC 20585-0002

US Department of Energy (2)

Office of Environment, Safety and Health

Attn: C. Borgstrom, EH-25

R. Pelletier, EH-231

Washington, DC 20585

US Department of Energy (2)

Idaho Operations Office

Fuel Processing and Waste Management Division

785 DOE Place

Idaho Fa11s, ID 83402

US Environmental Protection Agency (2)

Radiation Protection Programs

Attn: $M$. Oge

ANR - 460

Washington, DC 20460 
US Geological Survey (2)

Water Resources Division

Attn: R. Livingston

4501 Indian School NE

Suite 200

Albuquerque, NM 87110

US Nuclear Regulatory Commission Division of Waste Management

Attn: H. Marson

Mail Stop 4-H-3

Washington, DC 20555

Boards

Defense Nuclear Facilities Safety Board

Attn: D. Winters

625 Indiana Ave. NW, Suite 700

Washington, DC 20004

Nuclear Waste Technical Review Board (2)

Attn: Chairman S.J.S. Parry

1100 Wilson Blvd., Suite 910

Arlington, VA 22209-2297

Advisory Committee on Nuclear Waste

Nuclear Regulatory Commission

Attn: R. Major

7920 Norfolk Ave.

Bethesda, MD 20814

\section{State Agencies}

Environmental Evaluation Group (3)

Attn: Library

7007 Wyoming NE

Suite F-2

Albuquerque, NM 87109

NM Bureau of Mines and Mineral

Resources

Socorro, NM 87801

NM Energy, Minerals, and Natural

Resources Department

Attn: Library

2040 S. Pacheco

Santa Fe, NM 87505

NM Environment Department (3)

Secretary of the Environment

Attn: J. Espinosa

$1190 \mathrm{St}$. Francis Drive

Santa Fe, NM 87503-0968
NM Environment Department

WIPP Project Site

Attn: P. McCasland

PO Box 3090

Carlsbad, NM 88221

\section{Laboratories/Corporations}

Batte1le Pacific Northwest

Laboratories

Attn: R.E. Westerman, MSIN P8-44

Battelle Blvd.

Richland, WA 99352

INTERA Inc.

Attn: J.F. Pickens

6850 Austin Center Blvd.

Suite 300

Austin, TX 78731

INTERA Inc.

Attn: W. Stensrud

PO Box 2123

Carlsbad, NM 88221

IT Corporation

Attn: R.F. McKinney

Regional Office

5301 Central NE, Suite 700

Albuquerque, NM 87108

Los Alamos National Laboratory

Attn: B. Erdal, CNC-11

PO Box 1663

Los Alamos, NM 87544

RE/SPEC, Inc.

Attn: W. Coons

4775 Indian School NE

Suite 300

Albuquerque, NM 87110-3927

RE/SPEC, Inc.

Attn: J.L. Ratigan

PO Box 725

Rapid City, SD 57709

Southwest Research Institute (2)

Center for Nuclear Waste

Regulatory Analysis

Attn: P.K. Nair

6220 Culebra Road

San Antonio, TX 78228-0510

SAIC

Attn: D.C. Royer

101 Convention Center Dr.

Las Vegas, NV 89109 
SAIC

Attn: H.R. Pratt

10260 Campus Point Dr.

San Diego, CA 92121

SAIC (2)

Attn: M. Davis

J. Tollison

2109 Air Park Rd. SE

Albuquerque, NM 87106

Tech Reps Inc. (3)

Attn: J. Chapman

C. Crawford

T. Peterson

5000 Marble NE, Suite 222

Albuquerque, NM 87110

TRW Environmental Safety Systems

Attn: L. Wildman

2650 Park Tower Dr., Suite 1300

Vienna, VA 22180-7306

Westinghouse Electric Corporation (5)

Attn: Library

C. Cox

L. Fitch

B.A. Howard

R. Kehrman

PO Box 2078

Carlsbad, NM 88221

Westinghouse-Savannah River

Technology Center (13)

Attn: N. Bibler

J.R. Harbour

M.J. Plodinec

G.G. Wicks (10)

Aiken, SC 29802

\section{National Academy of Sciences, WIPP Panel}

Howard Adler

Oak Ridge Associated Universities

Medical Sciences Division

PO Box 117

Oak Ridge, TN 37831-0117

Ina Alterman

Board on Radioactive

Waste Management, GF456

2101 Constitution Ave.

Washington, DC 20418

Fred M. Ernsberger

250 O1d Mill Road

Pittsburgh, PA 15238
John D. Bredehoeft

Western Region Hydrologist

Water Resources Division

US Geological Survey ( $M / S$ 439)

345 Middlefield Road

Menlo Park, CA 94025

Rodney C. Ewing

Department of Geology

University of New Mexico

Albuquerque, NM $\mathbf{8 7 1 3 1}$

Charles Fairhurst, Chairman

Department of Civil and

Mineral Engineering

University of Minnesota

500 Pillsbury Dr. SE

Minneapolis, MN 55455-0220

B. John Garrick

PLG Incorporated

4590 MacArthur Blvd., Suite 400

Newport Beach, CA 92660-2027

Leonard F. Konikow

US Geological Survey

431 National Center

Reston, VA 22092

Peter B. Myers

National Academy of Sciences

Board on Radioactive

Waste Management

2101 Constitution Ave.

Washington, DC 20418

Jeremiah O'Driscoll

Jody Incorporated

505 Valley Hill Drive

Atlanta, GA 30350

Christopher G. Whipple

Clement International

160 Spear St., Suite 1380

San Francisco, CA 94105

\section{Individuals}

P. Drez

8816 Cherry Hills Rd. NE

Albuquerque, NM 87111

D.W. Powers

Star Route Box 87

Anthony, TX 79821 


\section{Universities}

University of New Mexico

Geology Department

Attn: Library

Albuquerque, NM 87131

University of Washington

College of Ocean

and Fishery Sciences

Attn: G.R.Heath

583 Henderson Hall

Seattle, WA 98195

\section{Libraries}

Thomas Brannigan Library

Attn: D. Dresp

106 W. Hadley St.

Las Cruces, NM 88001

Government Publications Department

Zimmerman Library

University of New Mexico

Albuquerque, NM 87131

Hobbs Public Libraxy

Attn: M. Lewis

509 N. Ship St.

Hobbs, NM 88248

New Mexico Junior College

Pannell Library

Attn: R. Hill

Lovington Highway

Hobbs, NM 88240

New Mexico State Library

Attn: N. McCallan

325 Don Gaspar

Santa Fe, NM 87503

New Mexico Tech

Martin Speere liemorial Library

Campus Street

Socorro, NM 87810

WIPP Public Reading Room

Carlsbad Public Library

Attn: Director

101 S. Halagueno St.

Carlsbad, NM 88220

\section{Foreign Addresses}

Studiecentrum Voor Kernenergie

Centre D'Energie Nucleaire (2)

Attn: A. Bonne

P. Van Iseghem

SCK/CEN Boeretang 200

B-2400 Mo1, BELGIUM

Atomic Energy of Canada, Ltd. (3)

Whiteshell Research Estab.

Attn: B. Goodwin

M. Stevens

D. Wushke

Pinewa, Manitoba, CANADA ROE 1LO

Francois Chenevier (2)

ANDRA

Route du Panorama Robert Schumann

B.P. 38

92266 Fontenay-aux-Roses, Cedex

FRANCE

Jean-Pierre Olivier

OECD Nuclear Energy Agency

Division of Radiation Protection and Waste Management

38, Boulevard Suchet

75016 Paris, FRANCE

Claude Sombret

Centre D'Etudes Nucleaires

De La Vallee Rhone

CEN/VALRHO

S.D.H.A. B.P. 171

30205 Bagnols-Sur-Ceze, FRANCE

Gesellschaft fur Reaktorsicherheit

(GRS) (2)

Attn: B. Baltes

W. Muller

Schwertnergasse 1

D-5000 Cologne, GERMANY

Bundesanstalt fur Geowissenschaften und Rohstoffe

Attn: M. Langer

Postfach 510153

3000 Hanover 51, GERMANY

Bundesministerium fur Forschung und Technologie

Postfach 200706

5300 Boñn 2, GERU'ANY 
Institut fur Tieflagerung (2)

Attn: K. Kuhn

Theodor-Heuss-Strasse 4

D-3300 Braunschweig, GERMANY

Kerforschungszentrum Karlshruhe Gmbh (2)

Institut fur Nukleare

Entsorgungstechnik

Attn: W. Lutze

E. Smailos

Postfach 3640

D-7500 Karlsruhe 1

GERMANY

Physikalisch-Technische Bundesanstalt Attn: P. Brenneke

Postfach 3345

D-3300 Braunschweig, GERMANY

Shingo Tashiro

Japan Atomic Energy Research Inst.

Tokai-Mura, Ibaraki-Ken, 319-11

JAPAN

Netherlands Energy Research

Foundation ECN

Attn: L.H. Vons

3 Westerduinweg

PO Box 1

1755 ZG Petten, THE NETHERLANDS

Svensk Karnbransleforsorjning $A B$

Attn: F. Karlsson

Project KBS

Karnbranslesakerhet

Box 5864

10248 Stockholm, SWEDEN

Nationale Genossenschaft für die

Lagerung radioaktiver Abfälle (2)

Attn: S. Vomvoris

P. Zuidema

Hardstrasse 73

CH-5430 Wettingen, SWITZERLAND

AEA Technology

Attn: J.H. Rees

D5W/29 Culham Laboratory

Abington, Oxfordshire OX14 3DB

UNITED KINGDOM
AEA Technology

Attn: W.R. Rodwe11

044/A31 Winfrith Technical Centre

Dorchester, Dorset DT2 8DH

UNITED KINGDOM

AEA Technology

Attn: J.E. Tinson

B4244 Harwe11 Laboratory

Didcot, Oxfordshire OX11 ORA

UNITED KINGDOM

D.R. Knowles

British Nuclear Fuels, plc

Risley, Warrington, Cheshire WA3 6AS

1002607 UNITED KINGDOM

\section{Internal}

$\begin{array}{ll}1502 & \text { J.C. Cummings } \\ 1832 & \text { N.R. Sorensen (10) } \\ 6000 & \text { D.L. Hartley } \\ 6119 & \text { E.D. Gorham } \\ 6119 & \text { Staff (14) } \\ 6121 & \text { J.R. Tillerson } \\ 6121 & \text { Staff (7) } \\ 6300 & \text { D.E. Ellis } \\ 6302 & \text { L.E. Shephard } \\ 6303 & \text { S.Y. Pickering } \\ 6303 & \text { W.D. Weart } \\ 6305 & \text { S.A. Goldstein } \\ 6305 & \text { A.R. Lappin } \\ 6306 & \text { A.L. Stevens } \\ 6342 & \text { D.R. Anderson } \\ 6342 & \text { Staff (20) } \\ 6343 & \text { V. Harper-Slaboszewicz } \\ 6343 & \text { Staff (2) } \\ 6345 & \text { R.C. Lincoln } \\ 6345 & \text { Staff (9) } \\ 6347 & \text { D.R. Schafer } \\ 6348 & \text { J.T. Holmes } \\ 6348 & \text { M.A. Molecke (10) } \\ 6348 & \text { Staff (4) } \\ 6351 & \text { R.E. Thompson } \\ 6352 & \text { D.P. Garber } \\ 6352 & \text { S.E. Sharpton } \\ 6352 & \text { WIPP Central Files (10) } \\ 7141 & \text { (WIPP/DHLW, 1.1.1.3.1) } \\ 7151 & \text { Technical Library (5) } \\ 7613-2 & \text { Technical Publications } \\ & \text { Document Processing for } \\ 8523-2 & \text { DoE/OSTI (10) } \\ & \text { Central Technical Files }\end{array}$



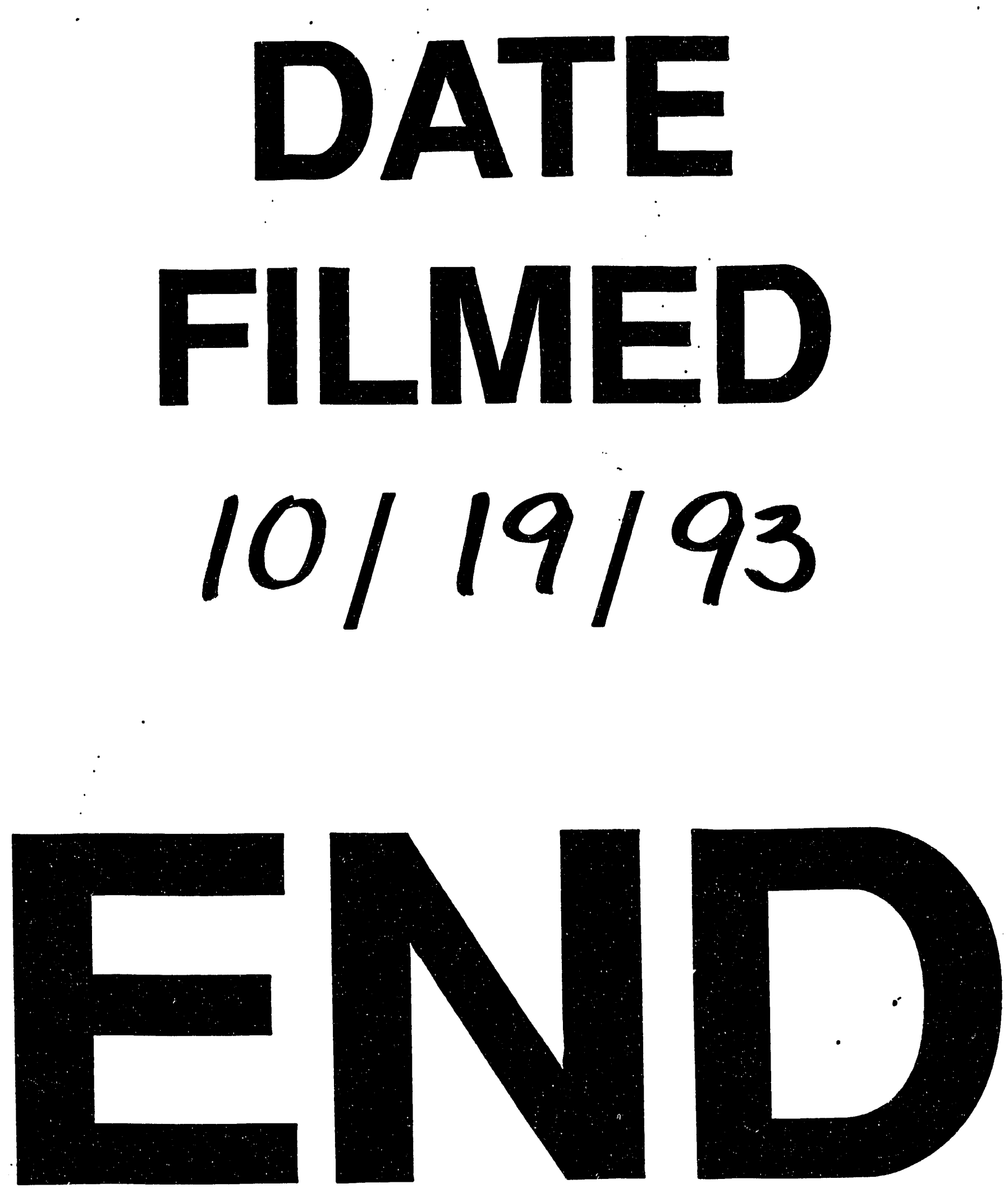
